THIAGO LUIS RODRIGUES DA SILVA

\title{
Análise da influência de variáveis meteorológicas e da hidrodinâmica sobre os padrões espaciais e temporais da qualidade da água e de florescimentos de cianobactérias e macrófitas em um reservatório urbano
}

\author{
Tese apresentada à Escola de Engenharia de São Carlos da \\ Universidade de São Paulo, como parte dos requisitos \\ necessários para a obtenção do título de Doutor em Ciências. \\ Área de concentração: Ciências da Engenharia Ambiental \\ Orientadora: Profa. Dra. Odete Rocha
}




\begin{abstract}
AUTORIZO A REPRODUÇÃO E DIVULGAÇÃO TOTAL OU PARCIAL DESTE TRABALHO, POR QUALQUER MEIO CONVENCIONAL OU ELETRÔNICO, PARA FINS DE ESTUDO E PESQUISA, DESDE QUE CITADA A FONTE.
\end{abstract}

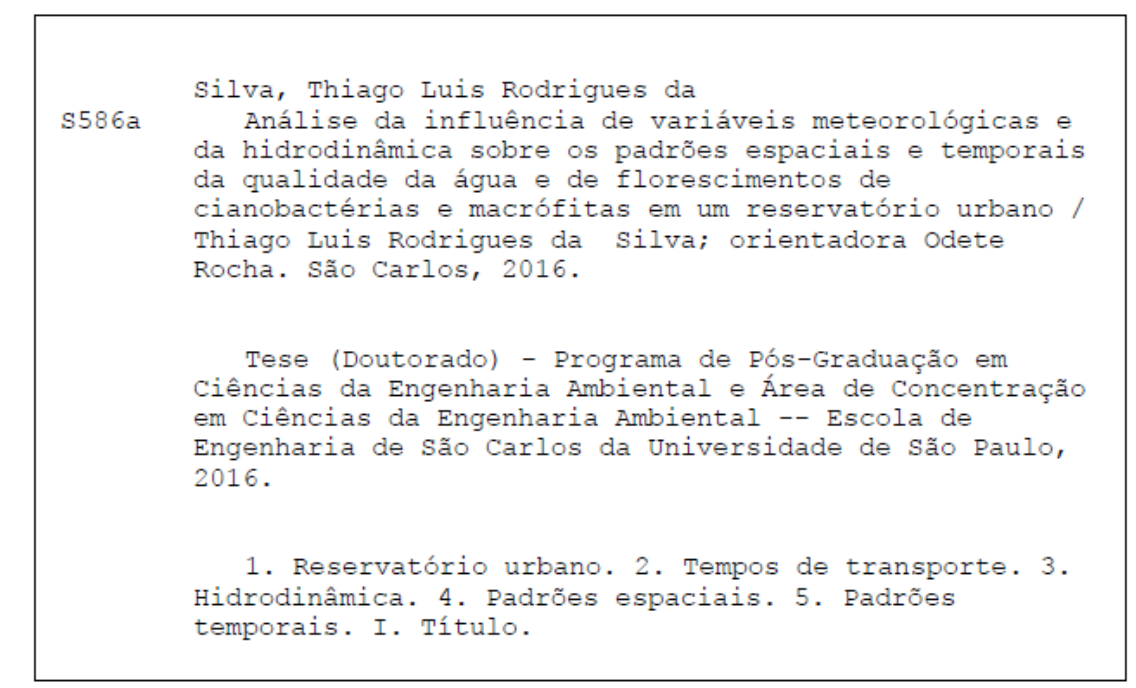




\section{FOLHA DE JULGAMENTO}

Candidato: Engenheiro THIAGO LUÍS RODRIGUES DA SILVA.

Título da tese: "Análise da influência de variáveis meteorológicas e da hidrodinâmica sobre os padrões espaciais e temporais da qualidade da água e florescimentos de cianobactérias e macrófitas em um reservatório urbano".

Data da defesa: 03/03/2016

\section{Comissão Julgadora:}

Profa. Dra. Odete Rocha

\section{(Orientadora)}

(Universidade Federal de São Carlos/UFSCar)

Prof. Associado Frederico Fabio Mauad

(Escola de Engenharia de São Carlos/EESC)

Prof. Dr. Evandro Mateus Moretto

(Escola de Artes, Ciências e Humanidades/EACH-USP)

Prof. Titular José Galizia Tundisi

(Escola de Engenharia de São Carlos/EESC)

Profa. Dra. Cristina de Souza Nordi

(Universidade Federal de São Paulo/UNIFESP)

\section{Resultado:}
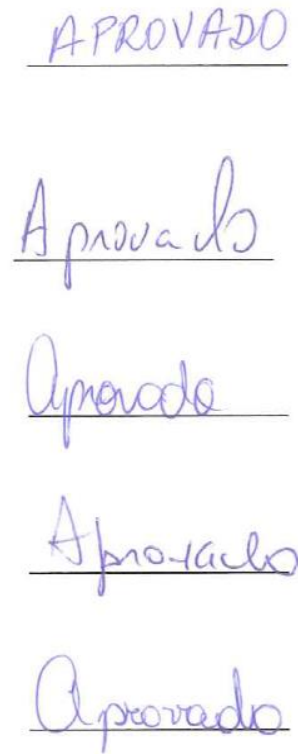

Coordenador do Programa de Pós-Graduação em Ciências da Engenharia Ambiental:

Prof. Associado Frederico Fabio Mauad

Presidente da Comissão de Pós-Graduação:

Prof. Associado Paulo César Lima Segantine 
O choro pode durar uma noite, mas a alegria vem pela manhã.

Salmos 30:5 
Dedico aos meus pais e à minha família, por todo o apoio, incentivo e inspiração. 


\section{AGRADECIMENTOS}

A Deus, por todo auxílio e força.

A meus pais e a toda a minha família pelo apoio e compreensão durante a realização deste trabalho.

À minha orientadora professora Dra. Odete Rocha, pela confiança, paciência e pelo exemplo de humildade e persistência que permitiu o desenvolvimento deste trabalho.

Ao professor Dr. Ângelo A. Saggio e à professora Dra. Cristina M. M. G. Rio que me apresentaram à Hidrologia e ao estudo dos Recursos Hídricos, pelos ensinamentos sobre esses temas e pelas oportunidades de aprendizagem e de pesquisa sem os quais esta tese não teria sido feita. Agradeço-lhes também pelo convívio e amizade.

A todos docentes do Programa de Pós-Graduação em Ciências da Engenharia Ambiental que contribuíram para a minha formação acadêmica.

A todo o pessoal do Departamento de Ecologia e Biologia Evolutiva da Universidade Federal de São Carlos (DEBE-UFSCar), do Instituto Oceanográfico da Universidade de São Paulo (IO-USP), do Centro de Recursos Hídricos e Ecologia Aplicada da Universidade de São Paulo (CRHEA-USP) e do Centre for Water Research da University of Western Australia CWR-UWA, pelas discussões e sugestões de trabalho, pela amizade, convívio e aprendizado.

À SABESP, pelos dados e apoio na realização dos experimentos, em especial ao Almir Andrade que nos acompanhou nos experimentos e desenvolvimento dos trabalhos.

À Embrapa São Carlos pela disponibilização dos equipamentos de espectroradiometria para testes, em especial ao Dr. Lúcio André de Castro Jorge, que nos auxiliou e acompanhou em vários experimentos.

Ao Instituto de Astronomia, Geofísica e Ciências Atmosféricas da Universidade de São Paulo (IAG-USP) pela disponibilização os dados meteorológicos.

Ao Instituto Nacional de Pesquisas Espaciais (INPE), pela disponibilização das imagens de satélite.

À Companhia Estadual de Tecnologia do Estado de São Paulo (CETESB), pela disponibilização dos dados de qualidade da água.

À Coordenadoria de Aperfeiçoamento de Pessoal do Ensino Superior (CAPES) pelo apoio concedido por meio da bolsa de doutorado direto.

A todos que direta ou indiretamente contribuíram para a realização deste trabalho. 


\section{RESUMO}

SILVA, T. L. R. Análise da influência das variáveis meteorológicas e da hidrodinâmica sobre padrões espaciais e temporais de qualidade da água e de florescimentos de cianobactérias e macrófitas em um reservatório urbano. 2016. 107 p. Tese (Doutorado) - Escola de Engenharia de São Carlos, Universidade de São Paulo, São Carlos, 2016.

Os reservatórios urbanos estão suscetíveis a uma variedade de interferências antropogênicas que acarretam grande variabilidade espacial e temporal. Contudo, possuem uma dinâmica própria na qual o hidroclima e micro e macro-eventos meteorológicos atuam sobre os processos físicos, químicos e biológicos resultando em respostas particulares de cada corpo de água. No presente estudo a existência de padrões espaciais e temporais na formação de florescimentos de algas, cianobactérias e macrófitas no reservatório Guarapiranga, São Paulo, SP, foi avaliada por meio de experimento de curta escala de tempo durante o evento da entrada de uma frente fria. Foram amostrados 64 pontos em todo o reservatório, e o estudo intensivo de florescimento algal e de cianobactérias em dois ciclos nictemerais, em um ponto selecionado no reservatório. Um modelo tridimensional de hidrodinâmica foi aplicado ao estudo compartimentalizado dos tempos de residência e imagens de satélite foram analisadas para determinação de padrões temporais e espaciais durante períodos de tempo mais amplos. Os resultados revelaram que os períodos mais favoráveis ao surgimento de florescimentos de cianobactérias são geralmente os meses mais quentes, de dezembro e janeiro, ou aqueles em que ocorrem estratificações mais fortes como no fim do inverno, em julho, e após as primeiras chuvas nos meses de setembro e outubro. Existem padrões espaciais recorrentes na formação dos florescimentos, controlados em grande parte pela ação do vento, que no reservatório Guarapiranga é predominantemente nas direções leste e sudeste empurrando os florescimentos na direção da foz dos tributários Embu Mirim e Embu Guaçu e ocasionalmente na direção da foz do rio Parelheiros. As simulações hidrodinâmicas evidenciam as forçantes que determinam os padrões observados e reforçam a importância de se discretizarem os tempos de residência de diferentes compartimentos do reservatório. As séries temporais amplas permitiram a determinação da qualidade da água em cada região e fornecem subsídios para o futuro manejo do reservatório. Como esse comportamento não se restringe ao reservatório Guarapiranga, o tipo de modelagem aqui utilizada pode ser útil para obter informações importantes no processo de planejamento e seleção de medidas para o gerenciamento de reservatórios urbanos tropicais polimíticos, em geral.

Palavras-chave: Reservatório urbano; Tempos de transporte; Hidrodinâmica; Padrões espaciais; Padrões temporais. 


\begin{abstract}
SILVA, T. L. R. Analysis of the influence of meteorological variables and the hydrodynamic on spatial and temporal patterns in the water quality and cyanobacterial and macrophyte blooms in urban reservoirs. 2016. 107 p. Thesis (Doctoral) - Escola de Engenharia de São Carlos, Universidade de São Paulo, São Carlos, 2016.
\end{abstract}

Urban reservoirs are susceptible to a variety of anthropogenic interferences, that leads to large spatial and temporal variability, however they have themselves a proper dynamics in which the hydroclimate and micro and macro meteorological events act upon physical, chemical and biological processes, resulting in a singular signature for each water body. In the present study the existence of spatial and temporal patterns for the formation of algal, cyanobacterial and macrophyte blooms in Guarapiranga Reservoir, São Paulo, SP, was evaluated by means of a short-time scale experiment during the event of a cold front passage. Sampling was carried out in 64 points in the whole reservoir and the intensive study of an algal and cyanobacterial during two nictemeral cycles, at a selected point in the reservoir. A tri-dimensional hydrodynamics model was applied to the study of discrete residence time of the main reservoir tributaries. Satellite images and long term data sets were analyzed aiming to determine spatial and temporal patterns at long time scale. The results obtained have shown that the most favorable periods for algal and cyanobacterial blooms are usually the hottest months, December and January, or those with stronger thermal stratification at the end of the winter in July and after the first rains in September and October months. There are recurrent spatial patterns in the formation of blooms, largely controlled by wind action, that in Guarapiranga Reservoir are predominantly from East and Southeast directions frequently pushing the blooms towards Embu Mirim and Embu Guaçu tributaries and occasionally towards Parelheiros River mouth. Hydrodynamic simulations evidenced the forcing functions that control the observed patterns and reinforced the importance of residence time discretization according to each main reservoir compartment. The temporal data series allowed to assess each compartment water quality and provided information for future reservoir management. Considering that the patterns found are not restricted to Guarapiranga Reservoir, the type of model here used could be useful to get relevant information to be used in the planning or selection of management actions for tropical polymictic urban reservoirs in general

Keywords: Urban Reservoir; Transport Time; Hydrodynamics; Spatial Patterns; Temporal Patterns. 


\section{LISTA DE FIGURAS}

Figura 1 - Localização da bacia hidrográfica e do reservatório Guarapiranga, com apresentação dos principais afluentes. 14

Figura 2 - Mapa esquemático mostrando a localização dos 64 pontos amostrados na represa nos dias 13 e 14 de setembro de 2010, foram realizadas medidas de varáveis físicas e químicas in situ e coletadas amostras de água

Figura 3 - Mapa do reservatório Guarapiranga, São Paulo, SP, mostrando a localização do ponto de amostragem no braço do rio Embu Mirim, utilizado para a realização do estudo de curta escala espacial e temporal.

Figura 4 - Mapa batimétrico do reservatório Guarapiranga, mostrando o ponto onde a bóia foi instalada para fixar o Sistema "Lake Diagnostic System (LDS)" um conjunto de sensores e equipamentos meteorológicos e hidrológicos.

Figura 5 - Parâmetros meteorológicos para o período simulado. 24

Figura 6 - Variação na temperatura do ar, medida na estação meteorológica flutuante instalada próximo à captação de água no reservatório Guarapiranga, com medidas a cada 10 minutos, das 10:00 h do dia 12/09/2010 às 10:00 h do dia 14/09/2010 ... 26

Figura 7 - Variações na velocidade e direção do vento medidos na estação meteorológica flutuante instalada próximo à captação de água no reservatório Guarapiranga, com medidas a cada 10 minutos, das 10:00 h do dia 12/09/2010 às 10:00 h do dia 14/09/2010. 26

Figura 8 - Variação nictemeral da temperatura da água no reservatório Guarapiranga, São Paulo, SP, para dois ciclos consecutivos, com medidas em intervalos de três horas, a cada $0,5 \mathrm{~m}$ de profundidade, em um ponto de uma baia no compartimento da desembocadura do rio Embu Mirim.

Figura 9 - Variação nos valores de temperaturas anuais máximas, médias e mínimas medidas na Estação Meteorológica do Instituto de Astronomia, Geofísica e Ciências Atmosféricas da Universidade de São Paulo - (IAG/USP) instalada no Parque Fontes do Ipiranga, São Paulo, SP, para o período de 1997 a 2014.

Figura 10 - Variação dos valores de temperaturas máximas, médias e mínimas mensais do ar, temperatura do ar registradas na Estação Meteorológica do Instituto de Astronomia, Geofísica e Ciências Atmosféricas da Universidade de São Paulo (IAG/USP) instalada no Parque Fontes do Ipiranga, São Paulo, SP, para o período de 1997 a 2015. 
Figura 11 - Variação das temperaturas médias: máximas, médias e mínimas mensais, da temperatura do ar registradas na Estação Meteorológica do Instituto de Astronomia, Geofísica e Ciências Atmosféricas da Universidade de São Paulo (IAG/USP) instalada no Parque Fontes do Ipiranga, São Paulo, SP, para o período de 1997 a 2015.

Figura 12 - Variação dos valores totais de precipitação anual registrados na Estação Meteorológica do Instituto de Astronomia, Geofísica e Ciências Atmosféricas da Universidade de São Paulo - (IAG/USP) instalada no Parque Fontes do Ipiranga, São Paulo, SP, para o período de 1997 a 2014. 34

Figura 13 - Variação dos valores mensais de precipitação total e curva representativa dos valores mensais médios obtidos a partir dos dados registrados na Estação Meteorológica do Instituto de Astronomia, Geofísica e Ciências Atmosféricas da Universidade de São Paulo - (IAG/USP) instalada no Parque Fontes do Ipiranga, São Paulo, SP, para o período de 1997 a 2015. 36

Figura 14 - Valores médios de precipitação mensal (em mm) para o período de 1933 a 2002 obtidos a partir de dados registrados na Estação Meteorológica do Instituto de Astronomia, Geofísica e Ciências Atmosféricas da Universidade de São Paulo (IAG/USP) instalada no Parque Fontes do Ipiranga, São Paulo, SP.

Figura 15 - Histograma direcional com as intensidade e frequência dos ventos registrados na Estação Meteorológica do Instituto de Astronomia, Geofísica e Ciências Atmosféricas da Universidade de São Paulo - (IAG/USP) no Parque Fontes do Ipiranga, São Paulo, SP, para o período de 1997 a 2015. 38

Figura 16 - Distribuição espacial da transparência da água no reservatório Guarapiranga, São Paulo, SP, avaliada por meio da profundidade de visibilidade do Disco de Secchi medida nos dias 13 e 14 de setembro de 2010 no reservatório de Guarapiranga, São Paulo, SP, em 64 pontos amostrais. 40

Figura 17 - Distribuição espacial das concentrações de Fósforo Total, em $\mu \mathrm{g} / \mathrm{L}$ medidas nos dias 13 e 14 de setembro de 2010 em 64 pontos do reservatório Guarapiranga, São Paulo, SP. 42

Figura 18 - Distribuição espacial das concentrações de Nitrogênio Total, em $\mu \mathrm{g} / \mathrm{L}$, medidas em 64 pontos do reservatório de Guarapiranga, São Paulo, SP, nos dias 13 e 14 de setembro de 2010

Figura 19 - Variação temporal dos valores de temperatura do ar e da água, da concentração de oxigênio dissolvido, pH, Nitrato e Nitrogênio amoniacal, medidos 
e disponibilizados pela CETESB na foz do Rio Embu-Mirim, no reservatório de Guarapiranga, São Paulo, SP, para uma série de anos compreendidos no período de 2004 a 2015. (Fonte: http://aguasinteriores.cetesb.sp.gov.br).

Figura 20 - Dados de Fósforo total e Turbidez, obtidos pela CETESB na foz do Rio Embu-Mirim, reservatório de Guarapiranga, São Paulo, SP, durante o período de 2004 a 2015. (Fonte: http://aguasinteriores.cetesb.sp.gov.br). 46

Figura 21 - Variações nos valores de Temperatura do ar e da água, Concentrações de Oxigênio, Nitrato e Nitrogênio amoniacal, registrados pela CETESB em ponto próximo à Captação de Água para abastecimento no reservatório Guarapiranga, São Paulo, SP, durante o período de 2004 a 2015. (Fonte: http://aguasinteriores.cetesb.sp.gov.br).

Figura 22 - Variação na concentração de Fósforo total, obtidos pela CETESB no ponto próximo à Captação de Água para abastecimento, reservatório de Guarapiranga, São Paulo, SP, durante o período de 2004 a 2015. (Fonte: http://aguasinteriores.cetesb.sp.gov.br). 48

Figura 23- Variação de longo prazo nas concentrações de fósforo total e de turbidez para as águas superficiais na região próxima à captação e na foz do Rio Parelheiros, reservatório de Guarapiranga, São Paulo, SP, durante o período de 2004 a 2015.( (Fonte: http://aguasinteriores.cetesb.sp.gov.br). 48

Figura 24 - Variação de longo prazo na Temperatura do ar e da água, na concentração de Oxigênio dissolvido, pH, e concentrações de Nitrato e Nitrogênio amoniacal, obtidos pela CETESB para as águas superficiais no compartimento foz do Rio Parelheiros, reservatório de Guarapiranga, São Paulo, SP, durante o período de 2004 a 2015. (Fonte: http://aguasinteriores.cetesb.sp.gov.br).

Figura 25 - Variação dos valores de Fósforo total, obtidos pela CETESB na foz do rio Parelheiros, reservatório de Guarapiranga, São Paulo, SP, durante o período de 2004 a 2015. (Fonte: http://aguasinteriores.cetesb.sp.gov.br). 50

Figura 26 - Dados de Temperatura do ar e da água, Oxigênio dissolvido, pH, Nitrato e Nitrogênio amoniacal, obtidos pela CETESB na foz do rio Embu-Guaçu, reservatório de Guarapiranga, São Paulo, SP, durante o período de 2004 a 2015. (Fonte: http://aguasinteriores.cetesb.sp.gov.br).

Figura 27 - Dados de Fósforo total e Turbidez, obtidos pela CETESB na foz do rio Embu-Guaçu, reservatório de Guarapiranga, São Paulo, SP, durante o período de 2004 a 2015. (Fonte: http://aguasinteriores.cetesb.sp.gov.br). 
Figura 28 - Distribuição espacial das concentrações de clorofila-a, em $\mu$ g L-1, no reservatório de Guarapiranga, São Paulo, SP, medidas nos dias 13 e 14 de setembro de 2010

Figura 29 - Distribuição espacial dos principais grupos fitoplanctônicos coletados em 64 pontos na superfície do reservatório de Guarapiranga, São Paulo, SP, do dia 13/09/2010. As densidades dos organismos de cada grupo estão expressas em células por $\mathrm{mL}$

Figura 30 - Distribuição espacial dos principais grupos fitoplanctônicos coletados em 64 pontos na superfície do reservatório de Guarapiranga, São Paulo, SP, do dia 14/09/2010. As densidades dos organismos de cada grupo estão expressas em células por $\mathrm{mL}$ 58

Figura 31 - Variação dos valores da concentração dos pigmentos Clorofila-a, Feofitinaa e densidade de cianobactérias obtidos pela CETESB na captação de água para abastecimento, na série temporal de 2004 a 2015. . (Fonte: http://aguasinteriores.cetesb.sp.gov.br).

Figura 32 - Variação dos valores da concentração dos pigmentos Clorofila-a e Feofitina-a ( $\mu \mathrm{g}$ L-1) e da densidade de cianobactérias (no. de células mL-1) obtidos pela CETESB na foz do rio Parelheiros, durante o período de 2004 a 2015. (Fonte: http://aguasinteriores.cetesb.sp.gov.br).

Figura 33 - Imagem do satélite Landsat5 coletada no dia 19/03/1999, para o reservatório de Guarapiranga, região metropolitana de São Paulo, SP. (Fonte: INPE)

Figura 34 - Imagem do satélite Landsat5 coletada no dia 26/08/1999, para o reservatório de Guarapiranga, região metropolitana de São Paulo, SP. (Fonte: INPE)

Figura 35 - Mapa de usos do solo da represa Guarapiranga, São Paulo, SP, com a delimitação das principais bacias hidrográficas (adaptado de PRIME, 1998).

Figura 36 - Batimetria do reservatório Guarapiranga, São Paulo, SP, em metros acima do nível do mar e setas azuis indicando os fluxos principais.

Figura 37 - Imagem do satélite Landsat5 coletada no dia 11/03/2002, para o reservatório Guarapiranga, São Paulo, SP. Fonte: INPE.

Figura 38 - Imagens do satélite Landsat 5 mostrando o crescimento exagerado de macrófitas (áreas na cor verde claro) no reservatório Guarapiranga, São Paulo, SP, durante o ano de 2010. 
Figura 39 - Foto mostrando o acúmulo de macrófitas na barragem do reservatório Guarapiranga no dia 25/04/2010.

Figura 40 - Vista das macrófitas flutuantes e enraizadas próximo à barragem do reservatório Guarapiranga no dia 25/04/2010.

Figura 41 - Histograma direcional com as velocidade dos ventos na cidade de São Paulo, SP, para o ano de 2010.

Figura 42 - Imagem de satélite WorldView obtida no dia 07/04/2014, para o reservatório de Guarapiranga, São Paulo, SP, mostrando a proliferação de macrófitas (àreas de coloração verde-claro). Fonte: (Google Earth). 71

Figura 43 - Evento de macrófitas na foz do rio Embu-Mirim, tributário do reservatório Guarapiranga, São Paulo, SP., durante o ano de 2014 (Fonte Google Earth). 72

Figura 44 - Simulação do transporte de água dos três principais tributários (EmbuMirim, Embu-Guaçu e Parelheiros) através do reservatório Guarapiranga, Sâo Paulo, SP, utilizando o modelo hidrodinâmico ELCOM, incluindo os três processos hidrodinâmicos selecionados: Vento, Morfometria, e Balanço de Calor. 75

Figura 45 - Simulação do transporte de água dos três principais tributários (EmbuMirim, Embu-Guaçu e Parelheiros) através do reservatório Guarapiranga utilizando o modelo de hidrodinâmica ELCOM, levando somente em consideração a morfometria do reservatório. 76

Figura 46 - Simulação do transporte de água dos três maiores tributários (Embu-Mirim, Embu Guaçu e Parelheiros) através do reservatório Guarapiranga, São Paulo, SP, utilizando o modelo hidrodinâmico ELCOM, introduzindo o momento induzido pelo vento mas sem o balanço de calor. 77

Figura 47 - Mapa das variações do tempo de residência no reservatório Guarapiranga, São Paulo, SP, obtidas na quarta simulação.

Figura 48 - Variações na massa total de traçador ao longo do tempo para os três maiores rios que alimentam o reservatório Guarapiranga, São Paulo, SP, computados por simulação numérica. $\mathrm{O}$ primeiro gráfico mostra a variação da concentração total ao longo do tempo, o segundo mostra o total acumulado e o terceiro mostra as vazões simuladas. 


\section{LISTA DE TABELAS}

Tabela 1 - Principais características do reservatório Guarapiranga..............................14

Tabela 2 - Localização geográfica dos pontos amostrados no reserv. Guarapiranga.....18

Tabela 3 - Direção e intensidade dos ventos durante o período em que foram realizadas coletas de água em 64 pontos para determinação das concentrações de clorofila a na camada de superfície do reservatório Guarapiranga, nos dias 13 e 14 de setembro de 2010 (Fonte: Santos et al., 2015). 55

Tabela 4 - Dados de precipitação diária referentes ao mês de março de 1999. .105

Tabela 5 - Dados de ventos diários referentes ao mês de março de 2002. 107 


\section{Sumário}

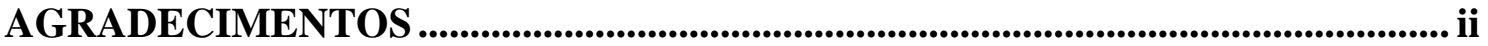

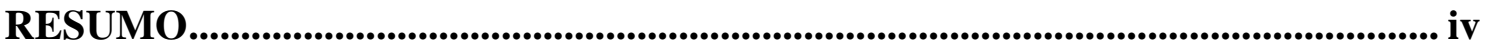

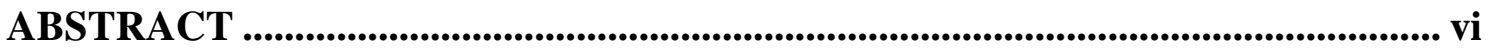

LISTA DE FIGURAS....................................................................................... viii

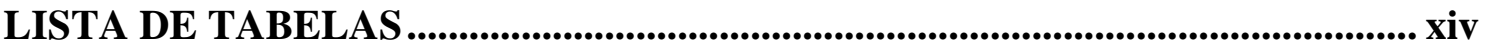

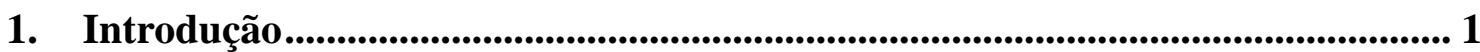

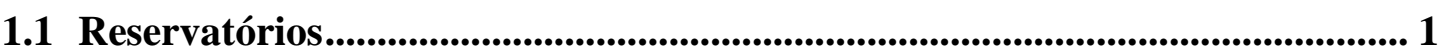

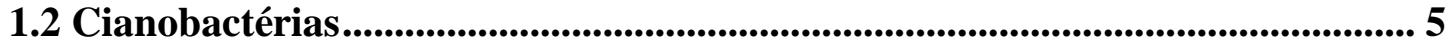

1.3 O Sensoriamento Remoto no Monitoramento de Reservatórios ........................ 7

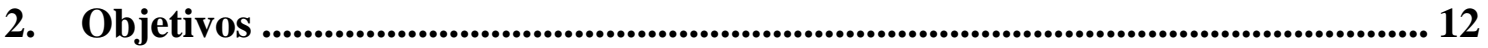

2.1 Objetivo geral..................................................................................................... 12

2.2 Objetivos Específicos............................................................................ 12

3. Materiais e Métodos ............................................................................................. 13

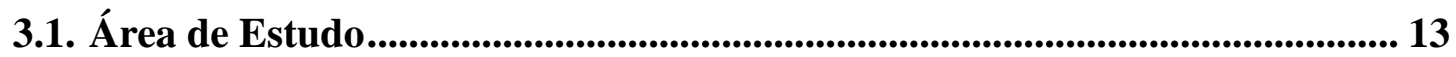

3.2. Variáveis Meteorológicas ............................................................................. 16

3.3. Variáveis Físicas, Químicas e Biológicas ............................................................ 17

3.3.1 Avaliação da qualidade da água em curta escala de tempo ....................................... 17

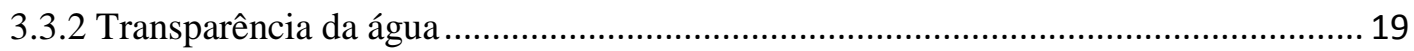

3.3.3 Potencial hidrogeniônico, condutividade elétrica, concentração de oxigênio dissolvido e temperatura da água ............................................................................. 19

3.3.4 Concentrações de Fósforo e Nitrogênio Totais ........................................................... 20

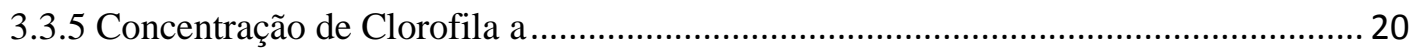

3.3.6 Análise da comunidade fitoplanctônica ................................................................... 21

3.4 Análise da Hidrodinâmica do Reservatório Guarapiranga ............................ 22

3.4.1 Modelo Tridimensional para Análise da Hidrodinâmica ........................................... 22

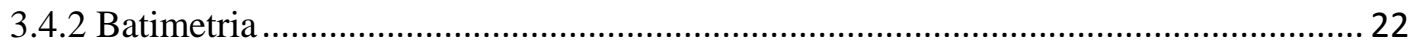

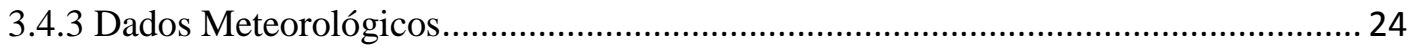

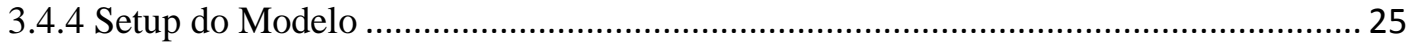

4 - Resultados e Discussão ......................................................................................... 26

4.1 - Análise dos padrões temporais de variação nas condições meteorológicas e hidrológicas no reservatório Guarapiranga. .......................................................... 26

4.1.1 Caracterização de um evento em curta escala de tempo .............................................. 26 
4.1.2 Padrões meteorológicos na região do reservatório Guarapiranga em longa escala temporal.

4.2 - Análise dos padrões espaciais de variação nas características físicas e químicas do reservatório Guarapiranga em diferentes escalas temporais.......... 40

4.2.1 Caracterização da qualidade de água em um evento de curta escala temporal ...........40

4.2.2 Avaliação dos padrões temporais de variação na qualidade da água do reservatório Guarapiranga em ampla escala temporal.

4.3 - Análise dos padrões espaciais de variação na comunidade fitoplanctônica do reservatório Guarapiranga. ........................................................................................... 53

4.3.1 Caracterização da comunidade fitoplanctônica em um evento de curta escala temporal

4.3.2 Caracterização da comunidade fitoplanctônica em um evento de longa escala temporal 60

4.4 - Análise dos padrões espaciais de variação nas comunidades fitoplanctônica e de macrófitas no reservatório Guarapiranga. 63

4.5 Análise da influência das componentes hidrodinâmicas no transporte da água dos rios principais dentro do reservatório................................................................... 74

4.5.1 Simulação um - Simulação com todos os processos hidrodinâmicos incorporados. . 74

4.5.2 Simulação dois - Simulação sem Balanço de Calor e sem Introdução de momento pelo Vento.

4.5.3 - Simulação três - Simulação com momento introduzido pelo vento, mas sem balanço de calor.

4.5.4 Simulação quatro - Simulação geral para análise de padrões espaciais...................... 78

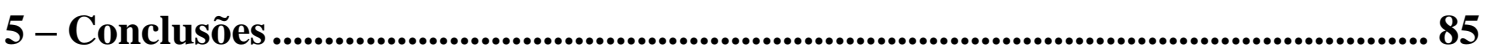

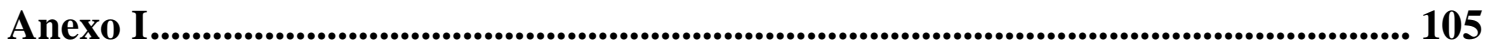




\section{Introdução}

\subsection{Reservatórios}

A água é um elemento essencial para a sobrevivência humana. Em todo o mundo, os principais assentamentos humanos se desenvolveram próximos a rios, lagos e estuários. Ao se localizarem próximo aos corpos de água eles tinham a vantagem de ter água potável e alimentos disponíveis. Com o crescimento dos assentamentos e o surgimento das cidades houve uma maior demanda por água e alimentos. Para atender essa demanda foram desenvolvidos sistemas artificiais de irrigação. Isso permitiu produzir alimentos nos períodos de estiagem e estender as áreas de produção localizadas em regiões áridas (PRISCOLLI, 1998; BUNTGEN et al. (2011).

Para garantir a disponibilidade de água para abastecimento, um grande avanço para a humanidade foi atingido com a construção de reservatórios. Na maior parte dos casos, eles surgiram a partir do barramento de rios, interrompendo o seu curso e inundando as áreas adjacentes. Com o armazenamento de grandes volumes buscou-se garantir o abastecimento humano e diversos outros tipos de demandas por água como: irrigação, hidroeletricidade (no Brasil, cerca de $85 \%$ da energia elétrica é produzida em hidrelétricas (TUNDISI, 2003)), mineração (lavagem e purificação), pesca, transporte, aquicultura e lazer. Contudo, esta prática atualmente desperta alguma preocupação. A construção de reservatórios resulta na redução do escoamento superficial e do transporte de sólidos para os oceanos gerando perturbações em todo o ciclo da água (VÖRÖSMARTY, 1997).

A hidrodinâmica de um reservatório difere bastante daquela de um rio. As velocidades são menores, as profundidades maiores e a área superficial em contato com o ar também aumenta. Isso faz com que as partículas permaneçam por mais tempo em uma região, aumentando também a possibilidade de sofrerem transformações físicas, químicas ou biológicas. Esse tempo, denominado tempo de residência, é um importante parâmetro na análise de um reservatório, já que representa o tempo teórico necessário para que a massa de água no interior de um reservatório seja completamente renovada. Straskraba \& Tundisi (2000) sugerem que um reservatório com água de boa qualidade pode tornar-se um reservatório com água de má qualidade, como resultado apenas do 
aumento do tempo de residência, uma vez que o tempo de retenção influencia vários outros fatores no reservatório, tais como as concentrações de oxigênio e os estoques de nutrientes dissolvidos, este último um fator primordial nos processos de produção primária do fitoplâncton (MATSUMURA-TUNDISI et al., 1997, ÖRNÓLFSDÓTTIR et al., 2004, PILKAITYTÉ \& RAZINKOVAS, 2007). Se o tempo de residência for curto, a qualidade da água será determinada principalmente pelas vazões das águas que entram no reservatório, mas se o tempo de residência for longo pode-se esperar influências de diversos processos internos, tanto na superfície como no fundo (FISCHER et al., 1979).

Os processos físicos são determinantes para o transporte das substâncias e dos organismos dentro do reservatório, desta forma influenciando grandemente diferentes características da água e do próprio reservatório como um todo; Os principais processos físicos são: a advecção que é o transporte gerado pelo sistema de correntes, o cisalhamento, que é a advecção do fluido com diferentes velocidades e diferentes posições; a convecção, que é o transporte vertical decorrente de instabilidade hidrostática; a difusão molecular, que é o espalhamento por movimentos randômicos moleculares; a difusão turbulenta, que é o espalhamento por movimentos randômicos turbulentos; a dispersão, que é o espalhamento de partículas pelos efeitos combinados de cisalhamento e difusão; a evaporação, que é o transporte de vapor de água para a atmosfera; a mistura, que é qualquer processo que faça com que uma parcela da água seja misturada ou diluída por outra e a sedimentação, que é o afundamento de partículas com densidades maiores que a do fluido (KUNDU \& COHEN, 2004).

Desta forma, os processos hidrodinâmicos, estarão sempre associados com os balanços de energia do reservatório. Uma das principais regiões de entrada de energia em reservatórios é a superfície da água. É através dela que o corpo de água recebe a radiação solar, faz as trocas de calor, e recebe as tensões decorrentes dos ventos (HUTCHINSON, 1957).

A estrutura térmica do reservatório tem um papel primordial na sua dinâmica já que produz vários efeitos nos campos de velocidade, na mistura turbulenta e na dispersão (RUTTNER, 1963). Uma pequena variação na temperatura da água já é suficiente para mudar a densidade de uma camada e gerar uma estratificação térmica. 
A profundidade de penetração da radiação de ondas curtas depende da claridade da água (IMBERGER, 1994). A claridade da água ou turbidez é o sombreamento causado por pequenas partículas ou sólidos suspensos na água (MARGALEF, 1983). O aumento da turbidez provoca o aumento da extinção da luz abaixo da superfície da água, concentrando a distribuição do calor na camada superficial, afetando a estratificação térmica, dessa forma, um parâmetro de qualidade de água tem efeito direto sobre a temperatura que por sua vez influencia a qualidade da água tornando o processo cíclico e interativo.

A estratificação térmica é a formação de camadas horizontais devido à estabilização de massas de água de diferentes temperaturas, com as camadas menos densas permanecendo próximas a superfície e as mais densas no fundo. Os reservatórios localizados nas regiões tropicais, normalmente se estratificam nas épocas mais secas.

Nos períodos chuvosos, a alta ocorrência de ventos e tempestades, associados com a baixa profundidade desses reservatórios faz com que ocorram vários eventos de mistura, muitas vezes seguidos de eventos de estratificação, diferentemente das regiões frias e temperadas, onde os reservatórios geralmente possuem apenas um ciclo de estratificação anual, sendo classificados como monomíticos, enquanto os tropicais são frequentemente polimíticos (WETZEL, 2001, MATSUMURA-TUNDISI \& TUNDISI, 2008).

Nas condições normais as isotermas são superfícies horizontais, sendo perturbadas apenas por ventos superficiais e pelas entradas dos rios, essas perturbações podem causar movimentos de ondas internas que provocam oscilações na estrutura térmica, mas não induzem a mistura. Já as tempestades com ventos fortes podem gerar mistura em todo o reservatório.

Os ventos inserem força de cisalhamento na superfície do lago, formando ondas que quebram e transferem momento para a água, o movimento da água principalmente quando as ondas quebram produz turbulência nas camadas superiores, a energia cinética produzida nas camadas superiores é transferida para as camadas inferiores por difusão turbulenta ou por movimentos advectivos como a circulação de Langmuir. 
A termoclina pode atuar como uma proteção para o hipolíminio impedindo a mistura em todas as profundidades, porém quando ocorrem ventos muito fortes e ou muito persistentes, a termoclina pode ser empurrada para baixo e a mistura poderá ocorrer em toda a coluna de água. Essa dificuldade de quebrar a estratificação que cria o isolamento do epilímnio restringindo muitas vezes o crescimento do fitoplâncton às camadas superficiais.

A análise e entendimento desses processos de mistura vertical são essenciais para a compreensão do comportamento da dinâmica horizontal no reservatório, já que a dinâmica do fitoplâncton em reservatórios tropicais e eutróficos é aparentemente dominada por exclusão devido à competição e pelas perturbações decorrentes da hidrodinâmica (STRASKRABA \& TUNDISI, 1999; CALIJURI, et al., 2002).

A grande quantidade de variáveis e fatores envolvidos na análise da hidrodinâmica de um reservatório requerem diversos tipos de estudos para a representação quantitativa dos processos que neles ocorrem (SAGGIO et al., 1998; ANTENUCCI et al., 2000; IMBERGER, 2004).

Segundo Tundisi (2003), em 2025, um terço da população humana estará vivendo em regiões com estresse hídrico. Os atuais sistemas de abastecimento público que levam água para as cidades a partir de grandes reservatórios centrais são altamente suscetíveis a propagação de doenças de veiculação hídrica. Essas doenças podem causar uma elevada mortalidade. Elas são mais frequentes em áreas com alta concentração populacional, onde a disposição inadequada dos resíduos provoca a contaminação das águas superficiais e permitem a dispersão de patógenos.

Apesar de a atual tecnologia permitir que se trate qualquer água e transformando-a em água potável, os custos de tratamento ficam muito altos (TUNDISI, 2003). Dessa forma, torna-se necessário um gerenciamento integrado de recursos hídricos a fim de garantir a quantidade e a qualidade da água. 


\subsection{Cianobactérias}

Uma das maiores preocupações em relação à qualidade da água em reservatórios, tanto para o abastecimento público quanto para outros diversos usos múltiplos diz respeito à ocorrência de densidades muito altas de algas e cianobactérias em ambientes eutrofizados. As cianobactérias representam um grupo muito antigo, que surgiu na Terra há cerca de 4 bilhões de anos (SCHIRRMEISTER, 2011, 2013) tendo, portanto, experimentado uma série de mudanças climáticas globais e evoluções (PAERL et al., 2011), o que explica sua ocorrência em ambientes e profundidades diversas, apesar de sua movimentação estar geralmente condicionada à hidrodinâmica do corpo de água.

Quando ocorrem eventos de mistura, elas são transportadas a profundidades com diferentes níveis de luz. Nessas condições as espécies que melhor sobrevivem são as que possuem capacidade de adaptação às alterações na intensidade de luz (IMBODEN 1990). Segundo Becker (2009) as flutuações na composição e biomassa do fitoplâncton são melhor compreendidas quando são conhecidas as características ecológicas de certas espécies-chave e de grupos taxonômicos ou grupos funcionais. A dominância de cianobactérias tem sido associada a fatores ambientais como: regime de mistura caracterizado por estratificação longa ou diária; escassa disponibilidade de luz; baixa razão da extensão da zona eufótica / zona de mistura; alta temperatura; baixa concentração de $\mathrm{CO}_{2}$ e alto $\mathrm{pH}$; altas concentrações de fósforo total; baixas concentrações de nitrogênio total e de nitrogênio inorgânico dissolvido e baixa razão $\mathrm{N} / \mathrm{P}$.

As espécies de cianobactérias que mais frequentemente ocorrem nos reservatórios brasileiros são pertencentes aos gêneros Microcystis, Anabaena, Cylindrospermopsis e Planktothrix (SANT`ANNA et al., 2006). As espécies dos dois primeiros gêneros apresentam vacúolos de gás (aerótopo) que lhes conferem a capacidade de flutuação levando à formação de densas populações na superfície de lagos e reservatórios (BECKER, 2009). Sua capacidade de flutuação também lhes permite migrar para as camadas superficiais para a realização da fotossíntese. 
As cianobactérias são excelentes competidoras por luz, pois elas possuem ficobilinas, que são pigmentos que absorvem luz na região do verde onde a clorofila não absorve. Essa habilidade permite que algumas espécies de cianobactérias habitem águas muito profundas e permaneçam fotossinteticamente ativas.

Assim, as cianobactérias tendem a formar "escumas" que são massas flutuantes de agregados celulares, nas regiões mais favoráveis como, por exemplo, em regiões com correntes mais baixas, temperaturas mais altas, alta concentração de nutrientes, além de outros processos físicos ou eventos que podem potencializar a acumulação. Essa acumulação pode estar associada também ao crescimento intenso de macrófitas aquáticas no reservatório (POMPEO, 2008), que formam barreiras físicas na superfície permitindo o acúmulo de cianobactérias e algas em determinadas áreas. Esse tipo de associação cianobactéria-macrófita é bastante comum, pois a eutrofização pode inicialmente desencadear o rápido desenvolvimento de cianobactérias e nos estágios mais avançados, o crescimento excessivo de macrófitas (TUNDISI, 2003).

\subsection{Macrófitas}

A maior parte das espécies de macrófitas apresentam características de vegetais terrestres e possuem grande adaptabilidade (ESTEVES, 1988). De acordo com COOK (1974) e IRGANG \& GASTAL JR (1996) elas são definidas como vegetais vasculares submersos ou flutuantes que podem sobreviver em águas doces ou salobras.

Elas contribuem para a estruturação física do ambiente aquático fornecendo abrigo e alimento para várias espécies de vertebrados e invertebrados, além de contribuir na ciclagem dos nutrientes (ESTEVES, 1998), na manutenção do equilíbrio ecológico (GASTAL, 1997) e no controle de erosão (IRGANG \& GASTAL JR, 1996). Algumas espécies podem ser ainda utilizadas como bioindicadores da qualidade da água (PEDRALLI, 2000).

Em áreas rasas, como nas planícies de inundação, elas colonizam áreas extensas e realizam a maior parte da produção primária aquática, funcionando como refúgio para desova e crescimento de indivíduos juvenis de peixes migradores (VAZZOLER et al., 
1997). Elas são fundamentais em áreas alagadas que tem perdido suas funções ecológicas e hidrológicas em função do desenvolvimento urbano.

As características estruturais e funcionais destes organismos são afetadas principalmente pelo regime hidrológico (HENRY, 2003), de acordo com as diferentes magnitudes, frequências e durações dos pulsos hidrológicos (SPINDOLA, 2007), elas podem migrar para outros lugares ou se deslocar do substrato em grandes eventos meteorológicos, indo para ambientes que podem favorecer o seu crescimento.

A proliferação excessiva de macrófitas pode acelerar o processo de eutrofização, levando a anoxia e formação de $\mathrm{H}_{2} \mathrm{~S}$, gerando efeitos nocivos as comunidades planctônicas e bentônicas, além de poder afetar a navegação, a captação de água e a geração de energia (SPINDOLA, 2007). Segundo Pompeo (2003), 95\% da biomassa total dos sistemas aquáticos concentra-se nas macrófitas. Assim, o conhecimento sobre a dinâmica das macrófitas auxilia em seu manejo, e colabora para o gerenciamento ambiental de todo o reservatório.

A distribuição espacial dos eventos de blooms, tanto de fitoplâncton como de macrófitas é difícil de ser captada por coletas pontuais. A elevada heterogeneidade nas características do reservatório afeta diretamente a distribuição no reservatório, tornando necessária uma amostragem sinótica, o qual só é possível com a utilização de ferramentas de sensoriamento remoto e análise de imagens aéreas.

\subsection{O Sensoriamento Remoto no Monitoramento de Reservatórios}

O sensoriamento remoto é definido por Novo (2002) como a tecnologia que permite a aquisição de informações sobre objetos sem contato físico com eles. Isso pode acontecer, através de sensores localizados na Terra ou em órbita. Esses sensores são capazes de coletar a energia proveniente dos objetos, convertendo-a em um sinal registrado e apresentado em forma adequada para extração de informações.

A disponibilidade de tecnologias de sensoriamento remoto com alta resolução espacial e espectral tem crescido muito nos últimos anos (PALMER et al., 2015). Isto 
tem motivado o desenvolvimento de métodos para a interpretação da vasta quantidade de espectros que os sensores fornecem (LEE \& CARDER, 2004).

O sensoriamento remoto tem sido muito útil para o monitoramento em corpos d' água interiores, fornecendo uma visão sinótica da distribuição algal em grande escala (GIN et al, 2001). Existem muitos estudos que buscaram determinar as concentrações de clorofila por meio da análise de imagens de satélite, porém, a maior parte destes estudos foi realizada em oceanos e regiões costeiras da zona temperada (GITELSON, 1993; GITELSON et al., 1993; KIRK, 1994; ARENZ et al., 1996; HAN \& RUNDQUIST, 1997; THIEMANN \& KAUFMANN, 2000, LI et al., 2015).

As técnicas de sensoriamento remoto são ferramentas adequadas para o estudo de algas em águas interiores. Com os avanços na correlação dos principais grupos taxonômicos com os pigmentos acessórios característicos abre-se a possibilidade de detecção destes pigmentos através de suas assinaturas espectrais (LONDE, 2005, LI et al., 2015). O acoplamento da análise das imagens, com os estudos de hidrodinâmica dos reservatórios e os dados coletados em campo, permitem grandes avanços na identificação dos processos formadores de padrões dos florescimentos algais.

As comunidades fitoplanctônicas geralmente se distribuem de forma heterogênea pelos corpos d' água, e usualmente formam agregações em alguns pontos gerando padrões e gradientes. OSTOS et al. (2009) analisaram os efeitos da hidrodinâmica na distribuição espacial das cianobactérias e das diatomáceas em um reservatório termicamente estratificado, no sudoeste da Espanha, e concluíram que o transporte advectivo e a capacidade de flutuação dos diferentes grupos do fitoplâncton determinavam a formação desses padrões.

O estudo de algas com o auxílio de técnicas de sensoriamento remoto teve início com tentativas de detecção de clorofila-a, o pigmento comum a todos os tipos de algas e portanto, indicador da presença de populações fitoplanctônicas, além de ser também um parâmetro com potencial de utilização para a quantificação de biomassa (LONDE, 2005). 
As pesquisas com o objetivo de identificar a clorofila-a foram o passo inicial, após o qual o interesse foi ampliado e passou a incluir outros pigmentos. Como eles estão presentes em diferentes proporções nos vários grupos algais, foi criada a hipótese de que a identificação dos pigmentos presentes em maior quantidade em um corpo d'água possibilitaria a identificação do grupo de organismos (algas ou cianobactérias) aos quais estes pigmentos estariam relacionados (BOLD e WYNNE, 1985; QUIBELL, 1992, TAMM et al., 2015).

Para classificar os pigmentos, a etapa inicial consiste em estabelecer uma "biblioteca espectral", um conjunto de espectros de diferentes grupos de algas, que serviria de referência para a etapa seguinte: a identificação do fitoplâncton via satélite. Ainda há muito a ser feito para a montagem de uma biblioteca espectral. Há uma grande diversidade de pigmentos a ser explorada. No grupo das clorofilas, por exemplo, além das clorofilas a e b, há todo o conjunto de clorofilas-c, que diferem de $5 \mathrm{a} 8 \mathrm{~nm}$ em sua absorção no azul (LONDE, 2005). Para isso seria necessária a utilização de sensores com altas resoluções espectrais (SON et al., 2015).

Hu et al. (2010) utilizaram um espectroradiômetro de resolução moderada para caracterizar blooms de cianobactérias, principalmente Microcystis aeruginosa, no Lago Taihu, o $3^{\circ}$ maior lago de água para abastecimento da China, onde foi analisada a concentração de algas presentes na camada superficial. Para isso eles coletaram imagens entre os anos de 2000 a 2008 e observaram a forte influência das cargas de nutrientes e dos fatores climáticos na produção dos padrões. Ainda neste mesmo lago os autores observaram que a disponibilidade de nutrientes variava ao longo do ano, sendo o nitrogênio o fator limitante para proliferação e manutenção dos blooms de Microcystis spp., levando-os a concluir que a redução da carga de nitrogênio lançada seria essencial para controlar a magnitude e duração dos florescimentos algais, além de ser também necessária a redução da carga de fósforo (HAI et al., 2010).

A análise da qualidade das águas tropicais é mais difícil de ser feita devido às complicações geradas pelas variadas quantidades de pigmentos fotossintéticos, a matéria orgânica dissolvida (principalmente ácido fúlvico e húmico) e os sólidos inorgânicos suspensos (MEYBECK, 1988). O aumento no escoamento superficial devido às tempestades e a existência de canteiros de obra na construção de grandes 
reservatórios podem gerar um aumento na quantidade de sólidos suspensos causando uma significante dispersão de luz (NITTROUER et al., 1995; LONERAGAN \& BUNN, 1991). Enquanto a matéria orgânica dissolvida absorve grande parte da radiação, principalmente da porção azul do espectro (JORGENSEN, 1999), esses efeitos são somados no espectro refletido pelo fitoplâncton, tornando complexos os algoritmos utilizados para estimativa da biomassa algal (GIN et al., 2001).

Para esse tipo de estudo é preciso obter a assinatura espectral da refletância da água, as amostras superficiais para análise das concentrações de clorofila $a$, ficocianina (VINCENT et al., 2004), sólidos suspensos e também os parâmetros de qualidade da água em cada estação, como: condutividade elétrica, temperatura, fluorescência, turbidez da água (ZHAO et al., 2010) e a concentração de oxigênio dissolvido.

Randolph et al. (2008) validaram a proposta semi-empírica de Simis et. al. (2005), para o mapeamento de cianobactérias por meio de pigmentos ativos em águas túrbidas. Para isso analisaram imagens hiperespectrais utilizando algoritmos, que separam os pigmentos como a clorofila a e a ficocianina.

Em um estudo por meio de imagens na Flórida, Fischer et al. (2009) analisaram dados abrangendo quinze meses de observações, nos quais buscaram determinar os principais fatores correlacionados com o aumento da biovolume total de cianobactérias. Os resultados indicaram que a temperatura, a concentração de nitrogênio total e a turbidez influenciaram diretamente o aumento. Porém, a variação de temperatura sozinha já causava mais de $54 \%$ da variabilidade no biovolume das algas evidenciando a necessidade e a possibilidade de se analisar a interação entre múltiplos fatores para explicar padrões espaciais e temporais na dinâmica das populações algais.

Alguns estudos mostram que a temperatura da superfície da Terra está aumentando à uma taxa maior nos últimos anos (IPCC, 2007). As comunidades aquáticas sofrem grande influência dessas alterações, já que as taxas de crescimento são dependentes da temperatura da água (O’NEIL, et al. 2012). No entanto, essa relação ocorre de forma distinta entre as espécies, pois conforme as temperaturas passam dos $20^{\circ} \mathrm{C}$, as taxas de crescimento de algumas espécies continuam a crescer enquanto as demais estabilizam ou começam a diminuir. 
Neste ponto, o aquecimento global pode favorecer as cianobactérias, pois as suas taxas de crescimento ótima geralmente ocorrem a altas temperaturas, normalmente maior do que $25^{\circ} \mathrm{C}$ (PAERL \& HAUISMANN, 2008), permitindo um crescimento maior e mais rápido do que os demais grupos nesta mesma faixa de temperatura.

O combate ao aquecimento global tem sido amplamente difundido pela mídia e pelos diversos meios de comunicação. Essa busca constante pela remoção do crescimento de algas nos lagos do mundo é compreensível, no entanto, impede que uma grande quantidade de carbono seja extraída da atmosfera e auxilie na redução do efeito estufa.

Assim, como em diversos outros problemas ambientais, é necessário se retomar o equilíbrio e para isso, é preciso ter pleno controle e conhecimento do que está acontecendo em todo o sistema. Neste contexto, o presente estudo busca analisar a problemática da formação dos florescimentos algais e de macrófitas sob diversas perspectivas. 


\section{Objetivos}

\section{$2.1 \quad$ Objetivo geral}

O objetivo geral do presente estudo foi investigar a formação de alguns florescimentos de algas, cianobactérias e macrófitas em um reservatório urbano destinado ao abastecimento público e identificar o papel da meteorologia e da hidrodinâmica nos padrões e eventos documentados, em diferentes escalas espaciais e temporais.

\subsection{Objetivos Específicos}

\section{- Investigar os padrões temporais de formação dos florescimentos algais.}

- Identificar os períodos em que o ambiente apresenta condições mais propícias ao surgimento de florescimentos algais, analisando a variabilidade climática, a estrutura térmica e a qualidade da água ao longo de vários anos.

Não se pretende determinar com exatidão os períodos em que ocorrerão os “blooms”, mas identificar os períodos mais propícios para o seu surgimento.

\section{- Investigar padrões espaciais de formação de florescimentos algais e de macrófitas.}

- Identificar as áreas de maior e menor mistura e as possíveis zonas de estagnação, que criam condições ideais para o crescimento ou acumulação do fitoplâncton, ou de macrófitas.

- Identificar os "caminhos" de formação dos "blooms" ao longo do reservatório.

Com isso, pretende-se mostrar que os "blooms" não se formam aleatoriamente, e que mesmo em um reservatório com grande disponibilidade de nutrientes, existem 
regiões com maior probabilidade de ocorrência e "caminhos de formação" que são recorrentes.

\section{- Investigar os padrões hidrodinâmicos que propiciam as formações dos padrões espaciais e temporais observados.}

- Identificar os mecanismos e processos hidrodinâmicos que propiciam a formação dos padrões anteriormente encontrados.

- Detalhar e analisar esses processos.

\section{Materiais e Métodos}

Este trabalho foi desenvolvido como parte do projeto "Sistema de Prognóstico e Diagnóstico da Qualidade de Água dos Reservatórios" desenvolvido no Laboratório de Limnologia, Departamento de Ecologia e Biologia Evolutiva da Universidade Federal de São Carlos, coordenado pelo Prof. Dr. Ângelo Saggio e com a colaboração da Profa. Tit. Odete Rocha e financiado pela SABESP (Companhia de Saneamento Básico do Estado de São Paulo) (Processo UFSCar/ PROEX: 23112.001431/2009-48).

\section{1. Área de Estudo}

O presente estudo foi realizado no reservatório Guarapiranga, um reservatório tropical polimítico localizado na bacia do Alto Tietê em São Paulo, Brasil. Este reservatório tem cerca de $30 \mathrm{~km}^{2}$ de lâmina d’água e uma profundidade máxima de aproximadamente $15 \mathrm{~m}$. Segundo a SABESP, atualmente este reservatório é a principal fonte do Sistema de Abastecimento de Água da Região Metropolitana de São Paulo (RMSP), abastecendo uma população de cerca de 5,8 milhões de pessoas.

O reservatório Guarapiranga foi construído no início do século XX (1906), para suprir a demanda de energia de municípios da Região Metropolitana de São Paulo (RMSP). Alguns anos depois, ele passou a ser utilizado para captação de água potável para abastecimento. A construção deste reservatório e também do reservatório Billings impulsionou o desenvolvimento de toda a área ao seu redor. No entanto, esse 
desenvolvimento ocorreu de forma desordenada, com ocupações irregulares e infraestrutura precária, acarretando na alta densidade populacional e na ausência de sistemas de esgoto que persiste em muitos locais até hoje (WHATELY \& CUNHA, 2006).

Com isso, durante os mais de 100 anos de existência, a diluição dos resíduos domésticos e industriais, somados ao escoamento superficial e a inundação de terrenos ricos em nutrientes, provocou a eutrofização do reservatório, ocasionando uma série de problemas que impactam a qualidade da água (HELOU \& SILVA, 1987, BEYRUTH, 1996, STRASKRABA \& TUNDISI,1999).

Na Figura 1 é apresentada a localização da bacia hidrográfica e do reservatório Guarapiranga. A bacia do Guarapiranga possui cerca de $639 \mathrm{~km}^{2}$ e está localizada na região sudoeste da cidade de São Paulo, Brasil. A Tabela 1 apresenta as principais características do sistema Guarapiranga.

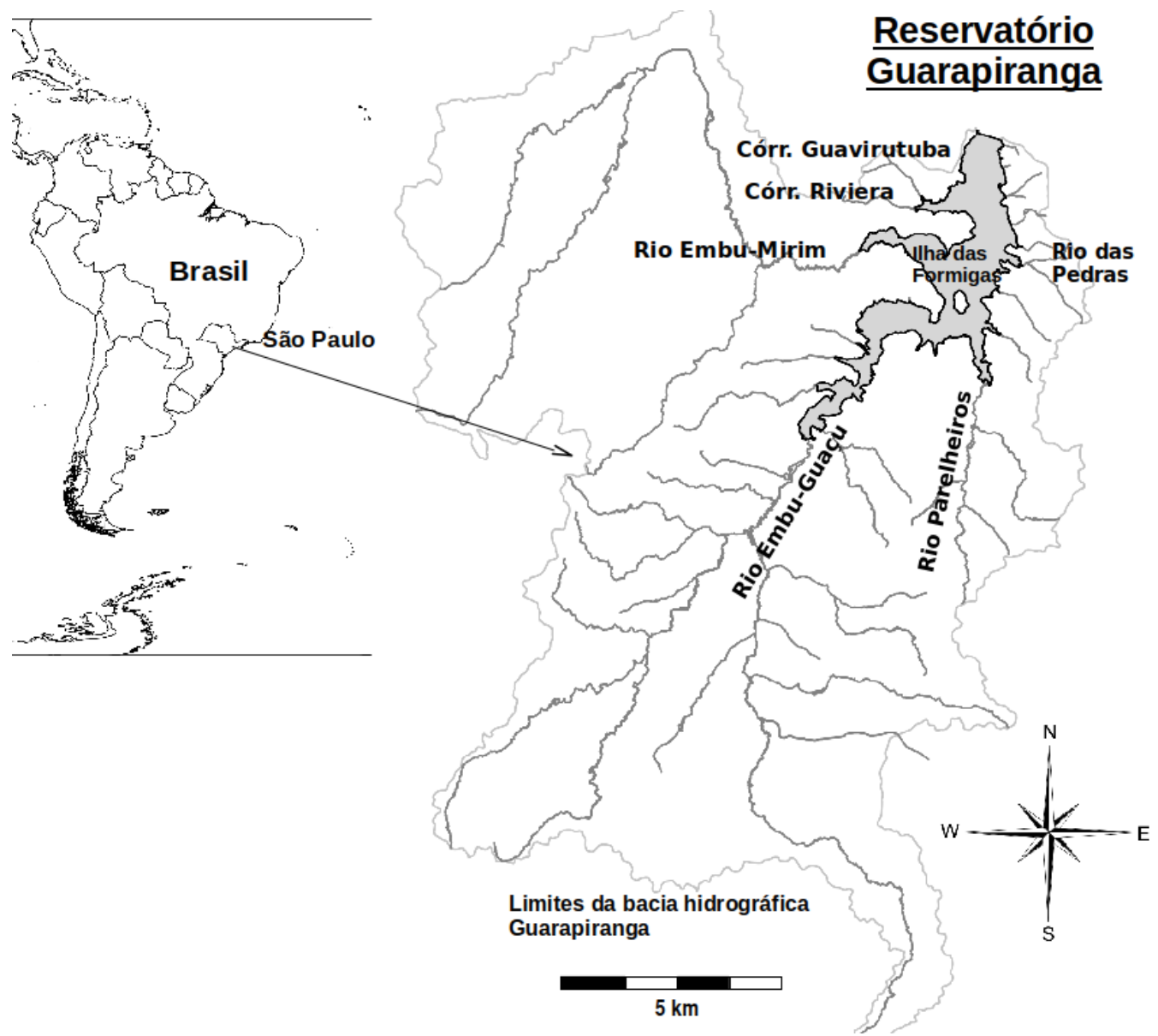

Figura 1 - Localização da bacia hidrográfica e do reservatório Guarapiranga, com apresentação dos principais afluentes. 
Tabela 1 - Principais características do reservatório Guarapiranga

\begin{tabular}{ll}
\hline Características & Reservatório Guarapiranga \\
\hline Bacia Hidrográfica & Alto Tietê \\
Área da bacia hidrográfica & $639 \mathrm{~km}^{2}$ \\
Altitude & $742 \mathrm{~m}$ \\
Profundidade média & $7 \mathrm{~m}$ \\
Área do espelho de água & $34 \mathrm{~km}^{2}$ \\
Volume & $195 \mathrm{milhões} \mathrm{de} \mathrm{m}^{3}$ \\
Tempo de residência médio & $120 \mathrm{dias}$ \\
Produção de água & $\sim 16 \mathrm{~m} 3 / \mathrm{s}$ \\
População abastecida & $5,8 \mathrm{milhões}$ \\
População residente na bacia & $\sim 1 \mathrm{milhão} \mathrm{de} \mathrm{pessoas}$ \\
\hline
\end{tabular}

Fonte: www.sabesp.com.br

O declínio da qualidade da água desse manancial tem sido crescente desde a década de 1970 (BEYRUTH et al., 1996), pelo constante aumento da população que vive às suas margens e pela ausência de um sistema de coleta e tratamento de esgotos em uma porção significativa da bacia hidrográfica, aumentando a cada ano o aporte de nutrientes e sedimentos à represa e fazendo com que ocorram eventos de florescimentos algais em várias épocas do ano.

Atualmente a represa Guarapiranga é o principal manancial da RMSP. Em 2014, houve uma grave crise hídrica no sistema de abastecimento que a colocou nessa condição. Anteriormente, o Sistema Cantareira era responsável pela maior parte do abastecimento de água da RMSP, contudo, após uma sequência de anos com precipitação abaixo da média e o constante aumento no consumo, as reservas de água do sistema diminuíram grandemente fazendo com que este operasse abaixo do nível normal de operação, utilizando-se o "volume morto" para manter o abastecimento da população.

Tendo em vista esse cenário, a SABESP passou a utilizar o reservatório Guarapiranga para suprir parte da demanda do Cantareira, para isso, a operadora do sistema, aumentou a quantidade de água aduzida do braço do Taquacetuba, que fica na represa Billings a cerca de 8 quilômetros e incluiu também a vazão de um interceptor de esgoto que iria para a estação de tratamento em Barueri. Essas medidas, em conjunto com uma grande campanha de uso racional da água e com o efetivo racionamento em 
diversas regiões da cidade, foram suficientes para atender com algumas limitações as demandas mais prementes da população durante o período.

No entanto, ter o reservatório Guarapiranga como principal manancial é uma situação crítica, pois o seu volume total é pequeno, cerca de 1/5 do sistema Cantareira. Além disso, a transposição do Taquacetuba provoca uma rápida deterioração da qualidade da água deste reservatório (NISHIMURA, 2012).

A garantia da qualidade da água de abastecimento público da represa de Guarapiranga tem exigido altos investimentos relacionados ao tratamento de água, o que reflete em maior custo da água fornecida para o consumidor e um maior impacto no meio ambiente.

\subsection{Variáveis Meteorológicas}

Um dos maiores avanços da Limnologia no último século foi a identificação de escalas espaciais e temporais muito menores do que se conhecia (IMBERGER, 1994). Por isso, é necessária a análise das várias escalas e das respectivas forçantes que se relacionam com as variações na qualidade da água.

Para a análise das variações de curto prazo, as variáveis meteorológicas foram obtidas por meio de uma estação meteorológica flutuante produzida pela Global Water Monitoring Systems instalada próximo à barragem e ao ponto de captação de água para abastecimento. Nela são captados os dados de temperatura do ar, velocidade e a direção do vento, registrados automaticamente a cada 10 minutos e armazenados em um "data logger". Os valores de precipitação pluviométrica foram fornecidos pela SABESP e coletados de um pluviômetro localizado próximo à barragem.

A análise de padrões temporais de longo prazo em meteorologia requer um conjunto de dados com duração e frequência de medições suficientes para se detectarem componentes periódicas de baixa frequência, para isso necessita-se de vários anos de dados. Por esta razão, para o presente estudo foram utilizados os dados meteorológicos fornecidos pela Estação Meteorológica do Instituto de Astronomia, Geofísica e Ciências Atmosféricas da Universidade de São Paulo - (IAG-USP), que foi fundada em 1932 e encontra-se instalada no Parque das Fontes do Ipiranga, a cerca de $10 \mathrm{~km}$ a nordeste do 
reservatório Guarapiranga. Os dados utilizados são dados mensais e anuais de temperatura do ar, velocidade e direção do vento e precipitação pluviométrica obtidos para o período de 1997 a 2015 solicitados ao IAG-USP. Esses dados serão utilizados para mostrar a consistência da existência dos eventos observados em curta escala de tempo.

\subsection{Variáveis Físicas, Químicas e Biológicas}

\subsubsection{Avaliação da qualidade da água em curta escala de tempo}

Nos dias 13 e 14 de setembro de 2010 foram realizadas duas amostragens em 64 pontos distribuídos ao longo de toda a extensão do reservatório Guarapiranga para análise dos padrões espaciais no eixo horizontal. Na Figura 2 é apresentado o mapa esquemático com a localização dos 64 pontos amostrados no reservatório, cujas coordenadas geográficas são apresentadas na Tabela 2. Nesses pontos foram realizadas medidas in situ de visibilidade do Disco de Secchi (transparência da água) e coleta da água para determinação das concentrações de clorofila-a, fósforo total e nitrogênio total. Para isso, foram utilizados 4 barcos com equipes de 3 pessoas, equipadas com os materiais para coleta. Os pontos foram divididos de tal forma que a distância percorrida pelas equipes foram semelhantes, permitindo realizar as coletas de forma simultânea.

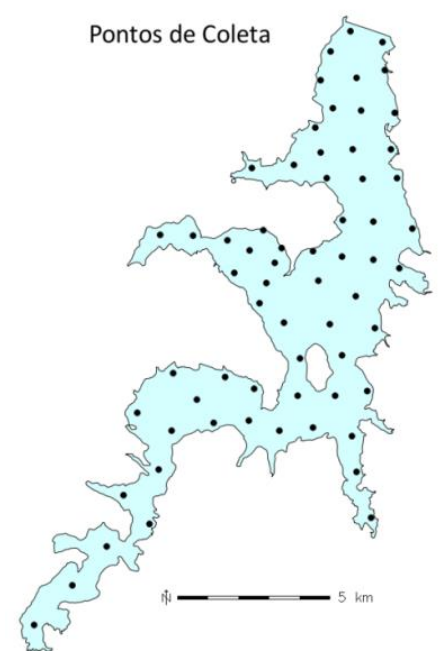

Figura 2 - Mapa esquemático mostrando a localização dos 64 pontos amostrados na represa nos dias 13 e 14 de setembro de 2010, foram realizadas medidas de varáveis físicas e químicas in situ e coletadas amostras de água 
Tabela 2. Localização geográfica dos pontos amostrados no reservatório Guarapiranga.

\begin{tabular}{|c|c|c|c|}
\hline Pontos & Coordenadas geográficas & Pontos & Coordenadas geográficas \\
\hline 1 & $23^{\circ} 40^{\prime} 23,75^{\prime \prime} \mathrm{S}$ e $46^{\circ} 43^{\prime} 36,21^{\prime \prime W}$ & 33 & $23^{\circ} 42^{\prime} 53,49^{\prime \prime} \mathrm{S}$ e $46^{\circ} 44^{\prime} 32,48^{\prime \prime} \mathrm{W}$ \\
\hline 2 & $23^{\circ} 40^{\prime} 31,05^{\prime \prime} \mathrm{S}$ e $46^{\circ} 43^{\prime} 13,40^{\prime \prime} \mathrm{W}$ & 34 & $23^{\circ} 43^{\prime} 6,43^{\prime \prime} \mathrm{S}$ e $46^{\circ} 44^{\prime} 38,65^{\prime \prime} \mathrm{W}$ \\
\hline 3 & $23^{\circ} 40^{\prime} 36,88^{\prime \prime} \mathrm{S}$ e $46^{\circ} 43^{\prime} 50,78^{\prime \prime} \mathrm{W}$ & 35 & $23^{\circ} 43^{\prime} 19,34^{\prime \prime} \mathrm{S}$ e $46^{\circ} 44^{\prime} 44,09^{\prime \prime} \mathrm{W}$ \\
\hline 4 & $23^{\circ} 40^{\prime} 55,23^{\prime \prime} \mathrm{S}$ e $46^{\circ} 43^{\prime} 58,08^{\prime \prime} \mathrm{W}$ & 36 & $23^{\circ} 43^{\prime} 5,22^{\prime \prime S}$ e $46^{\circ} 44^{\prime} 1,57^{\prime \prime} \mathrm{W}$ \\
\hline 5 & $23^{\circ} 40^{\prime} 54,28^{\prime \prime} \mathrm{S}$ e $46^{\circ} 43^{\prime} 32,37^{\prime \prime} \mathrm{W}$ & 37 & $23^{\circ} 43^{\prime} 15,69^{\prime \prime} \mathrm{S}$ e $46^{\circ} 43^{\prime} 35,08^{\prime \prime} \mathrm{W}$ \\
\hline 6 & $23^{\circ} 40^{\prime} 49,24^{\prime \prime} \mathrm{S}$ e $46^{\circ} 43^{\prime} 12,12^{\prime \prime} \mathrm{W}$ & 38 & $23^{\circ} 43^{\prime} 32,57^{\prime \prime} \mathrm{S}$ e $46^{\circ} 44^{\prime} 26,64^{\prime \prime} \mathrm{W}$ \\
\hline 7 & $23^{\circ} 41^{\prime} 13,63^{\prime \prime S}$ e $46^{\circ} 43^{\prime} 49,57^{\prime \prime W}$ & 39 & $23^{\circ} 43^{\prime} 33,59^{\prime \prime} \mathrm{S}$ e $46^{\circ} 43^{\prime} 53,82^{\prime \prime} \mathrm{W}$ \\
\hline 8 & $23^{\circ} 41^{\prime} 15,41^{\prime \prime S}$ e $46^{\circ} 43^{\prime} 29,23^{\prime \prime W}$ & 40 & $23^{\circ} 43^{\prime} 36,55^{\prime \prime} \mathrm{S}$ e $46^{\circ} 43^{\prime} 21,37^{\prime \prime} \mathrm{W}$ \\
\hline 9 & $23^{\circ} 41^{\prime} 17,24^{\prime \prime S}$ e $46^{\circ} 43^{\prime} 5,50^{\prime \prime} \mathrm{W}$ & 41 & $23^{\circ} 43^{\prime} 55,87^{\prime \prime} \mathrm{S}$ e $46^{\circ} 44^{\prime} 15,48^{\prime \prime} \mathrm{W}$ \\
\hline 10 & $23^{\circ} 41^{\prime} 25,96^{\prime \prime} \mathrm{S}$ e $46^{\circ} 44^{\prime} 2,48^{\prime \prime} \mathrm{W}$ & 42 & $23^{\circ} 43^{\prime} 53,87^{\prime \prime} \mathrm{S}$ e $46^{\circ} 43^{\prime} 44,91^{\prime \prime} \mathrm{W}$ \\
\hline 11 & $23^{\circ} 41^{\prime} 52,04^{\prime \prime} \mathrm{S}$ e $46^{\circ} 44^{\prime} 48,25^{\prime \prime} \mathrm{W}$ & 43 & $23^{\circ} 44^{\prime} 20,07^{\prime \prime} \mathrm{S}$ e $46^{\circ} 44^{\prime} 17,53^{\prime \prime} \mathrm{W}$ \\
\hline 12 & $23^{\circ} 41^{\prime} 50,01^{\prime \prime S}$ e $46^{\circ} 44^{\prime} 18,22^{\prime \prime W}$ & 44 & $23^{\circ} 44^{\prime} 20,37^{\prime \prime S}$ e $46^{\circ} 43^{\prime} 50,34^{\prime \prime} \mathrm{W}$ \\
\hline 13 & $23^{\circ} 41^{\prime} 42,36^{\prime \prime} \mathrm{S}$ e $46^{\circ} 43^{\prime} 58,71^{\prime \prime} \mathrm{W}$ & 45 & $23^{\circ} 44^{\prime} 17,51^{\prime \prime S}$ e $46^{\circ} 43^{\prime} 27,39^{\prime \prime} \mathrm{W}$ \\
\hline 14 & $23^{\circ} 41^{\prime} 40,34^{\prime \prime} \mathrm{S}$ e $46^{\circ} 43^{\prime} 35,52^{\prime \prime} \mathrm{W}$ & 46 & $23^{\circ} 44^{\prime} 42,58^{\prime \prime} \mathrm{S}$ e $46^{\circ} 44^{\prime} 30,54^{\prime \prime} \mathrm{W}$ \\
\hline 15 & $23^{\circ} 41^{\prime} 40,64^{\prime \prime} \mathrm{S}$ e $46^{\circ} 43^{\prime} 8,34^{\prime \prime} \mathrm{W}$ & 47 & $23^{\circ} 44^{\prime} 40,50^{\prime \prime} \mathrm{S}$ e $46^{\circ} 44^{\prime} 6,75^{\prime \prime} \mathrm{W}$ \\
\hline 16 & $23^{\circ} 41^{\prime} 58,89^{\prime \prime} \mathrm{S}$ e $46^{\circ} 43^{\prime} 54,44^{\prime \prime} \mathrm{W}$ & 48 & $23^{\circ} 44^{\prime} 46,28^{\prime \prime} \mathrm{S}$ e $46^{\circ} 43^{\prime} 38,82^{\prime \prime} \mathrm{W}$ \\
\hline 17 & $23^{\circ} 41^{\prime} 59,95^{\prime \prime S}$ e $46^{\circ} 43^{\prime} 28,97^{\prime \prime W}$ & 49 & $23^{\circ} 45^{\prime} 9,75^{\prime \prime} \mathrm{S}$ e $46^{\circ} 43^{\prime} 35,74^{\prime \prime} \mathrm{W}$ \\
\hline 18 & $23^{\circ} 41^{\prime} 59,44^{\prime \prime} \mathrm{S}$ e $46^{\circ} 43^{\prime} 4,35^{\prime \prime} \mathrm{W}$ & 50 & $23^{\circ} 45^{\prime} 39,57^{\prime \prime} \mathrm{S}$ e $46^{\circ} 43^{\prime} 25,92^{\prime \prime} \mathrm{W}$ \\
\hline 19 & $23^{\circ} 42^{\prime} 26,41^{\prime \prime} \mathrm{S}$ e $46^{\circ} 43^{\prime} 43,40^{\prime \prime} \mathrm{W}$ & 51 & $23^{\circ} 44^{\prime} 15,04^{\prime \prime} \mathrm{S}$ e $46^{\circ} 44^{\prime} 48,39^{\prime \prime} \mathrm{W}$ \\
\hline 20 & $23^{\circ} 42^{\prime} 27,37^{\prime \prime} \mathrm{S}$ e $46^{\circ} 43^{\prime} 21,70^{\prime \prime} \mathrm{W}$ & 52 & $23^{\circ} 44^{\prime} 35,31^{\prime \prime} \mathrm{S}$ e $46^{\circ} 44^{\prime} 52,51^{\prime \prime} \mathrm{W}$ \\
\hline 21 & $23^{\circ} 42^{\prime} 32,39^{\prime \prime} \mathrm{S}$ e $46^{\circ} 42^{\prime} 53,77^{\prime \prime} \mathrm{W}$ & 53 & $23^{\circ} 44^{\prime} 6,97^{\prime \prime S}$ e $46^{\circ} 45^{\prime} 9,12^{\prime \prime} \mathrm{W}$ \\
\hline 22 & $23^{\circ} 42^{\prime} 46,42^{\prime \prime} \mathrm{S}$ e $46^{\circ} 44^{\prime} 5,24^{\prime \prime} \mathrm{W}$ & 54 & $23^{\circ} 44^{\prime} 4,20^{\prime \prime} \mathrm{S}$ e $46^{\circ} 45^{\prime} 46,44^{\prime \prime} \mathrm{W}$ \\
\hline 23 & $23^{\circ} 42^{\prime} 49,78^{\prime \prime} \mathrm{S}$ e $46^{\circ} 43^{\prime} 44,06^{\prime \prime} \mathrm{W}$ & 55 & $23^{\circ} 44^{\prime} 21,59^{\prime \prime} \mathrm{S}$ e $46^{\circ} 45^{\prime} 29,69^{\prime \prime} \mathrm{W}$ \\
\hline 24 & $23^{\circ} 42^{\prime} 52,40^{\prime \prime} \mathrm{S}$ e $46^{\circ} 43^{\prime} 22,03^{\prime \prime} \mathrm{W}$ & 56 & $23^{\circ} 44^{\prime} 36,58^{\prime \prime} \mathrm{S}$ e $46^{\circ} 45^{\prime} 17,99^{\prime \prime} \mathrm{W}$ \\
\hline 25 & $23^{\circ} 42^{\prime} 58,07^{\prime \prime} \mathrm{S}$ e $46^{\circ} 43^{\prime} 3,43^{\prime \prime} \mathrm{W}$ & 57 & $23^{\circ} 44^{\prime} 29,69^{\prime \prime} \mathrm{S}$ e $46^{\circ} 46^{\prime} 12,25^{\prime \prime} \mathrm{W}$ \\
\hline 26 & $23^{\circ} 42^{\prime} 34,27^{\prime \prime} \mathrm{S}$ e $46^{\circ} 45^{\prime} 54,13^{\prime \prime} \mathrm{W}$ & 58 & $23^{\circ} 44^{\prime} 41,70^{\prime \prime} \mathrm{S}$ e $46^{\circ} 45^{\prime} 47,80^{\prime \prime} \mathrm{W}$ \\
\hline 27 & $23^{\circ} 42^{\prime} 35,31^{\prime \prime S}$ e $46^{\circ} 45^{\prime} 30,81^{\prime \prime W}$ & 59 & $23^{\circ} 45^{\prime} 6,59^{\prime \prime} \mathrm{S}$ e $46^{\circ} 45^{\prime} 57,45^{\prime \prime} \mathrm{W}$ \\
\hline 28 & $23^{\circ} 42^{\prime} 38,48^{\prime \prime} \mathrm{S}$ e $46^{\circ} 45^{\prime} 6,24^{\prime \prime} \mathrm{W}$ & 60 & $23^{\circ} 45^{\prime} 22,71^{\prime \prime} \mathrm{S}$ e $46^{\circ} 46^{\prime} 23,13^{\prime \prime} \mathrm{W}$ \\
\hline 29 & $23^{\circ} 42^{\prime} 31,98^{\prime \prime} \mathrm{S}$ e $46^{\circ} 44^{\prime} 40,70^{\prime \prime} \mathrm{W}$ & 61 & $23^{\circ} 45^{\prime} 41,68^{\prime \prime} \mathrm{S}$ e $46^{\circ} 46^{\prime} 4,71^{\prime \prime} \mathrm{W}$ \\
\hline 30 & $23^{\circ} 42^{\prime} 45,16^{\prime \prime} \mathrm{S}$ e $46^{\circ} 44^{\prime} 50,73^{\prime \prime} \mathrm{W}$ & 62 & $23^{\circ} 45^{\prime} 56,18^{\prime \prime} \mathrm{S}$ e $46^{\circ} 46^{\prime} 35,49^{\prime \prime} \mathrm{W}$ \\
\hline 31 & $23^{\circ} 42^{\prime} 59,67^{\prime \prime} \mathrm{S}$ e $46^{\circ} 45^{\prime} 1,51^{\prime \prime} \mathrm{W}$ & 63 & $23^{\circ} 46^{\prime} 20,89^{\prime \prime} \mathrm{S}$ e $46^{\circ} 47^{\prime} 0,44^{\prime \prime} \mathrm{W}$ \\
\hline 32 & $23^{\circ} 42^{\prime} 43.83^{\prime \prime} \mathrm{S}$ e $46^{\circ} 44^{\prime} 27,27^{\prime \prime} \mathrm{W}$ & 64 & $23^{\circ} 46^{\prime} 46,35^{\prime \prime} \mathrm{S}$ e $46^{\circ} 47^{\prime} 27,96^{\prime \prime} \mathrm{W}$ \\
\hline
\end{tabular}

No compartimento Embu-Mirim, foi realizado um estudo nictemeral em um ponto amostral, cuja localização é indicada na Figura 3, durante 48 horas foram 18 
realizadas medidas in situ e amostragens de água e material biológico a cada 3 horas. Foram feitas coletas nas profundidades $0 \mathrm{~m}, 2 \mathrm{~m}, 4 \mathrm{~m}$ e $6 \mathrm{~m}$.

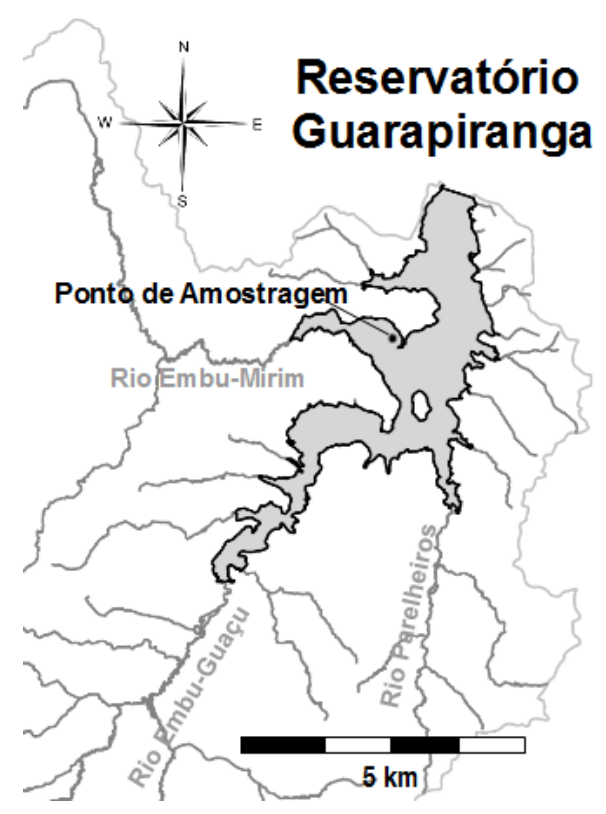

Figura 3 - Mapa do reservatório Guarapiranga, São Paulo, SP, mostrando a localização do ponto de amostragem no braço do rio Embu Mirim, utilizado para a realização do estudo de curta escala espacial e temporal.

\subsubsection{Transparência da água}

A transparência da água foi determinada pela leitura do Disco de Secchi. Foram feitas leituras com um disco de 0,30 m de diâmetro e de cor branca. Para isso, o disco foi abaixado verticalmente na coluna d'água, na sombra. O valor médio entre as profundidades em que o disco de Secchi desaparecia e reaparecia foi tomado como a medida da transparência da água.

\subsubsection{Potencial hidrogeniônico, condutividade elétrica, concentração de oxigênio dissolvido e temperatura da água}

A medida das variáveis físicas e químicas $(\mathrm{pH}$, condutividade elétrica da água, concentração de oxigênio dissolvido e temperatura da água) foram realizadas "in situ" em toda a coluna d'àgua, utilizando-se um multisensor da marca HORIBA ${ }^{\circledR}$, modelo U10. 


\subsubsection{Concentrações de Fósforo e Nitrogênio Totais}

As amostras de água para as análises do fósforo total e de nitrogênio total foram coletadas na superfície da água, acondicionadas em frascos de polietileno e congeladas até a análise e processamento, que ocorreu posteriormente, no laboratório da Divisão de Gestão e Desenvolvimento Operacional de Recursos Hídricos Metropolitano pelo método de digestão em microondas e cromatografia iônica (COLINA \& GARDINER, 1999).

\subsubsection{Concentração de Clorofila a}

Para a determinação da concentração de clorofila $a$ foi empregada a técnica da extração com metanol a quente descrita em Nush (1980). De acordo com este método cerca de 0,3 a 0,5 litro de água foi filtrada sob vácuo, em filtros de fibra de vidro GF/C de $5 \mathrm{~cm}$ de diâmetro e $1,2 \mu \mathrm{m}$ de abertura de poro para retenção do material algal, após isso os filtros foram armazenados no escuro em frascos com sílica gel e mantidos em freezer até o momento da extração da clorofila. Para a extração foi utilizado como solvente o etanol $80 \%$ a quente.

Os filtros foram então macerados em almofariz, sob luz reduzida. Após a maceração o material foi mantido em geladeira por 24 horas. Após esse período, foi deixado em temperatura ambiente até chegar ao equilíbrio térmico, centrifugado e o sobrenadante (extrato) transferido para um balão volumétrico, completando-se o volume para $10 \mathrm{~mL}$. A leitura da absorbância do extrato da clorofila foi determinada utilizandose um espectrofotômetro, nos comprimentos de onda de $663 \mathrm{~nm}$, utilizando-se a solução de metanol à $80 \%$ como referência (branco).

Após a leitura da absorbância da clorofila, foi feita a determinação da feofitina, que é um produto da decomposição da clorofila, por meio da acidificação do extrato com solução de $\mathrm{HCl}$ 4N. Após agitação por cinco segundos, a absorbância foi novamente determinada no espectrofotômetro, nos comprimentos de onda de 663 e também a $750 \mathrm{~nm}$. 
Para o cálculo da concentração da clorofila e da feofitina foram utilizadas as fórmulas propostas por Golterman et al., (1978).

\subsubsection{Análise da comunidade fitoplanctônica}

Para a análise do fitoplâncton do reservatório Guarapiranga foram coletadas amostras de $250 \mathrm{~mL}$ de água em cada um dos 64 pontos. Estas amostras foram tomadas diretamente da superfície da água, sem a utilização de rede de plâncton, e foram fixadas com solução de formol em concentração de $4 \%$.

Para identificação e quantificação das densidades das populacões fitoplanctônicas as amostras foram posteriormente fixadas com solução de lugol. A análise da composição taxonômica dos organismos fitoplanctônicos presentes nas amostras foi realizada em lâminas e lamínulas sob microscópio binocular pela bióloga Renata Martins dos Santos (SANTOS, 2014) de acordo com as características morfológicas e morfométricas dos mesmos. Essa análise foi efetuada ao menor nível taxonômico possível com base em bibliografia especializada (ANAGNOSTIDIS \& KOMÁREK, 1988; KOMÁREK \& ANAGNOSTIDIS 1989; 1999 para Cyanophyceae; KOMÁREK \& FOTT, 1983 para Chlorococcales; SIMONSEN, 1979 para Bacillariophyceae, BOURRELLY, 1968 para a classe Dinophyceae; BICUDO, 2005 para as demais).

A análise quantitativa do fitoplâncton foi realizada com microscópio invertido, após prévia sedimentação em câmara de Utermöhl. Foram utilizadas câmaras de sedimentação com volumes de 10 e $20 \mathrm{~mL}$, com tempo de sedimentação de três horas para cada centímetro de altura da câmara (MARGALEF,1983).

No presente estudo foram utilizados apenas os dados quantitativos em nível de grande grupo (Classe) para Cyanophyta e Algas. 


\subsection{Análise da Hidrodinâmica do Reservatório Guarapiranga}

\subsubsection{Modelo Tridimensional para Análise da Hidrodinâmica}

A simulação numérica para este estudo foi baseada no modelo ELCOM (Estuary and Lake Computer Model), um modelo tridimensional de hidrodinâmica para lagos, desenvolvido no Centre for Water Research, Australia, o qual tem sido amplamente utilizado em muitos estudos de hidrodinâmica de lagos e reservatórios ao redor do mundo (SAGGIO et al., 1998; ANTENUCCI et al., 2000; IMBERGER, 2004; LABORDE et al., 2010; VILHENA et al., 2010; NG, et. al., 2010; OKELY et al., 2010). Este modelo permite a simulação do balanço de calor em consequência do resfriamento ou aquecimento da camada superficial, a mistura de escalares e cálculo do momentum utilizando o modelo para a mistura de camadas, introduzindo momentum por meio da energia fornecida pelo vento, solucionando equações de evolução da superfície livre e campos de velocidade, o cálculo do tempo de difusão horizontal, a advecção horizontal e difusão de escalares. O balanço de calor na superfície é governado pelo modelo padrão de transferência de (IMBERGER \& PATTERSON, 1981). As equações utilizadas para transporte foram a de Navier-Stokes Reynoldsponderada com a aproximação de Boussinesq e sem os termos de pressão nãohidrostática. A evolução da superfície livre é governada por uma equação de evolução derivada pela integração vertical da equação de continuidade aplicada às condições de contorno cinemática da ponderação de Reynolds (HODGES \& DALLIMORE, 2009).

\subsubsection{Batimetria}

Para a simulação hidrodinâmica o reservatório Guarapiranga foi dividido em células de $100 \mathrm{~m}$ x 100m x 0.33m de profundidade, como é apresentado na Figura $4 \mathrm{em}$ relação à batimetria da represa. Esta discretização do reservatório foi baseada em um levantamento batimétrico realizado em 2004 pela Hidrocart Cartografia Ltd., para a Companhia Metropolitana de Água e Energia (EMAE, Brazil). Os dados brutos estavam disponíveis para seções com espaçamento de 50m, com leituras ecobatimétricas georeferenciadas (UTM Stream Alegre, zone 23S, EPUSP elevation). Esta informação foi processada com o software GRASS GIS, juntamente com os mapas digitais de 
elevação da bacia de captação, malha hidrográfica e registros de descargas de efluentes disponibilizados pela SABESP.

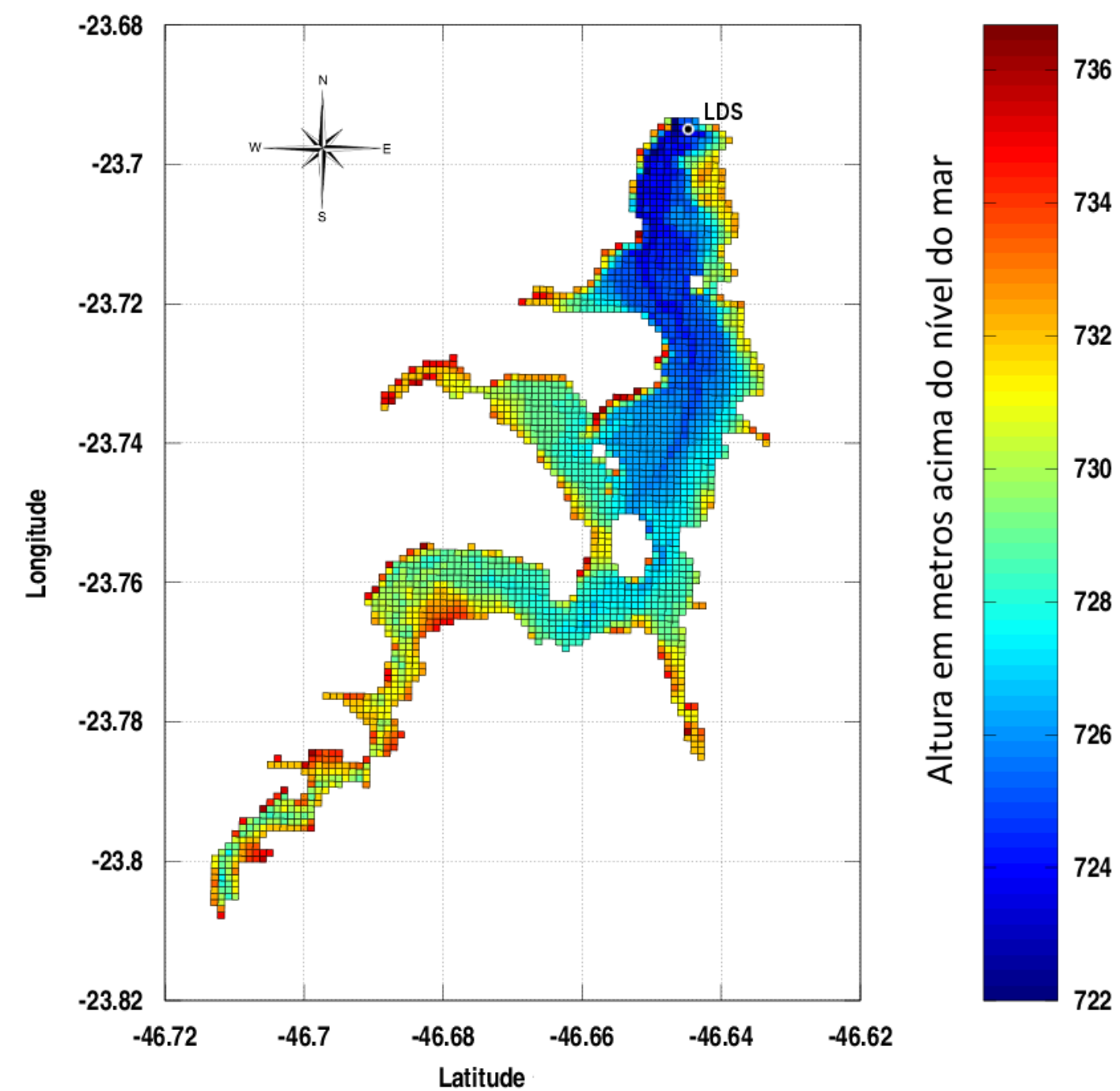

Figura 4 - Mapa batimétrico do reservatório Guarapiranga, mostrando o ponto onde a bóia foi instalada para fixar o Sistema "Lake Diagnostic System (LDS)” um conjunto de sensores e equipamentos meteorológicos e hidrológicos.

A área simulada foi dividida em um grid de células horizontais de 100 x 100 m analisada com a rotina surf.rst (interpolação e análise topográfica, utilizando superfícies regularizadas com tensão). Adotou-se uma espessura de camada de 0,33 m para boa resolução e rápida execução de simulações prolongadas. O nível máximo de operação do reservatório de água situa-se a $737 \mathrm{~m}$ acima do nível do mar. Neste nível, a profundidade máxima é 15,0 m, e o volume 200 GL. 


\subsubsection{Dados Meteorológicos}

Os dados meteorológicos de entrada do modelo foram obtidos de uma estação meteorológica instalada no ponto LDS e são apresentados na Figura 5. Esta estação portava sensores Vaisala HMP45 para temperatura e umidade. Sensores Monitor para velocidade e direção do vento, o EQ08 / E radiômetro para radiação global e o pirradiômetro CN1-R para o fluxo líquido de radiação total. Estes sensores estavam colocados a aproximadamente $2 \mathrm{~m}$ acima da superfície da água e a estação meteorológica foi posicionada sobre um sistema flutuante, ao qual uma cadeia de termístores foi presa, cada um espaçado a $0,25 \mathrm{~m}$ de distância entre si e com um "data logger" que armazenava os dados coletados a cada $10 \mathrm{~min}$, formando o que é também conhecido por "Lake Diagnostic System (LDS)". O modelo foi verificado por comparação com os resultados obtidos pela cadeia contínua de termístores na estação fixa. Os dados meteorológicos do período simulado são mostrados na Figura 5.
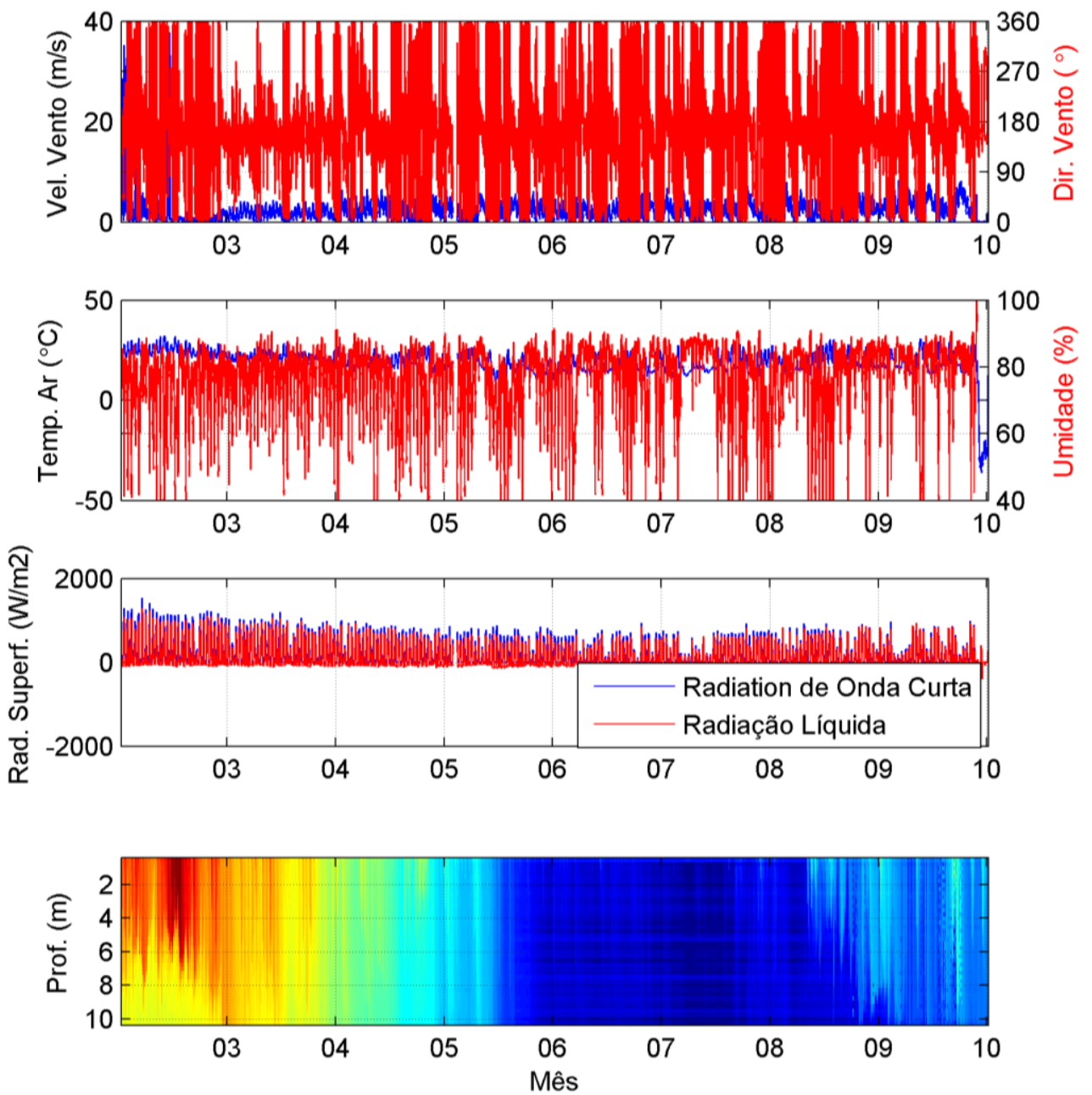
18
20
22
26
28

Figura 5 - Parâmetros meteorológicos para o período simulado. 


\subsubsection{Setup do Modelo}

As simulações tiveram o objetivo de analisar a influência dos principais componentes da simulação hidrodinâmica (força de fricção do vento, e balanço de calor) sobre o transporte de água dos três principais tributários do reservatório. Para este propósito as seguintes configurações foram adotados: na primeira simulação todas as forças foram incorporadas, enquanto na segunda o vento e o balanço de calor foram negligenciados e na terceira, somente o balanço de calor foi deixado de fora. A data de início das simulações foi 18 de abril de 2009, mas os traçadores não foram liberados até 10 dias mais tarde, de modo que eles não foram muito influenciados pelas condições iniciais. A concentração total do traçador liberada em cada uma dos três tributários foi a mesma em cada ponto de entrada, especificamente 1,46 x 10 6 atu (unidade arbitrária de traçador, adimensional). Para tornar isto possível, diferentes concentrações do traçador foram virtualmente lançadas dentro dos rios, sendo estas proporcionais aos respectivos fluxos do dia: A taxa de fluxo no rio Embu-Guaçu foi igual a $0,17 \mathrm{atu} / \mathrm{m}^{3}$, no rio Embu Mirim 0,2 atu $/ \mathrm{m}^{3}$ e no rio Parelheiros $1.00 \mathrm{atu} / \mathrm{m}^{3}$. Liberando a mesma quantidade nos diferentes pontos, é possível identificar quais rios tem maior potencial para a dispersão e quais processos resultam em maior dispersão.

Para a inicialização do modelo, foi escolhido um período em que a coluna d'água estava uniforme e as isotermas planas. Isto foi checado pelos dados dos termístores e alguns perfis coletados com um sensor CTD, sonda multi-parâmetro de alta frequência.

Tanto as informações fornecidas pela agência responsável pela captação, tratamento e abastecimento urbano da região metropolitana de São Paulo, a SABESP, como pela agência responsável pelo monitoramento da qualidade da água e fiscalização de agentes poluidores nas águas superficiais do estado de São Paulo, a CETESB, indicam a gradativa perda de qualidade da água, o que evidencia a necessidade de busca de soluções para que este processo seja revertido ainda nesta década. Experiências similares em outros países e continentes mostram que a gestão apropriada para manutenção da qualidade da água requer um profundo conhecimento das características e dos processos funcionais do ecossistema aquático (TUNDISI, 2003), o estudo dos quais requer uma abordagem multidisciplinar. 


\section{4 - Resultados e Discussão}

\section{1 - Análise dos padrões temporais de variação nas condições meteorológicas e hidrológicas no reservatório Guarapiranga.}

\subsubsection{Caracterização de um evento em curta escala de tempo}

As variações meteorológicas e hidrológicas de curta escala de tempo foram obtidas em um experimento de variação nictemeral realizado no periodo de 12 a 14 de setembro de 2010. Nas Figuras 6 e 7, respectivamente, são apresentados os dados da temperatura do ar, velocidade e direção do vento. Os dados de precipitação não são apresentados, pois não ocorreu eventos de chuva durante o experimento, nem na semana anterior.

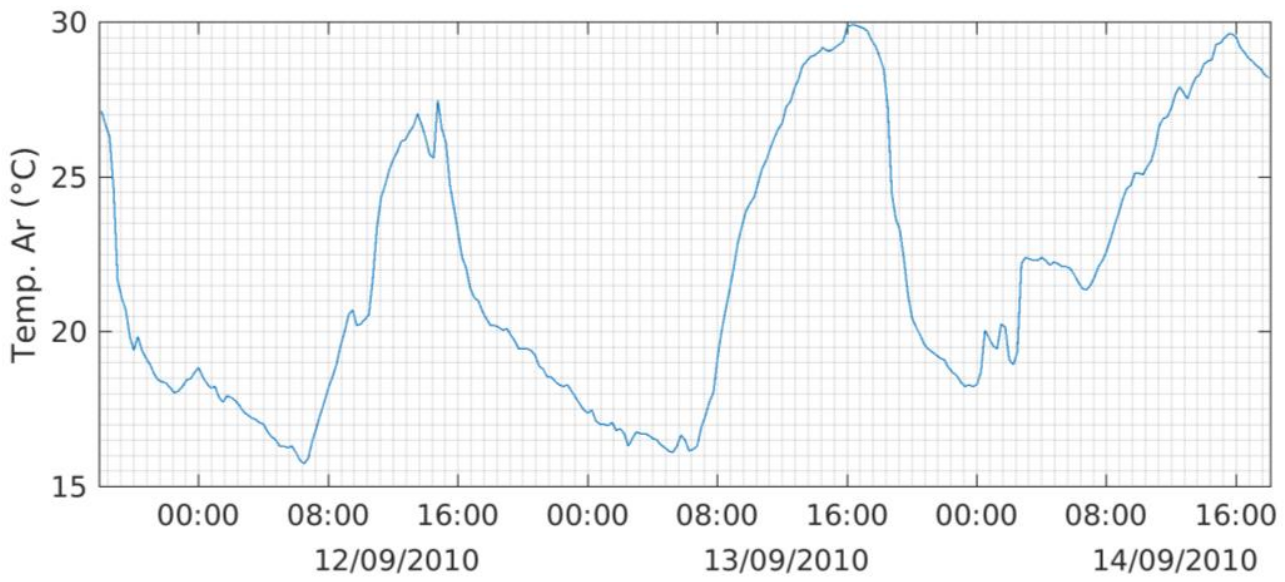

Figura 6 - Variação na temperatura do ar, medida na estação meteorológica flutuante instalada próximo à captação de água no reservatório Guarapiranga, com medidas a cada 10 minutos, das 10:00 h do dia $12 / 09 / 2010$ às $10: 00 \mathrm{~h}$ do dia 14/09/2010.

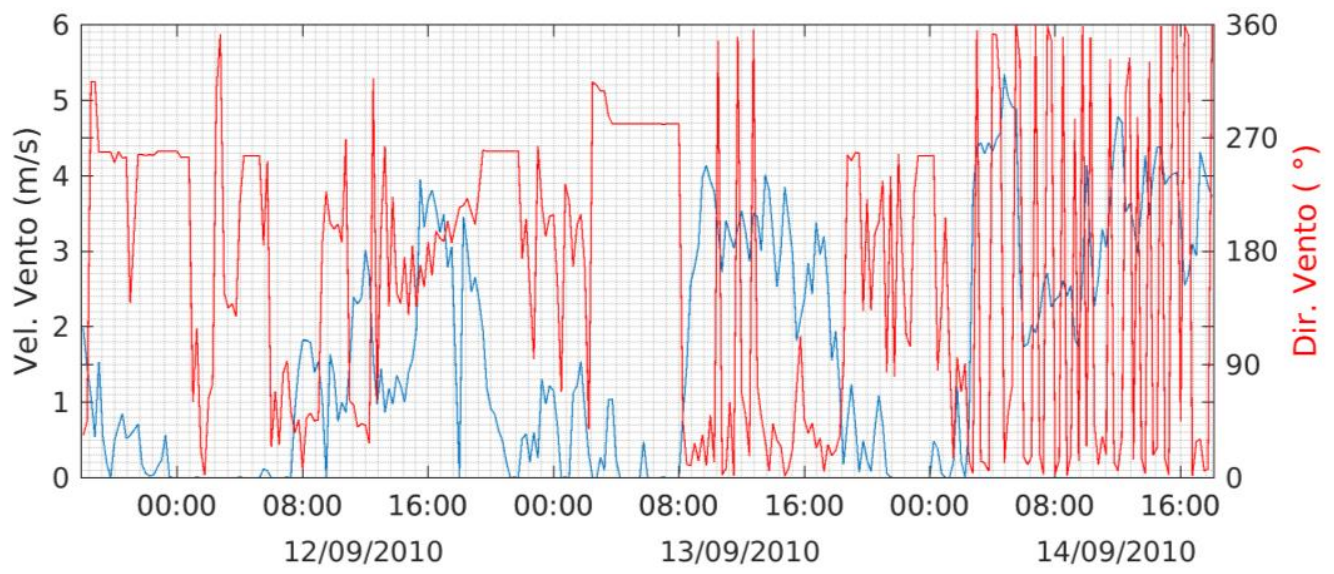

Figura 7 - Variações na velocidade e direção do vento medidos na estação meteorológica flutuante instalada próximo à captação de água no reservatório Guarapiranga, com medidas a cada 10 minutos, das 10:00 h do dia 12/09/2010 às 10:00 h do dia 14/09/2010. 
A caracterização de um evento hidrológico de curta escala de tempo ilustrando o caráter polimítico do reservatório Guarapiranga é sintetizado na Figura 8, que apresenta a sequência de eventos relativos à estratificação térmica da coluna d' água da represa, em dois ciclos completos de variação nictemeral (48 h).

O estudo deste evento teve início às 10:00 h da manhã do dia 12 de setembro de 2010, neste momento a estrutura térmica da coluna de água no ponto amostrado estava levemente estratificada, a temperatura do ar estava amena, por volta de $20{ }^{\circ} \mathrm{C}$ e a velocidade do vento igual a $1,5 \mathrm{~m} / \mathrm{s}$ vindo de Sul. A partir das 13:00 $\mathrm{h}$ ocorreu a elevação da temperatura da água superficial junto com um gradual abaixamento da termoclina, isso ocorreu devido ao aumento na temperatura do ar que chegou a $26,5{ }^{\circ} \mathrm{C}$. Por volta das 15:30 h a velocidade do vento subiu para quase $4 \mathrm{~m} / \mathrm{s}$ vindo de SulSudeste, mantendo-se elevada até as 18:30 h, levando à mistura das camadas superiores da coluna de água.

O vento cessou após as 19:00 h e iniciou-se um período de resfriamento noturno da temperatura do ar. A camada superficial da água resfriou-se, tornou-se mais densa e por convecção induziu a circulação no epilímnio e contribuiu para o máximo abaixamento da termoclina na profundidade de 4,0 m às 07:00 h da manhã.

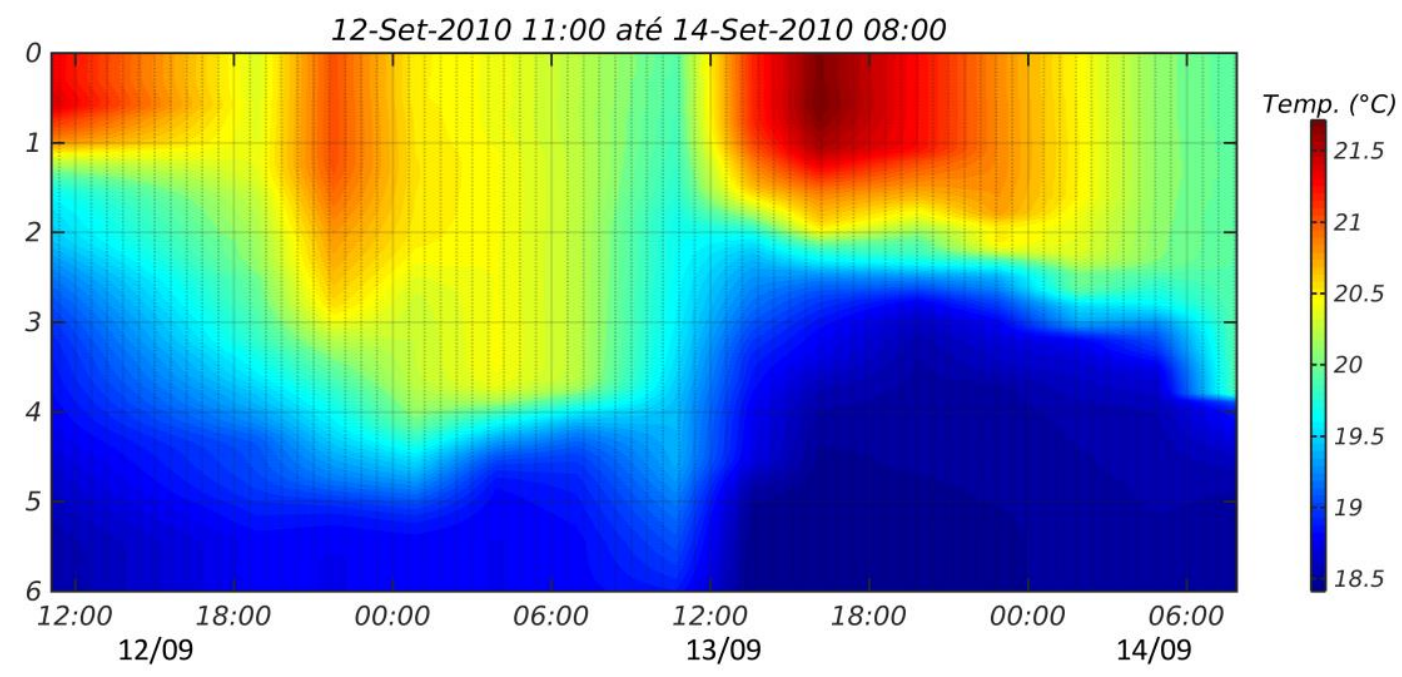

Figura 8 - Variação nictemeral da temperatura da água no reservatório Guarapiranga, São Paulo, SP, para dois ciclos consecutivos, com medidas em intervalos de três horas, a cada 0,5 $\mathrm{m}$ de profundidade, em um ponto de uma baía no compartimento da desembocadura do rio Embu Mirim. 
Em relação às condições meteorológicas e hidrológicas no período, os resultados obtidos revelaram que a partir das 09:30 h do dia 13 de setembro de 2010, ocorreu um aumento da velocidade do vento vindo da direção Norte, o qual atingiu $4 \mathrm{~m} / \mathrm{s}$, concomitante com o aumento na temperatura do ar, que passou de $17^{\circ} \mathrm{C}$ às $07: 00$ para $30^{\circ} \mathrm{C}$ às 16:00. Teve início uma rápida subida da termoclina, e a intensificação da estratificação térmica da coluna d’água. O ponto amostrado situa-se numa baía dentro do braço do Rio Embu-Mirim. A norte-nordeste do ponto situam-se as margens do reservatório e ao sul do ponto localiza-se a parte central do braço do reservatório. Com isso é possível compreender as diferentes alterações na hidrodinâmica para ventos de mesma intensidade, porém com direções opostas.

No segundo ciclo nictemeral, observou-se novo evento de abaixamento da termoclina e circulação do epilímnio, desencadeado com o cessar dos ventos e resfriamento da atmosfera (19:00 h), propiciando o abaixamento e posterior subida da termoclina com eventos similares aos observados no primeiro ciclo nictemeral, no dia anterior. A termoclina mais acentuada foi verificada às 16:00 h do dia 13 de setembro de 2010 com variação máxima de $3,7^{\circ} \mathrm{C}$.

Os resultados deste estudo nictemeral permitiram visualizar como eventos de curto prazo podem influenciar a dinâmica de reservatórios tropicais pouco profundos, como é o caso do reservatório Guarapiranga. Variações diurnas na temperatura do ar, de cerca de $10^{\circ} \mathrm{C}$ e alterações na velocidade do vento ainda que moderadas, de menos que e $4 \mathrm{~m} \mathrm{~s}^{-1}$ podem desencadear marcantes alterações no padrão térmico de um reservatório e influenciar a distribuição dos organismos fitoplanctônicos como já demonstrado para o próprio reservatório Guarapiranga por Santos et al. (2015).

Para um reservatório tropical raso, a represa do Lobo (Broa, Itirapina, SP), Tundisi et al. (2004) mostraram que a passagem de uma frente fria provocou profundas alterações físicas, químicas e biológicas neste reservatório e que estes eventos são comuns a todos reservatórios pouco profundos no sudeste do Brasil, uma região bastante sujeita a micro e macro eventos climatológicos. Estes autores enfatizam ainda que o conhecimento destas respostas tem grande aplicabilidade para o manejo destes reservatórios, particularmente em relação à dinâmica das populações fitoplanctônicas e desenvolvimento dos blooms de cianobactérias. As interações do hidroclima do 
reservatório do Lobo com eventos meteorológicos de curta duração foram detalhadamente analisados por Rio (2003) a qual mostrou que mudanças rápidas nas forçantes meteorológicas, como tempestades, chuvas intensas ou frentes frias resultam em pulsos internos importantes, como por exemplo, uma simples tempestade ocorrida no dia 30 de março de 2001, que resultou no abaixamento das isotermas na região da direção do vento, mistura nas camadas superficiais e afloramento de águas profundas, mais frias, na região oposta, de origem do vento, as quais tiveram provavelmente importantes consequências para as comunidades biológicas.

Estas respostas são similares àquelas observadas no experimento no reservatório Guarapiranga no experimento de 12 e 13 de setembro de 2009, onde houve a entrada de uma frente fria, resultando em acúmulo de algas e cianobactérias na baia do rio EmbuMirim, com abaixamento da termoclina e posterior balanço, formando ondas internas e forçando a reorganização das populações fitoplanctônicas na coluna d'água (SANTOS et al., 2015). 


\subsubsection{Padrões meteorológicos na região do reservatório Guarapiranga em longa escala temporal}

A análise dos ciclos anuais das variáveis meteorológicas permite identificar anomalias, distinguindo-as da sazonalidade típica da região em que se encontra o reservatório, permite ainda buscar as razões para a ocorrência do desenvolvimento de eventos atípicos, e apesar das incertezas inerentes ao clima, permite o avanço no prognóstico da qualidade da água do reservatório.

\subsubsection{Temperatura do ar}

Os dados de temperatura média anual do ar para o período de 1997 a 2014 são apresentados na Figura 9. Como pode ser observado, existem grandes diferenças entre a temperatura máxima e mínima a cada ano, por volta de $30^{\circ} \mathrm{C}$, e uma variação interanual relativamente pequena da temperatura na região onde se situa o reservatório Guarapiranga.

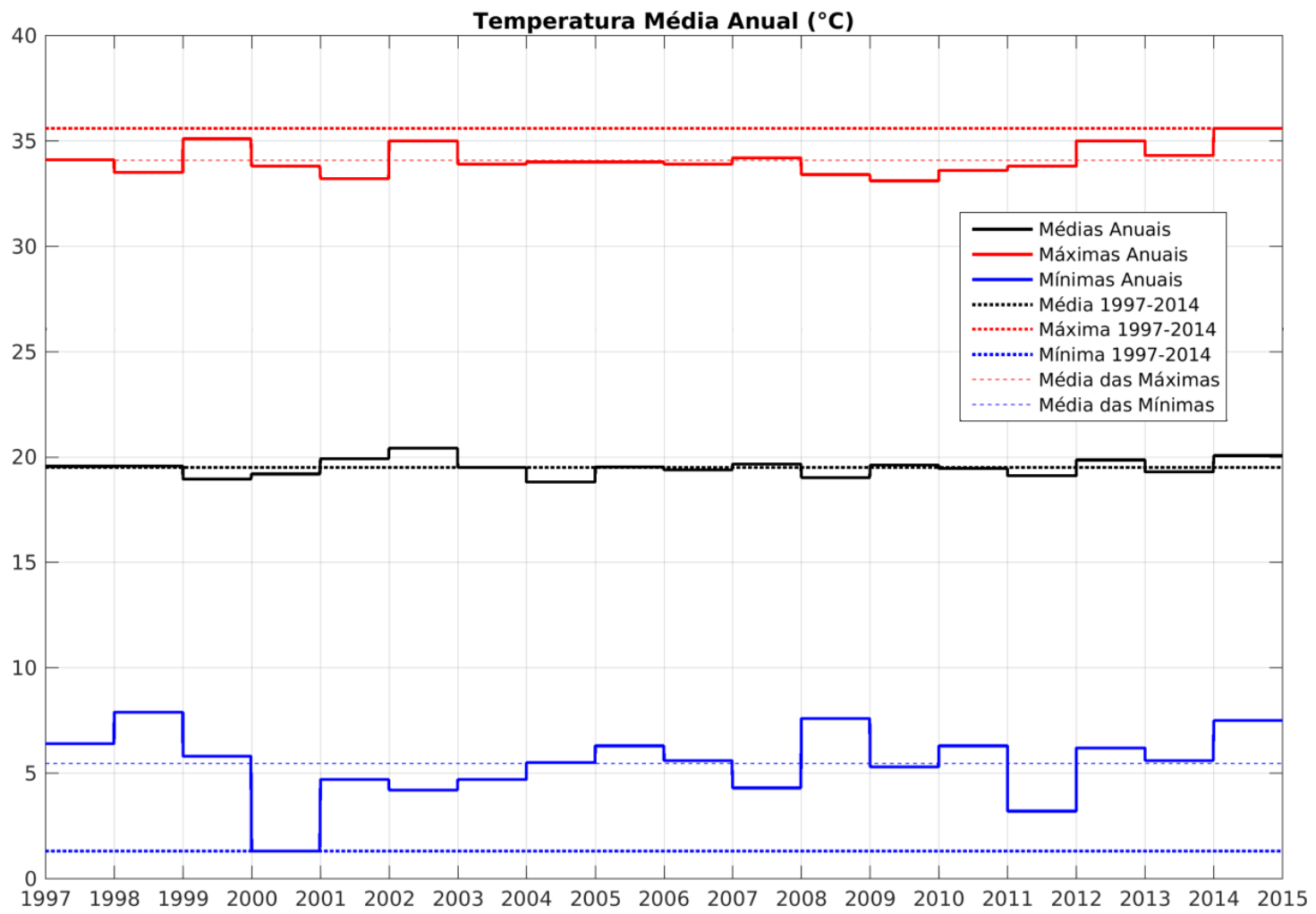

Figura 9 - Variação nos valores de temperaturas anuais máximas, médias e mínimas medidas na Estação Meteorológica do Instituto de Astronomia, Geofísica e Ciências Atmosféricas da Universidade de São Paulo - (IAG/USP) instalada no Parque Fontes do Ipiranga, São Paulo, SP, para o período de 1997 a 2014. 
A temperatura média dos últimos 18 anos é igual a $19,5^{\circ} \mathrm{C}$, com a média anual mais alta ocorrendo em $2002,20,5{ }^{\circ} \mathrm{C}$, e a mais baixa em $2004,18,8{ }^{\circ} \mathrm{C}$. A média das temperaturas máximas é igual a $34,1{ }^{\circ} \mathrm{C}$, com a máxima das máximas ocorrendo em $2014,35,6^{\circ} \mathrm{C}$ e a mínima das máximas ocorrendo em $2009,33,1{ }^{\circ} \mathrm{C}$. A média das temperaturas mínimas é $5,5^{\circ} \mathrm{C}$, com a máxima das mínimas ocorrendo em $1998,7,9^{\circ} \mathrm{C}$ e a mínima das mínimas ocorrendo em $2000,1,3{ }^{\circ} \mathrm{C}$. As variações anuais não parecem ser suficientes para definir algum tipo de componente periódica. Na Figura 10 são apresentadas a variação mensal de temperatura para este mesmo período. Os dados revelam o aumento das temperaturas mínimas mensais nos últimos três anos, e mostra, além disso, invernos mais quentes, particularmente, no ano de 2015. Essa tendência se confirmada pode influenciar diretamente a dinâmica dos organismos e processos relevantes ligados ao funcionamento do reservatório Guarapiranga, já que as espécies que possuem maior taxa de crescimento em ambientes quentes podem ser privilegiadas.
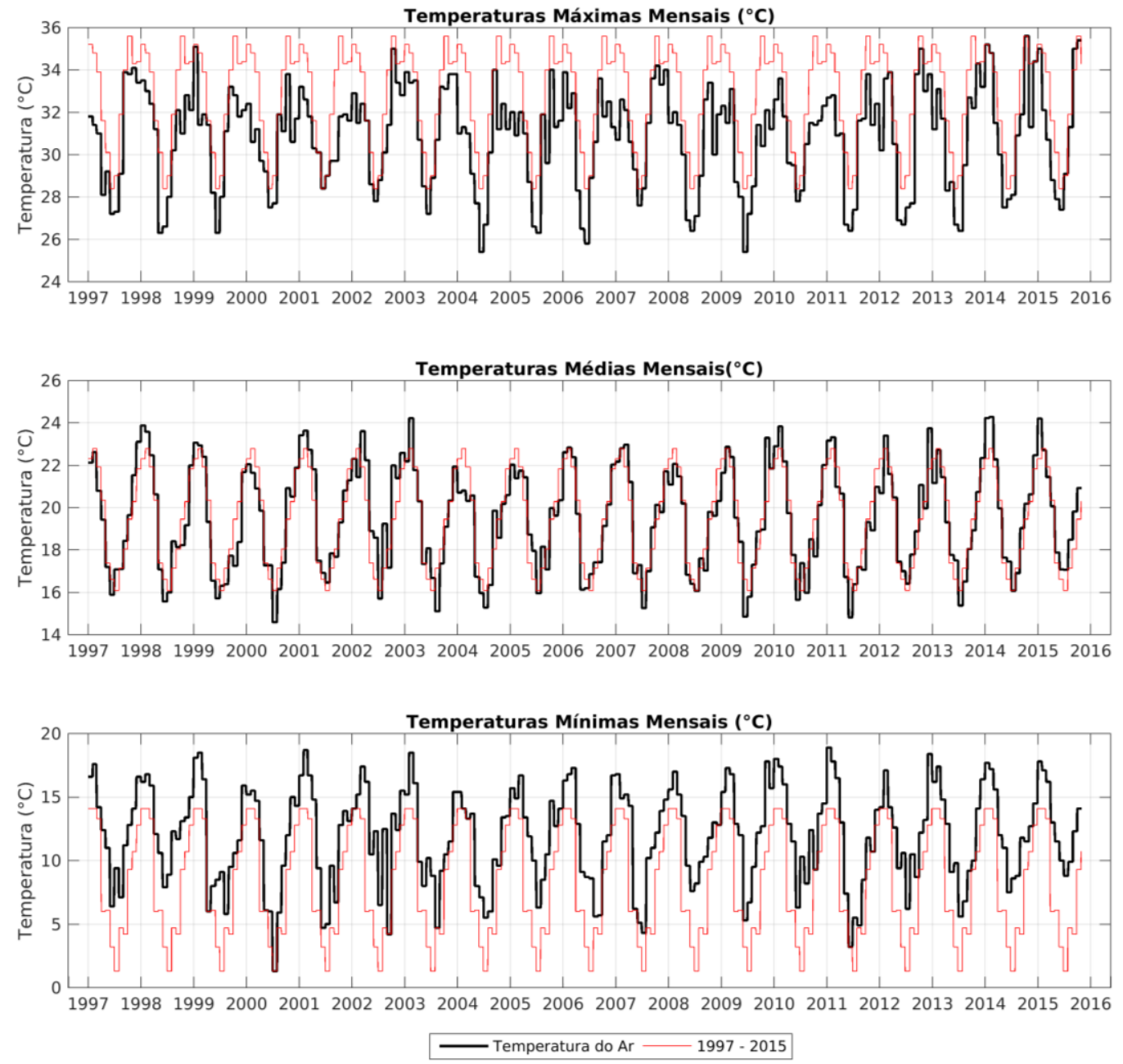

Figura 10 - Variação dos valores de temperaturas máximas, médias e mínimas mensais do ar, temperatura do ar registradas na Estação Meteorológica do Instituto de Astronomia, Geofísica e Ciências Atmosféricas da Universidade de São Paulo - (IAG/USP) instalada no Parque Fontes do Ipiranga, São Paulo, SP, para o período de 1997 a 2015. 
No ano de 2010, no qual ocorreu um evento de denso florescimento de macrófitas, as temperaturas médias mensais foram bem próximas da média histórica desses 18 anos, no entanto, as mínimas mensais foram muito superiores, cerca de $3{ }^{\circ} \mathrm{C}$ maiores e as máximas foram em geral $2{ }^{\circ} \mathrm{C}$ menores.

O ciclo anual das médias mensais, apresentado na Figura 11 ilustra a variação sazonal para a localidade estudada mostrando a amplitude das variações térmicas entre os meses de inverno e verão. Embora a dinâmica de estratificação térmica nas regiões tropicais e em reservatórios rasos seja rápida e frequente, ainda assim, é possível estabelecer os períodos mais propícios para o surgimento de estratificações térmicas fortes.

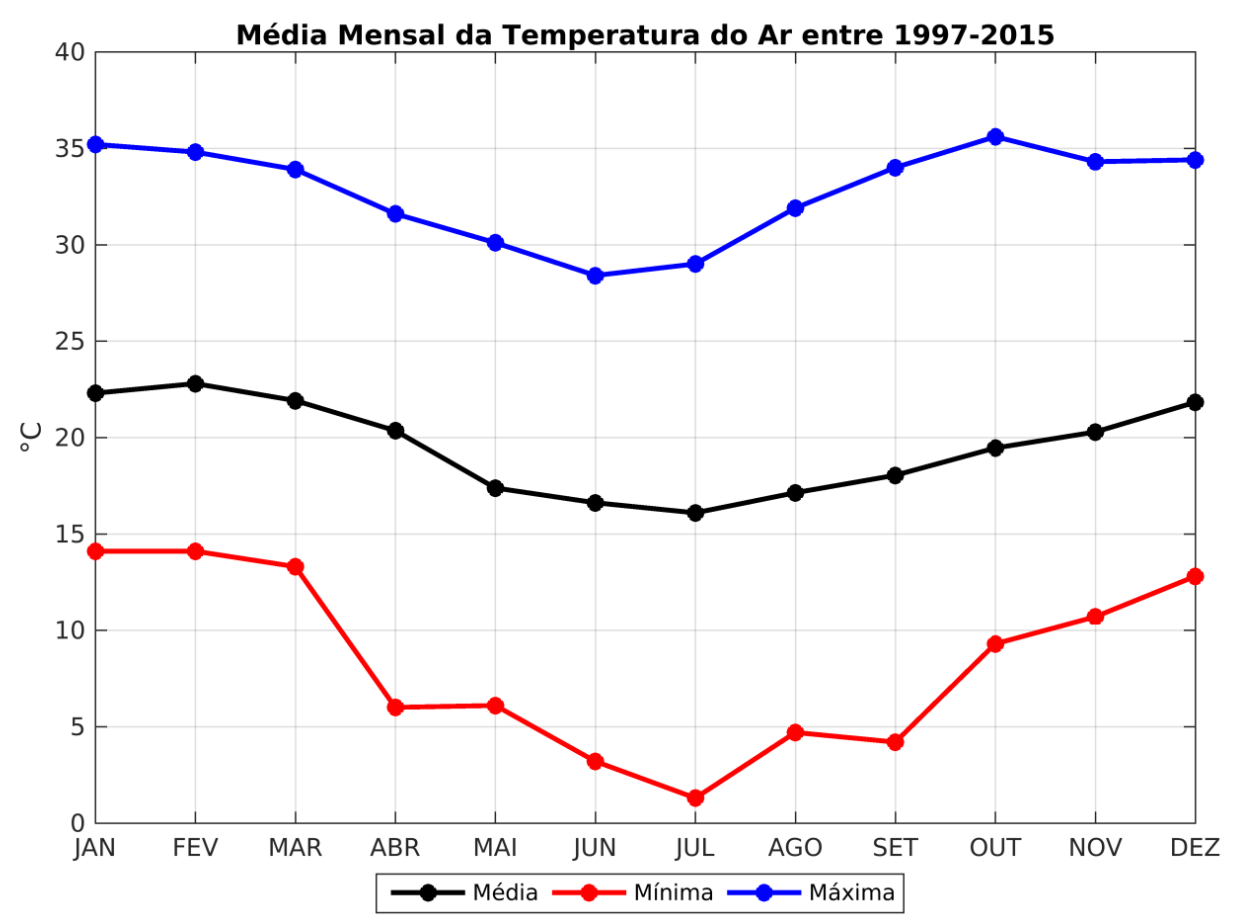

Figura 11- Variação das temperaturas médias: máximas, médias e mínimas mensais, da temperatura do ar registradas na Estação Meteorológica do Instituto de Astronomia, Geofísica e Ciências Atmosféricas da Universidade de São Paulo - (IAG/USP) instalada no Parque Fontes do Ipiranga, São Paulo, SP, para o período de 1997 a 2015.

Geralmente, esses eventos ocorrem no final do inverno e no início da primavera, pois a perda de calor na superfície durante o inverno faz com que a coluna de água apresente temperaturas baixas, principalmente nas camadas inferiores. Com o aumento da temperatura do ar e maior incidência de radiação solar no início da primavera as camadas superficiais são aquecidas podendo formar fortes estratificações térmicas, que 
podem ser potencializadas em função das primeiras chuvas que ocorrem após o período de seca no início da primavera, trazendo água com grande quantidade de sais.

\subsubsection{Precipitação pluviométrica}

Além da distribuição anual da temperatura do ar são necessárias informações sobre a pluviometria, já que a quantidade de sais ou sólidos afluentes também pode alterar a densidade da água. Na Figura 12 são apresentadas as variações da precipitação total anual na estação no Parque das Fontes do Ipiranga, São Paulo, SP, para o período de 1997 a 2014. 


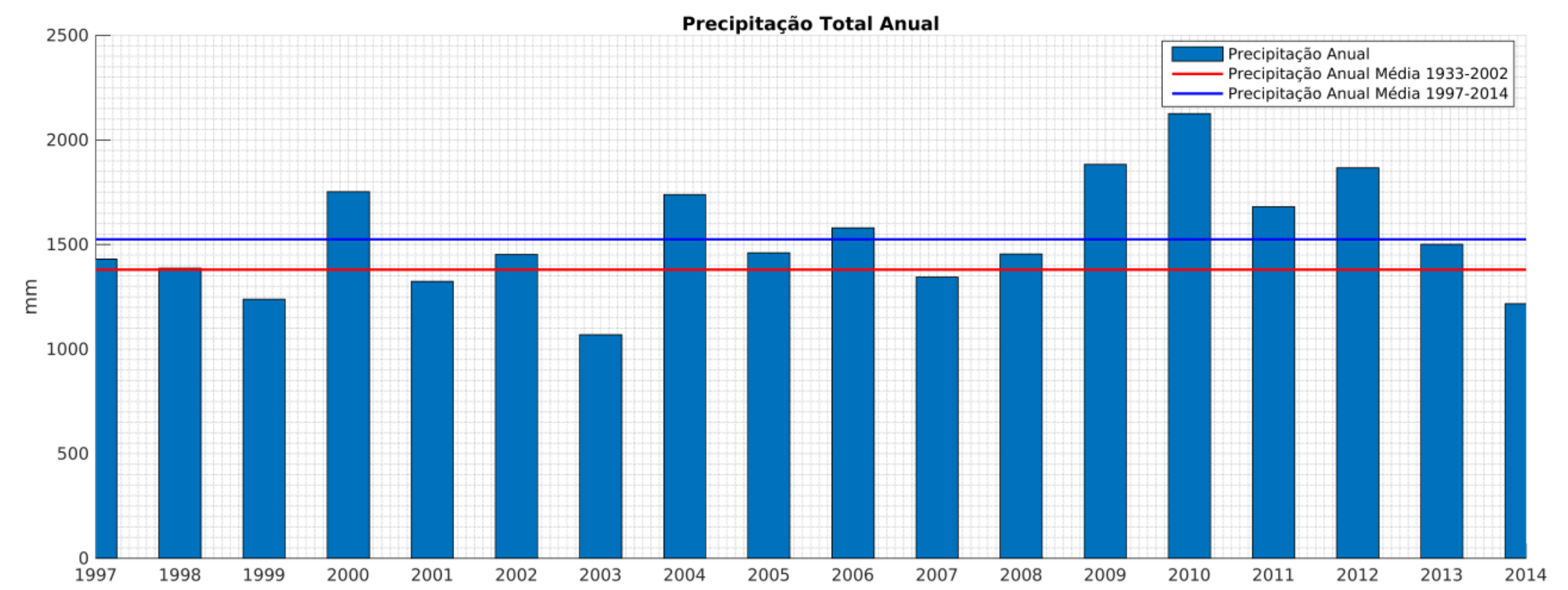

Figura 12 - Variação dos valores totais de precipitação anual registrados na Estação Meteorológica do Instituto de Astronomia, Geofísica e Ciências Atmosféricas da Universidade de São Paulo - (IAG/USP) instalada no Parque Fontes do Ipiranga, São Paulo, SP, para o período de 1997 a 2014. 
Assim como ocorreu com os dados de temperatura do ar, não foi possível determinar uma componente periódica interanual clara. Para validar a existência de oscilações de longa escala seria necessário o registro contínuo em um intervalo de tempo maior.

A maior precipitação anual durante esses 18 anos ocorreu em 2010 com um total de $2125 \mathrm{~mm}$ de chuva, e segundo os dados de precipitação mensal, mostrados na Figura 13, este foi um ano com vários eventos atípicos, o que sugere que essa seja uma das possíveis razões para a ocorrência de aglomeração macrófitas no reservatório. $\mathrm{O}$ ano de 2010 inteiro foi bastante chuvoso, sendo que o mês de dezembro de 2009 foi o mais chuvoso dos últimos 18 anos com 653 mm e o mês de janeiro de 2010 está entre os três meses mais chuvosos de todo o período. 


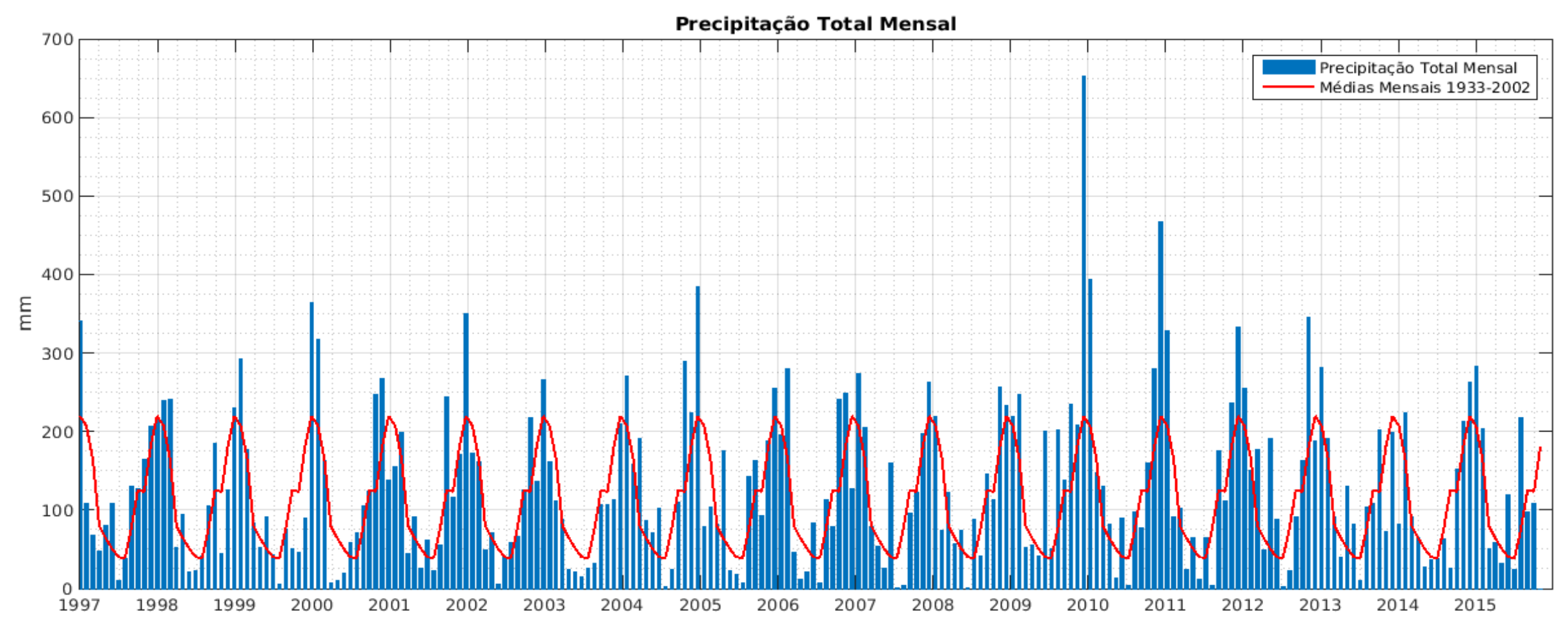

Figura 13- Variação dos valores mensais de precipitação total e curva representativa dos valores mensais médios obtidos a partir dos dados registrados na Estação Meteorológica do Instituto de Astronomia, Geofísica e Ciências Atmosféricas da Universidade de São Paulo - (IAG/USP) instalada no Parque Fontes do Ipiranga, São Paulo, SP, para o período de 1997 a 2015. 
Não há uma periodicidade identificável nas variações interanuais. Os padrões temporais se restringem ao ciclo anual com períodos de chuva e seca, como ilustrado pelos valores médios de precipitação mensal extraídos de uma longa série temporal para o período de 1933 a 2002, apresentados na Figura 14. Com exceção das anomalias que ocorreram nos anos de 2010 e 2011, há um padrão bem definido.

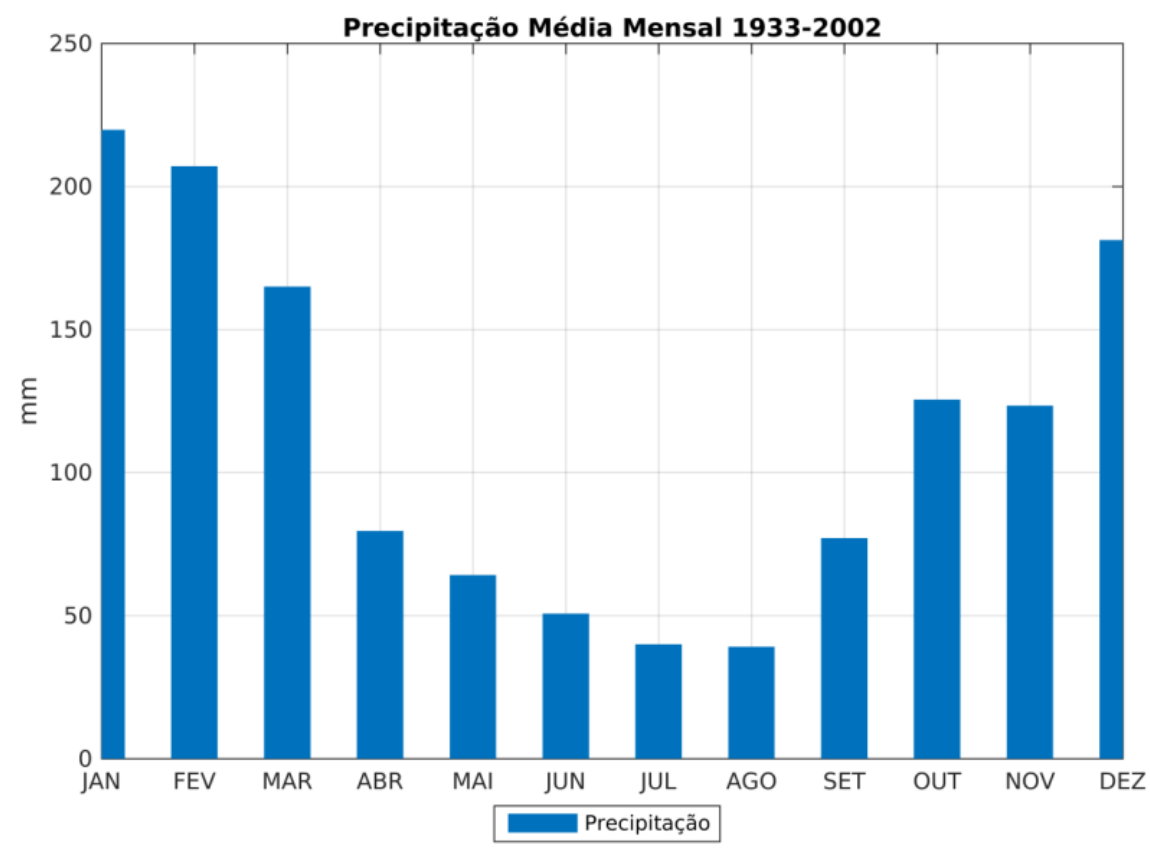

Figura 14- Valores médios de precipitação mensal (em mm) para o período de 1933 a 2002 obtidos a partir de dados registrados na Estação Meteorológica do Instituto de Astronomia, Geofísica e Ciências Atmosféricas da Universidade de São Paulo - (IAG/USP) instalada no Parque Fontes do Ipiranga, São Paulo, SP.

As precipitações médias históricas apresentam um padrão de variação anual semelhante ao da temperatura do ar, sendo que para a localidade avaliada a primavera e o verão são quentes e chuvosos enquanto o outono e o inverno são frios e secos.

Assim, esses dados corroboram com aqueles observados em um experimento realizado por Tundisi et al. (2006) em 1999, é mostrada a variação térmica nos reservatórios Guarapiranga e Rio Grande ao longo de um ano, e evidenciados os períodos de estabilidade e de mistura, destacando-se a sazonalidade e a entrada de frentes frias. 


\subsubsection{Ventos}

Por meio da análise da série temporal de medidas da velocidade e direção de ventos para o período de 1997 a 2015, verificou-se que o padrão de ventos obtidos na estação meteorológica do Instituto de Astronomia, Geofísica e Ciências Atmosféricas da Universidade de São Paulo - (IAG/USP) no Parque Fontes do Ipiranga é caracterizado por ventos predominantes provenientes do Sul-Sudeste, Sudeste, Leste-Sudeste e Leste, e em menor frequência por ventos vindos do Norte, conforme representados na Figura

15.

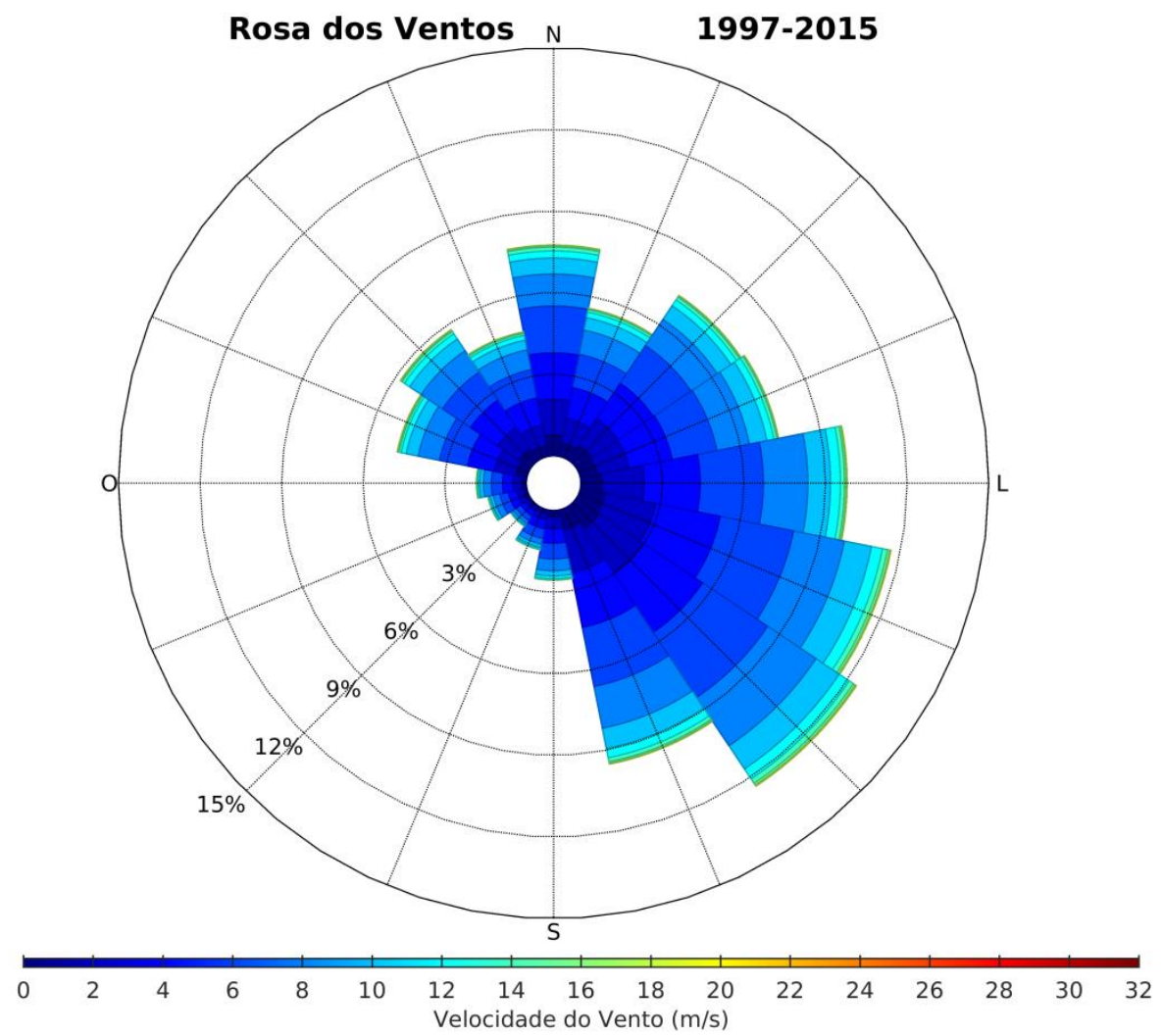

Figura 15- Histograma direcional com as intensidade e frequência dos ventos registrados na Estação Meteorológica do Instituto de Astronomia, Geofísica e Ciências Atmosféricas da Universidade de São Paulo - (IAG/USP) no Parque Fontes do Ipiranga, São Paulo, SP, para o período de 1997 a 2015.

Isso evidencia a consistência na distribuição espacial do vento nesta região, que ainda sofre influências da Serra do Mar na região sul do reservatório.

A combinação de alta umidade nas camadas mais baixas da atmosfera, que é típica em regiões costeiras, com o ar quente e a ascensão forçada pelas montanhas, cria condições termodinamicamente instáveis quase todos os dias. A interação entre 
perturbações de grande escala e essa instabilidade convectiva local pode gerar fortes e persistentes precipitações (SELUCHI \& CHOU, 2009).

Segundo Morais et. al (2008) a frequência de frentes frias na região do reservatório é elevada, em intervalos de tempo de aproximadamente 10 dias, e durante a passagem delas, observam-se fortes ventos de norte nos dias anteriores à virada, seguidos pelo predomínio de ventos de sudeste nos dias seguintes, o que esclarece a predominância de ventos nessas direções. 


\section{2 - Análise dos padrões espaciais de variação nas características físicas e químicas do reservatório Guarapiranga em diferentes escalas temporais}

\subsubsection{Caracterização da qualidade de água em um evento de curta escala temporal}

Para identificação dos padrões de qualidade da água em curta escala de tempo serão analisados os dados coletados no reservatório Guarapiranga em setembro de 2010.

\subsubsection{Transparência da água}

A turbidez é dada pelos efeitos combinados da cor das águas, da turbidez mineral e da presença de algas ou de outros organismos (STRASKRABA \& TUNDISI, 2000). Na Figura 16 são mostrados os resultados obtidos para a transparência da água medida em 64 pontos do reservatório nos dias 13 e 14 de setembro de 2010 e apresentados na forma de gradiente.
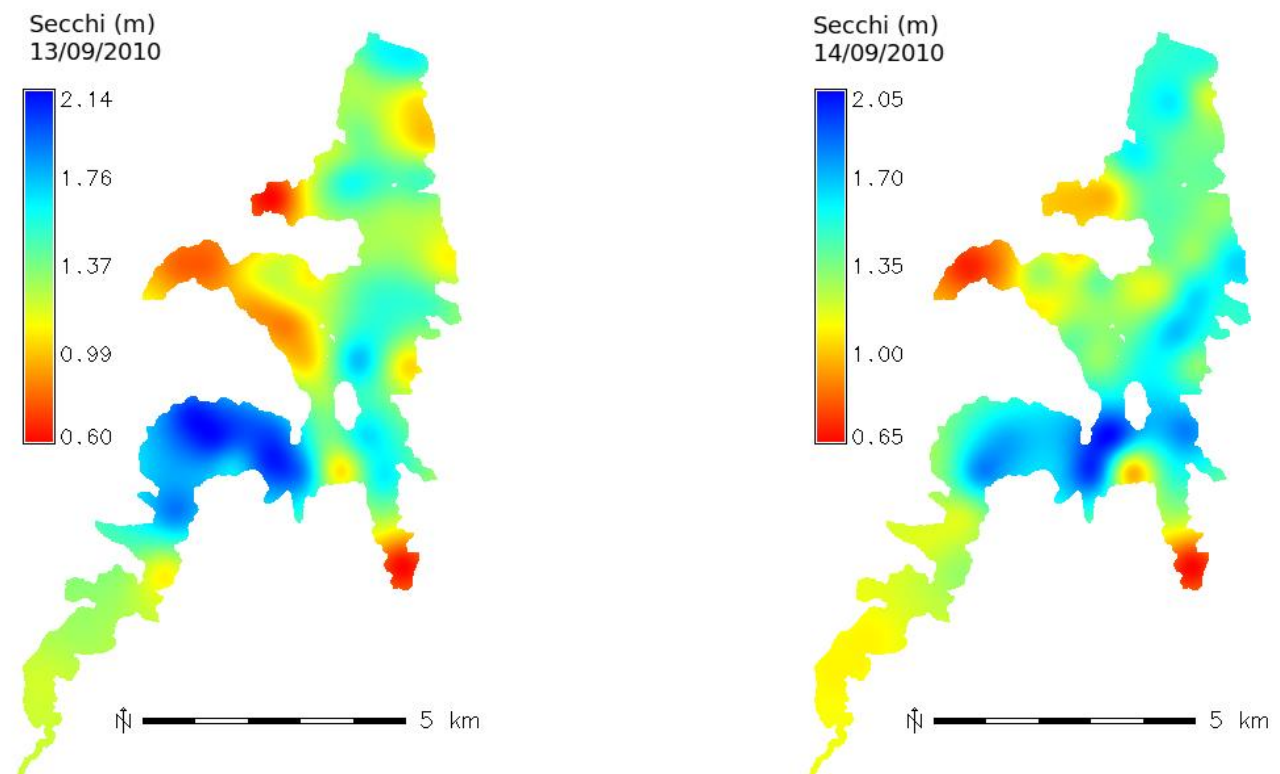

Figura 16- Distribuição espacial da transparência da água no reservatório Guarapiranga, São Paulo, SP, avaliada por meio da profundidade de visibilidade do Disco de Secchi medida nos dias 13 e 14 de setembro de 2010 no reservatório de Guarapiranga, São Paulo, SP, em 64 pontos amostrais.

Observa-se grande heterogeneidade na transparência da água do reservatório no período estudado. Apenas uma porção limitada da represa na porção superior entre aproximadamente 5 a $8 \mathrm{Km}$ de distância da entrada do rio Embu-Guaçu na represa 
Guarapiranga, apresentou elevada transparência, com valores de Secchi de cerca de 1,8 a $2,14 \mathrm{~m}$.

As regiões de maior turbidez corresponderam às porções afluentes e represadas dos tributários Parelheiros, Embu-Guaçu e Embu-Mirim respectivamente, as quais apresentaram valores de profundidade de Secchi variando de aproximadamente 0,60 a $1,0 \mathrm{~m}$.

Isso ocorre, pois os rios afluentes ao reservatório Guarapiranga carregam uma grande quantidade de cargas afluentes de suas respectivas bacias, reduzindo a transparência na foz. Condições intermediárias, com valores de Secchi entre 1,0 e 1,5 m predominaram no corpo central e na porção inferior do reservatório, próximo à barragem e captação da água. O volume de material em suspensão transportado depende dos tipos de uso do solo nas bacias, do tipo de solo e da cobertura vegetal, mas também varia de acordo com os processos que ocorrem no reservatório como a sedimentação e a mistura que ocorre nessas regiões.

\subsubsection{Nutrientes}

Os resultados relativos às concentrações de fósforo total na camada de superfície da água do reservatório são apresentados na Figura 17, e os de nitrogênio total, na Figura 18. Os dados obtidos revelam que as concentrações de nutrientes em todo o reservatório foram elevadas e que as razões N/P foram iguais ou maiores que 20, dessa forma, indicando que neste curto período de tempo o fósforo pode ser considerado um nutriente limitante. 

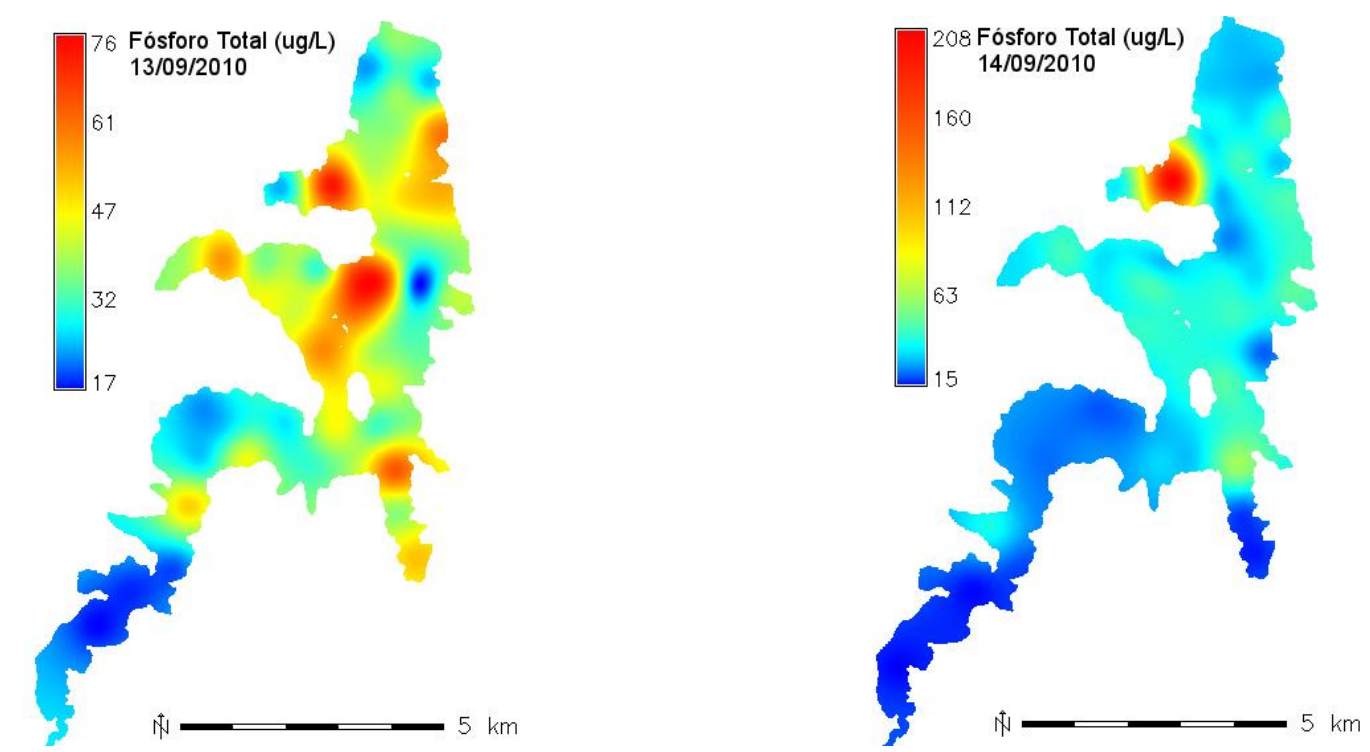

Figura 17 - Distribuição espacial das concentrações de Fósforo Total, em $\mu$ g/L medidas nos dias 13 e 14 de setembro de 2010 em 64 pontos do reservatório Guarapiranga, São Paulo, SP.
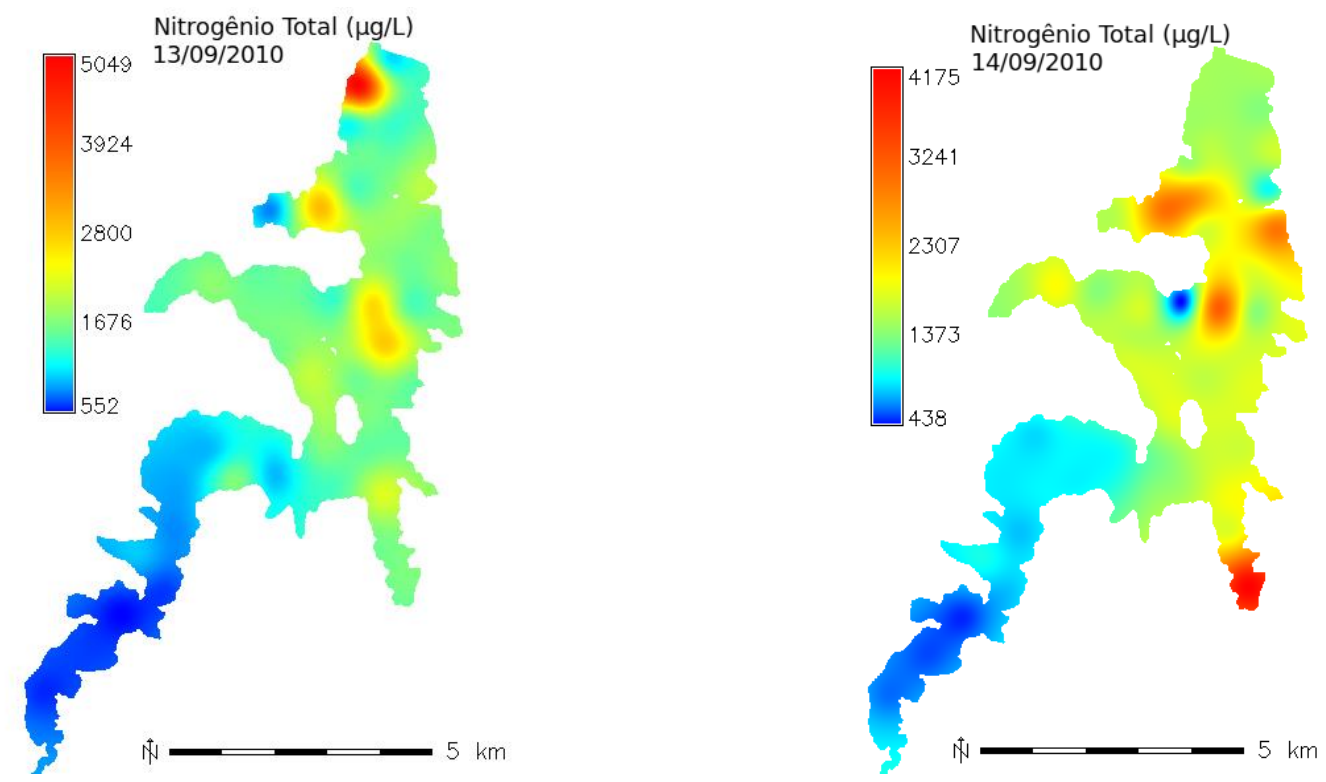

Figura 18 - Distribuição espacial das concentrações de Nitrogênio Total, em $\mu \mathrm{g} / \mathrm{L}$, medidas em 64 pontos do reservatório de Guarapiranga, São Paulo, SP, nos dias 13 e 14 de setembro de 2010.

O fósforo é relativamente raro em ambientes naturais, mas como é necessário para o crescimento dos organismos autótrofos, sua demanda em relação ao nitrogênio é muito maior, sendo geralmente o nutriente limitante.

Os resultados de turbidez e das concentrações de nutrientes na represa Guarapiranga neste estudo de curta escala de tempo ressaltam a grande heterogeneidade do sistema e as diferenças na qualidade da água entre os compartimentos bastante 
visíveis, caracterizando a porção superior do reservatório correspondente ao compartimento Embu-Guaçu e a região inferior, da captação, como as de melhor qualidade da água em contraste com as regiões de foz dos tributários Parelheiros, EmbuMirim e Guavirutuba, como as de menor qualidade.

Neste estudo comprovou-se também o papel primordial do vento nas mudanças da qualidade da água. $\mathrm{O}$ evento do aumento na intensidade do vento com a entrada de uma frente fria causou grande distúrbio no sistema, deslocando massas de água e provocando o afloramento de águas mais profundas ricas em nutrientes nas regiões litorâneas na direção do vento, como evidenciado pelo grande aumento na turbidez, na concentração de fósforo e de nutrientes na foz dos tributários Parelheiros, Embu-Mirim, e Guavirutuba, um dia após a entrada da frente fria.

O possível papel dos eventos meteorológicos na qualidade da água do reservatório Guarapiranga já havia sido proposto por Tundisi et al. (2004) e Tundisi et al. (2006) e pôde ser experimentalmente demonstrado no presente estudo. Como observado por Chalar (2006), os aumentos nas precipitações decorrentes das mudanças climáticas podem aumentar os processos erosivos e consequentemente a carga de fósforo afluente ao reservatório. 


\subsubsection{Avaliação dos padrões temporais de variação na qualidade da água do reservatório Guarapiranga em ampla escala temporal}

A Resolução Conama 357 de 2005 estabelece as classes de água doce de acordo com seus usos preponderantes e define os respectivos padrões de qualidade. Para verificar o atendimento a esses padrões, a CETESB realiza monitoramentos da qualidade da água nos principais corpos de água do estado de São Paulo, a cada dois meses e esses dados obtidos entre 2004 e 2014 são públicos e disponibilizados gratuitamente. Para o presente estudo foram utilizados os dados disponíveis para diferentes anos buscando-se a comparação e ratificação dos padrões observados nos experimentos realizados.

As águas do reservatório Guarapiranga são classificadas na Classe 1, pois são destinadas ao abastecimento humano, à proteção das comunidades aquáticas e à recreação de contato primário. Os valores-limite em corpos de água de Classe 1 para as variáveis aqui analisadas são: $10 \mu \mathrm{g} \mathrm{L}^{-1}$ para Clorofila a; 20.000 cél/mL para a densidade de cianobactérias; $10 \mathrm{mg} \mathrm{L}^{-1}$ para a concentração de Nitrato; valores de $0,5 \mathrm{e}$ $3,7 \mathrm{mg} \mathrm{L}^{-1}$ para Nitrogênio Amoniacal, respectivamente para as faixas de $\mathrm{pH} \geq 8,5$, e $\mathrm{pH} \leq 7,5$, e $0,025 \mathrm{mg} \mathrm{L}^{-1}$ para as concentrações de Fósforo Total.

A variação temporal da temperatura do ar e temperatura da água e das concentrações de oxigênio dissolvido e $\mathrm{pH}$ em um ponto de monitoramento situado na foz do rio Embu-Mirim, são mostrados na Figura 19. A temperatura da água em geral seguiu o padrão de variação apresentado pela temperatura do ar, embora com alguns eventos excepcionais. A amplitude de variação térmica no ar $\left(15\right.$ a $\left.28.5^{\circ} \mathrm{C}\right)$ foi maior do que aquela da temperatura da água, a qual variou entre 15 e $25^{\circ} \mathrm{C}$. Os valores mais altos geralmente ocorreram nas coletas realizadas nos meses de janeiro e março e os valores mais baixos nas coletas de julho.

O pH manteve-se em média próximo a 7,0 em todo o período, mas com pequenas oscilações. Já a concentração de oxigênio dissolvido variou amplamente, com valores entre 1,0 a $8,0 \mathrm{mg} \mathrm{L}^{-1}$, com grandes oscilações. Os valores mais elevados ocorreram na maioria das vezes nos períodos mais secos, com picos localizados entre maio e julho. 
Os valores do nitrogênio amoniacal variaram entre 0 e $5 \mathrm{mg} \mathrm{L}^{-1}$ na maior parte do tempo, os maiores valores geralmente ocorreram em julho e setembro.

As concentrações de nitrato variaram entre 0 e $8 \mathrm{mg} \mathrm{L}^{-1}$ tendo ocorrido o registro de um único valor de $15 \mathrm{mg} \mathrm{L}^{-1}$ no início de 2004. Os maiores valores também ocorreram nos períodos de seca. Contudo, em alguns anos como 2004 e 2006 foram registradas baixas concentrações nas coletas de maio e setembro respectivamente, possivelmente, devido às elevadas precipitações ocorridas nos meses anteriores.

As concentrações de fósforo total variaram entre 0,007 e $1,0 \mathrm{mg} \mathrm{L}^{-1}$ verificandose grande variabilidade em relação aos meses em que ocorreram os máximos e mínimos.

A turbidez da água e as concentrações de fósforo são apresentadas na Figura 20. A turbidez variou entre 0 e 30 UNT com um pico de 90 UNT em janeiro de 2004. Os maiores valores foram sempre registrados nos períodos de chuva.
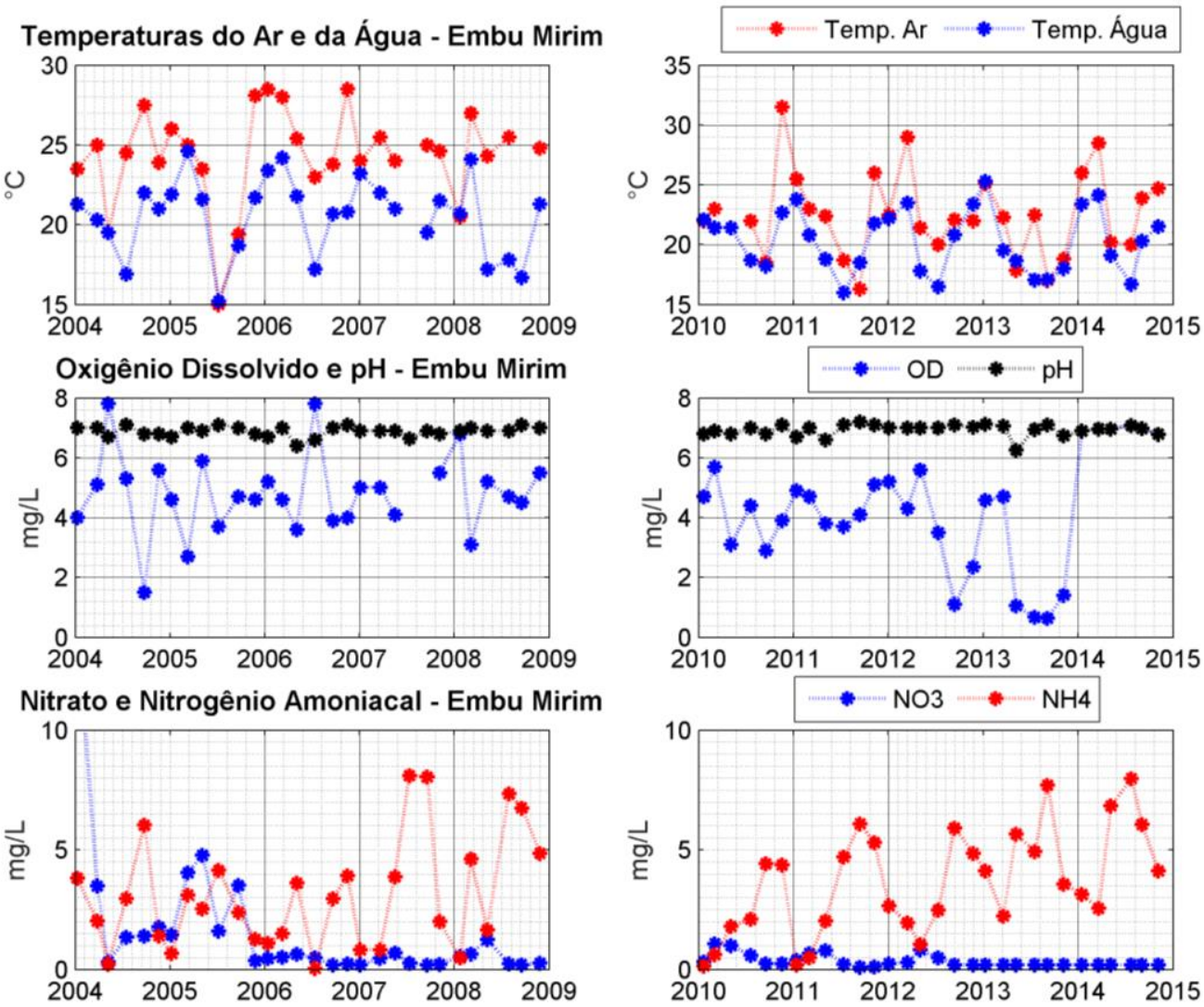

Figura 19- Variação temporal dos valores de temperatura do ar e da água, da concentração de oxigênio dissolvido, $\mathrm{pH}$, Nitrato e Nitrogênio amoniacal, medidos e disponibilizados pela CETESB na foz do Rio Embu-Mirim, no reservatório de Guarapiranga, São Paulo, SP, para uma série de anos compreendidos no período de 2004 a 2015. (Fonte: http://aguasinteriores.cetesb.sp.gov.br). 

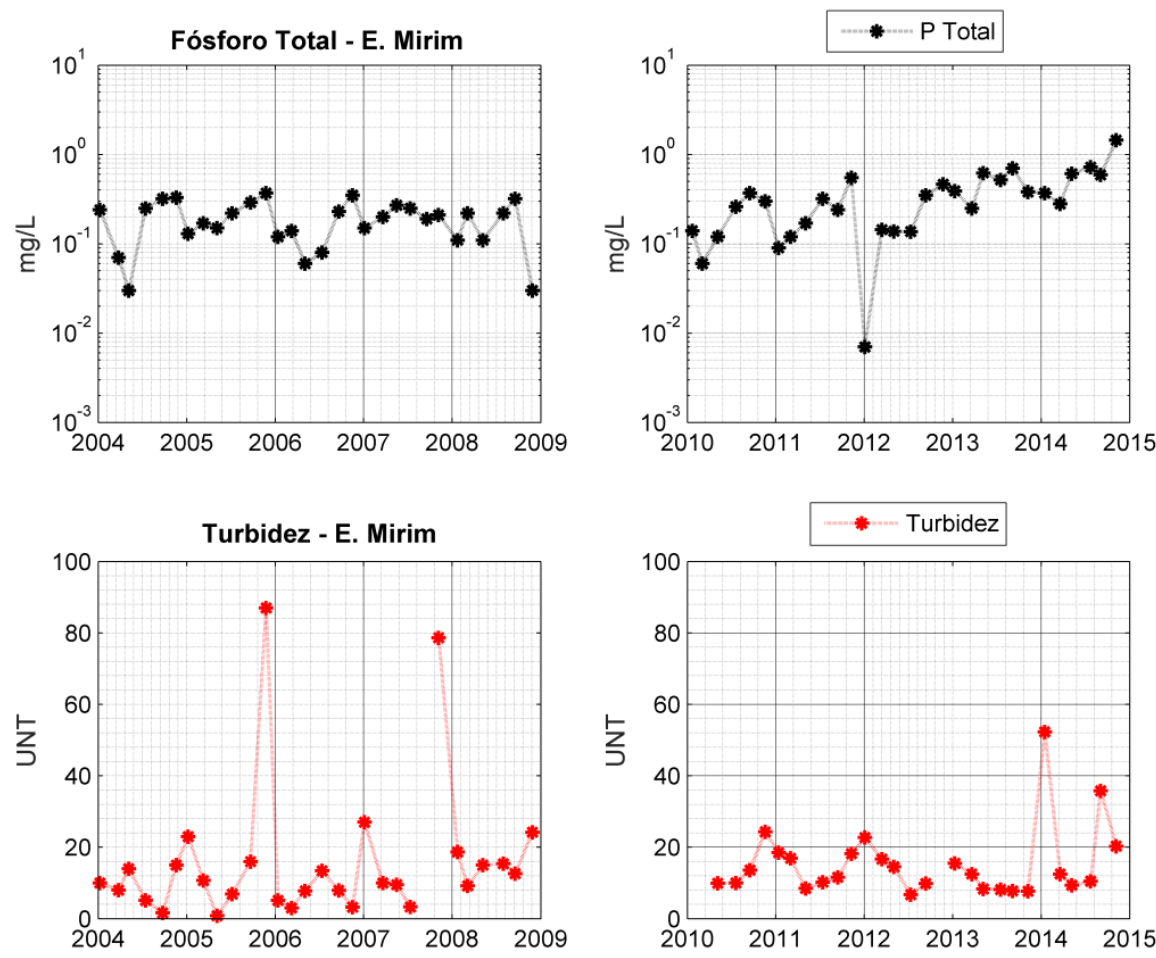

Figura 20 - Dados de Fósforo total e Turbidez, obtidos pela CETESB na foz do Rio Embu-Mirim, reservatório de Guarapiranga, São Paulo, SP, durante o período de 2004 a 2015. (Fonte: http://aguasinteriores.cetesb.sp.gov.br).

Para o ponto próximo ao local onde se realiza a captação da água para abastecimento, os resultados obtidos são apresentados nas Figuras 21 e 22, para a temperatura da água e do ar e para a concentração de fósforo total, respectivamente. A temperatura da água variou de 17 a $27{ }^{\circ} \mathrm{C}$ e o $\mathrm{pH}$ variou entre 7,0 e 8,0 com pequenas oscilações. Já a concentração de oxigênio dissolvido variou de 4,0 a $14,0 \mathrm{mg} \mathrm{L}{ }^{-1}$, com oscilações amplas, atingindo valores bastante elevados, por se tratar de reservatório com intensos florescimentos algais.

Os valores do nitrogênio amoniacal variaram entre 0,0 e $0,5 \mathrm{mg} \mathrm{L}^{-1}$, e ao contrário do observado na desembocadura do rio Embu Mirim, os maiores valores ocorreram no período de chuva, possivelmente por acúmulo de cargas advindas das massas de água de todos os tributários. As concentrações de nitrato neste compartimento variaram entre 0,0 e $3,8 \mathrm{mg} \mathrm{L}^{-1}$ com os maiores valores sendo registrados nos períodos de seca. As concentrações de fósforo total mantiveram-se entre 0,02 e $0,1 \mathrm{mg} \mathrm{L}^{-1}$, com um único pico de $1 \mathrm{mg} \mathrm{L}^{-1}$.

Ambas formas de nitrogênio apresentaram pequena variação nas concentrações provavelmente em decorrência dos aportes ao reservatório, oriundos da bacia, nos períodos chuvosos. Diferentemente do observado no compartimento Embu-Mirim, neste 
ponto próximo à Captação de Água para abastecimento a forma de nitrogênio predominante é o nitrato, em decorrência da maior oxigenação da coluna d’água.

Embora o amônio seja a forma combinada de nitrogênio energeticamente mais favorável às algas e cianobactérias em geral, tanto marinhas como de água doce, a forma de nitrato é igualmente utilizada (REYNOLDS,1984) indicando que uma outra forma de nitrogênio disponíveis nos diferentes compartimentos do reservatório favorecem igualmente o crescimento do fitoplâncton.
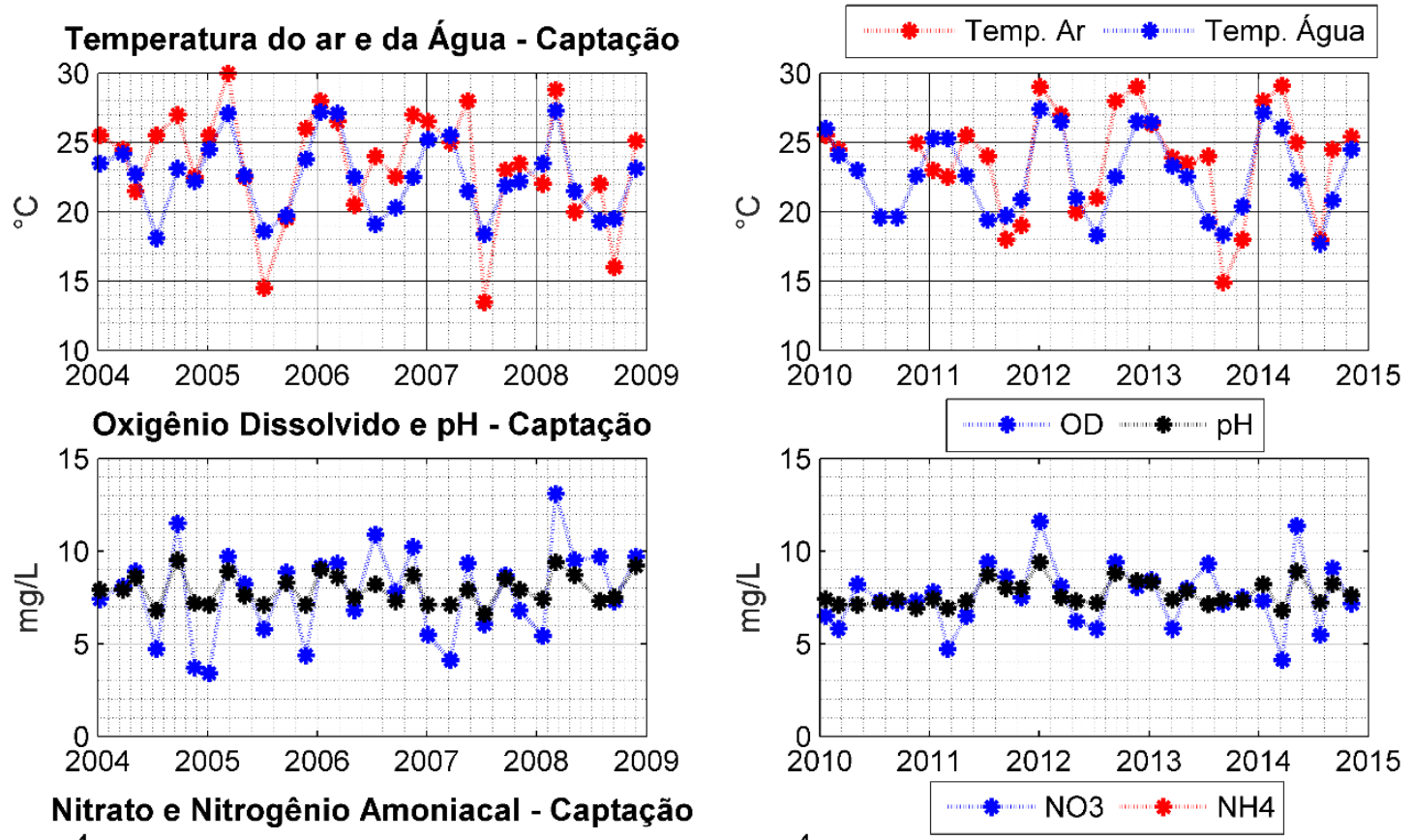

Nitrato e Nitrogênio Amoniacal - Captação
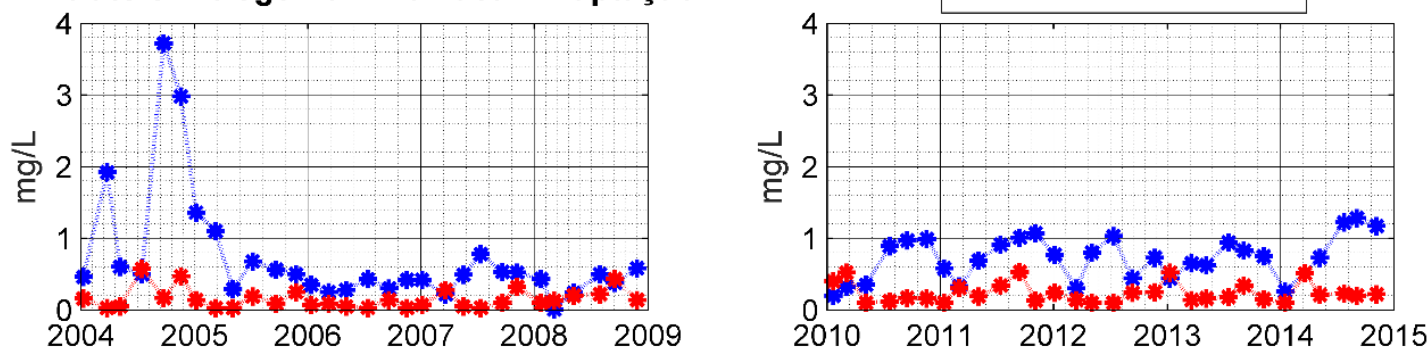

Figura 21- Variações nos valores de Temperatura do ar e da água, Concentrações de Oxigênio, Nitrato e Nitrogênio amoniacal, registrados pela CETESB em ponto próximo à Captação de Água para abastecimento no reservatório Guarapiranga, São Paulo, SP, durante o período de 2004 a 2015. (Fonte: http://aguasinteriores.cetesb.sp.gov.br). 

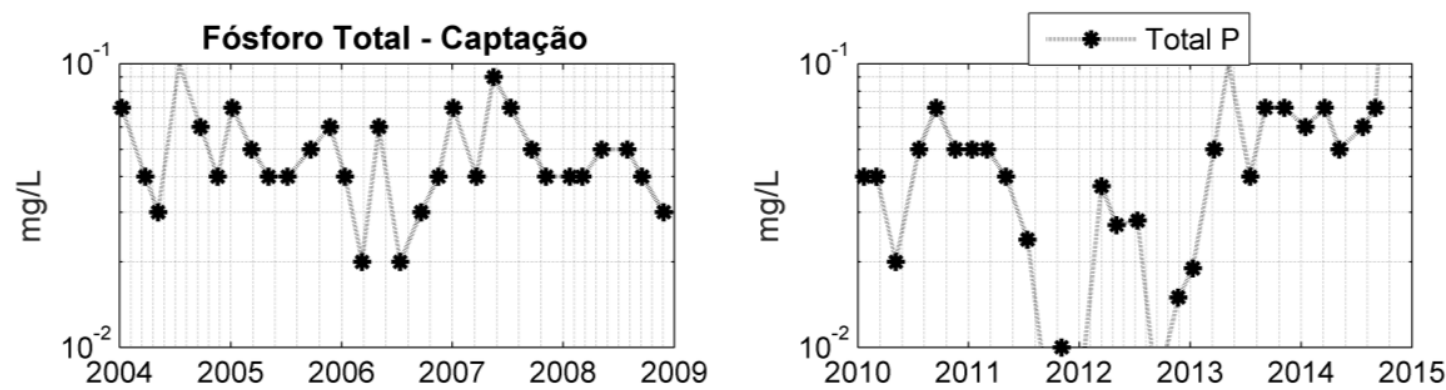

Figura 22- Variação na concentração de Fósforo total, obtidos pela CETESB no ponto próximo à Captação de Água para abastecimento, reservatório de Guarapiranga, São Paulo, SP, durante o período de 2004 a 2015. (Fonte: http://aguasinteriores.cetesb.sp.gov.br).

Na Figura 23 são apresentados os dados relativos à variação de longo prazo nos valores de turbidez para o ponto próximo à captação e no rio Parelheiros, com os pontos máximos e mínimos ocorrendo em períodos próximos, mas com valores geralmente bem mais elevados no rio Parelheiros.
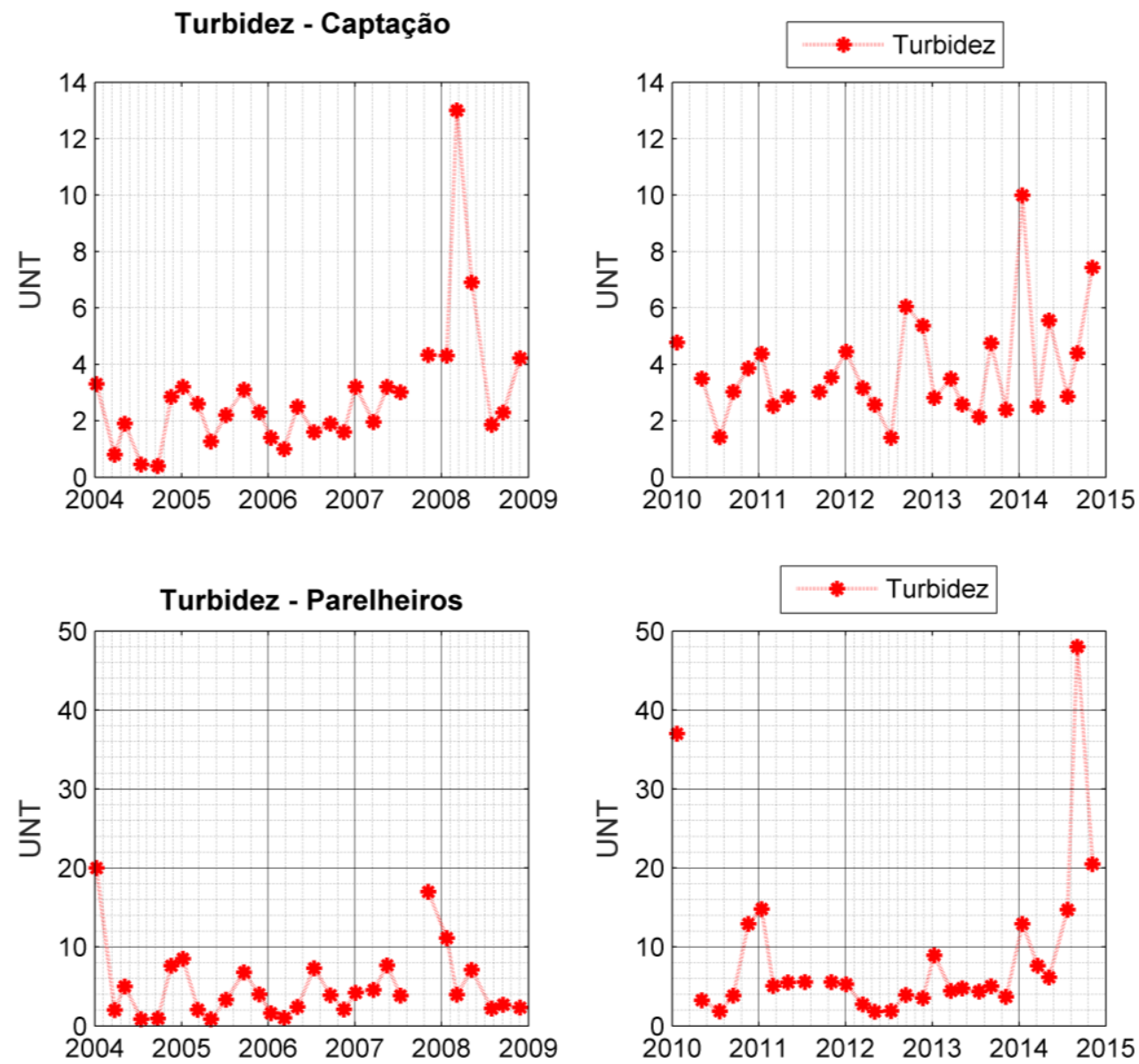

Figura 23- Variação de longo prazo nas concentrações de fósforo total e de turbidez para as águas superficiais na região próxima à captação e na foz do Rio Parelheiros, reservatório de Guarapiranga, São Paulo, SP, durante o período de 2004 a 2015.( (Fonte: http://aguasinteriores.cetesb.sp.gov.br). 
Os dados relativos a outras variáveis monitoradas no rio Parelheiros são apresentados nas Figuras 24 e 25. Pode-se observar que similarmente aos outros compartimentos analisados, a temperatura da água neste compartimento do reservatório também variou entre 17 a $27{ }^{\circ} \mathrm{C}$ e o pH manteve-se entre 7 e 8 com pequenas oscilações. Já as concentrações de oxigênio dissolvido variaram de 0,5 a $14,0 \mathrm{mg} \mathrm{L}^{-1}$, com amplas oscilações.

Os valores das concentrações de nitrogênio amoniacal variaram entre 0,0 e 5,0 $\mathrm{mg} \mathrm{L}^{-1}$, valores bem menores do que os registrados no Rio Embu Mirim. Já o nitrato variou entre 0,0 e $1,0 \mathrm{mg} \mathrm{L}^{-1}$ apresentando um único pico de $10 \mathrm{mg} \mathrm{L}^{-1}$ em 2004 tendo os maiores valores sido registrados nos períodos de seca. As concentrações de fósforo variaram amplamente com valores entre 0,007 e $3,0 \mathrm{mg} \mathrm{L}^{-1}$.
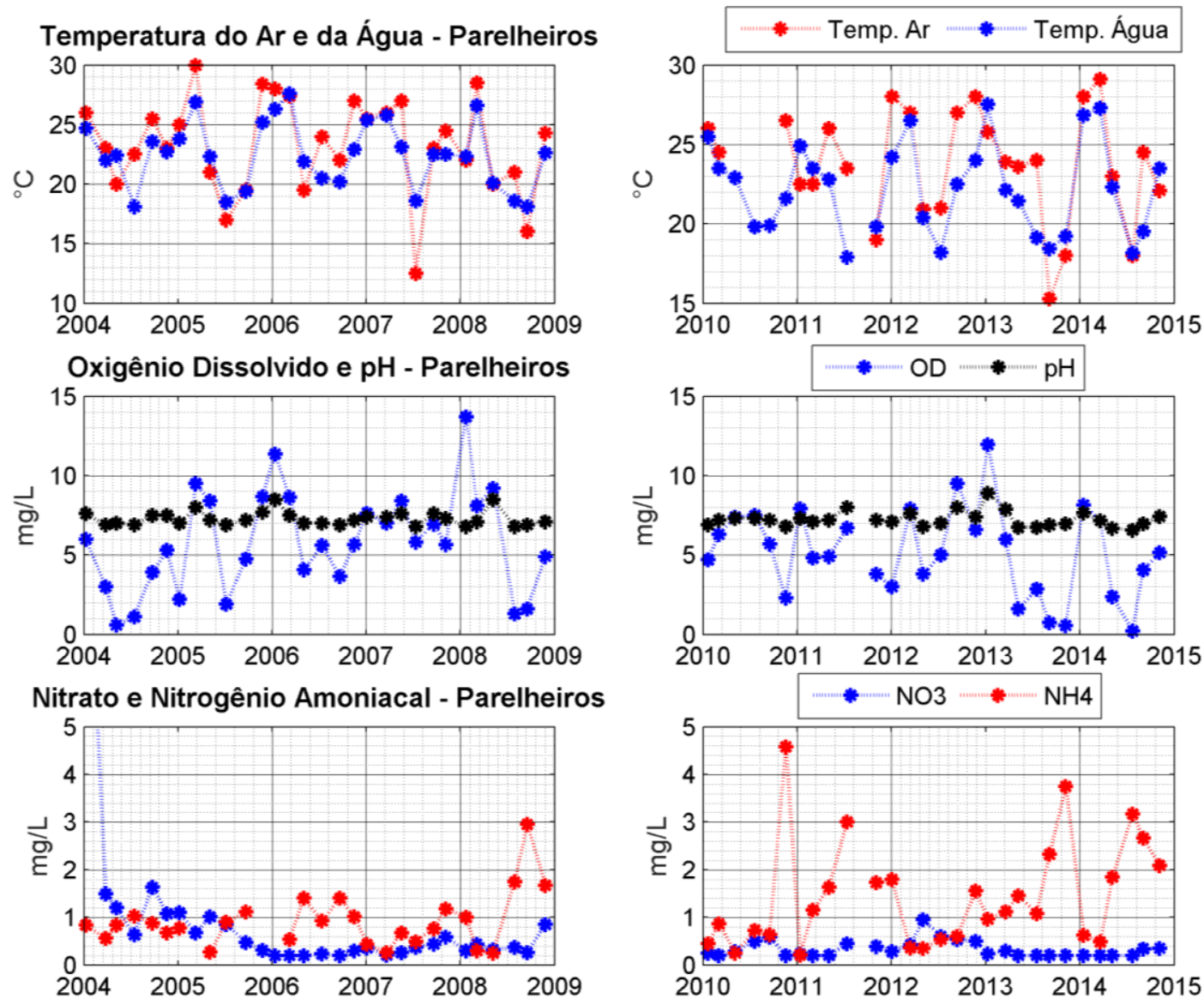

Figura 24 - Variação de longo prazo na Temperatura do ar e da água, na concentração de Oxigênio dissolvido, pH, e concentrações de Nitrato e Nitrogênio amoniacal, obtidos pela CETESB para as águas superficiais no compartimento foz do Rio Parelheiros, reservatório de Guarapiranga, São Paulo, SP, durante o período de 2004 a 2015. (Fonte: http://aguasinteriores.cetesb.sp.gov.br). 

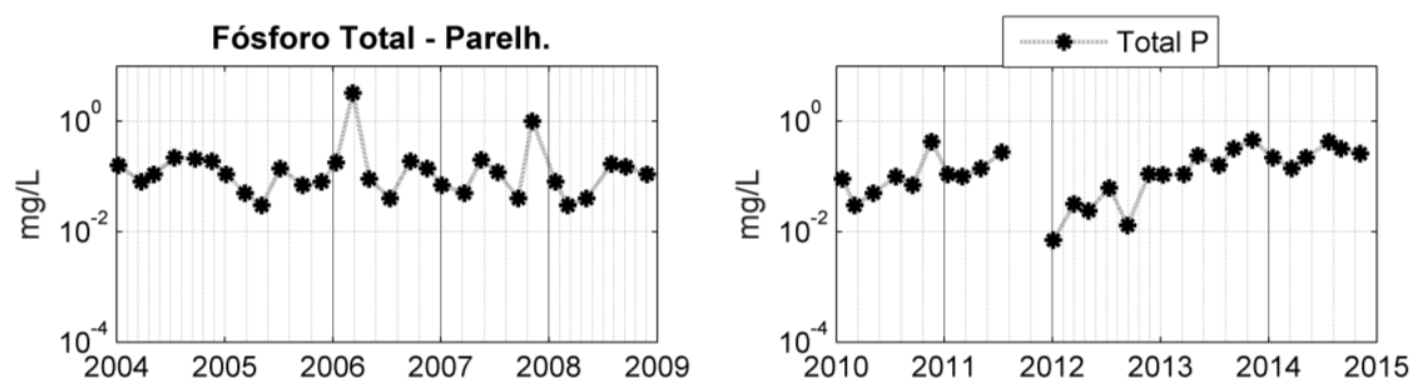

Figura 25 - Variação dos valores de Fósforo total, obtidos pela CETESB na foz do rio Parelheiros, reservatório de Guarapiranga, São Paulo, SP, durante o período de 2004 a 2015. (Fonte: http://aguasinteriores.cetesb.sp.gov.br).

No rio Embu Guaçu, cujos resultados são apresentados nas Figuras 26 e 27, a temperatura da água, foi um pouco mais baixa, variando entre 15 e $25{ }^{\circ} \mathrm{C}$, sendo portanto este o de menor temperatura entre os compartimentos principais. $\mathrm{O} \mathrm{pH}$ manteve-se entre 6,0 e 7,0 com pequenas oscilações. Já as concentrações de oxigênio dissolvido variaram de 5,0 a 9,0 $\mathrm{mg} \mathrm{L}^{-1}$, com ampla oscilações.

As concentrações do nitrogênio amoniacal variaram entre 0,1 e $0,8 \mathrm{mg} \mathrm{L}^{-1}$, com um pico de $5 \mathrm{mg} \mathrm{L}^{-1}$, enquanto os valores de nitrato variaram entre 0,2 e $0,4 \mathrm{mg} \mathrm{L}^{-1}$ apresentando um único pico de $4,0 \mathrm{mg} \mathrm{L}^{-1}$, tendo os maiores valores geralmente ocorrido nos períodos de seca.

As concentrações de fósforo total mantiveram-se entre 0,007 e $0,2 \mathrm{mg} \mathrm{L}^{-1}$ enquanto os valores de turbidez variaram amplamente entre 0,0 e 70,0 UNT acompanhando as oscilações das demais variáveis, com apenas dois picos acima de 100 UNT no ano de 2006, sendo este valor extremamente elevado ocasionado por turbidez orgânica em decorrência provavelmente de um florescimento excessivo de algas. 

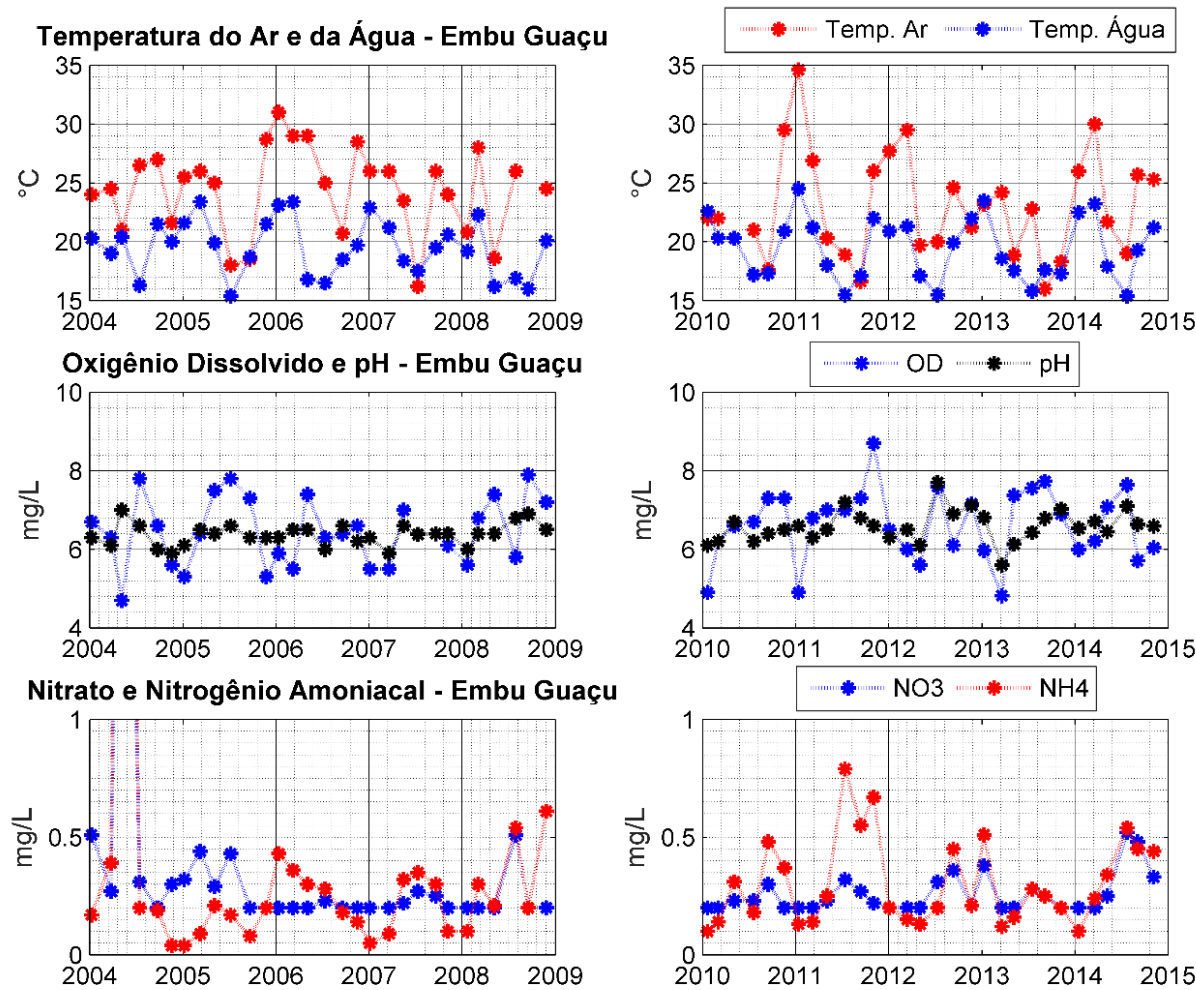

Figura 26- Dados de Temperatura do ar e da água, Oxigênio dissolvido, pH, Nitrato e Nitrogênio amoniacal, obtidos pela CETESB na foz do rio Embu-Guaçu, reservatório de Guarapiranga, São Paulo, SP, durante o período de 2004 a 2015. (Fonte: http://aguasinteriores.cetesb.sp.gov.br).
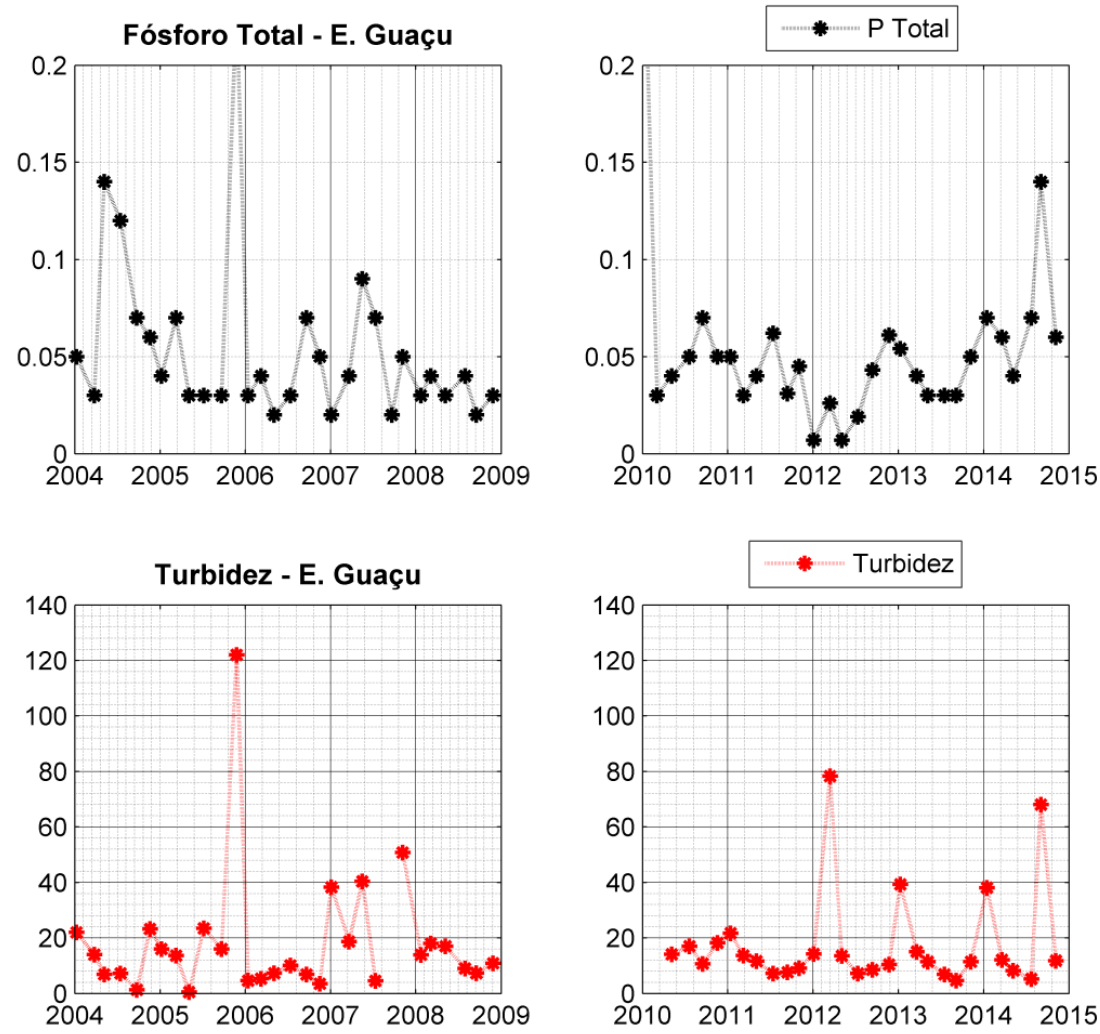

Figura 27 - Dados de Fósforo total e Turbidez, obtidos pela CETESB na foz do rio Embu-Guaçu, reservatório de Guarapiranga, São Paulo, SP, durante o período de 2004 a 2015. (Fonte: http://aguasinteriores.cetesb.sp.gov.br). 
O reservatório Guarapiranga é um corpo de grande heterogeneidade, com qualidade de água bastante variável de acordo com cada um de seus diversos compartimentos, definidos principalmente pela qualidade da água afluente de cada tributário, como se depreende dos padrões de curto e longo prazo obtidos para as concentrações de nutrientes ( $\mathrm{N}$ e P), clorofila a e de turbidez que neste reservatório são indicadoras do grau de trofia do sistema. Comparando-se a série de longo prazo (onze anos) e os dados do experimento de curto prazo, observa-se que os compartimentos Captação e Embu-Guaçu tem melhor qualidade da água, em termos de enriquecimento por nutrientes do que os compartimentos Embu-Mirim, e Parelheiros.

Este padrão espaço-temporal obtido é persistente e tem sido evidenciado em estudos anteriormente realizados neste reservatório (TUNDISI et al., 2006; ABE et al., 2006), e pelos dados disponibilizados pela agência responsável pela captação e distribuição da água para abastecimento público (SABESP). 


\section{3 - Análise dos padrões espaciais de variação na comunidade fitoplanctônica do reservatório Guarapiranga.}

Os processos biológicos podem ser descritos em várias escalas. Processos individuais como: movimento, reprodução, crescimento e respiração; processos que englobam toda a comunidade como: colonização e interação trófica; e processos que envolvem todo o ecossistema como os ciclos de nutrientes. Para analisar as diferentes escalas de processos foram analisados dados coletados em um experimento de curta duração e longa duração.

\subsubsection{Caracterização da comunidade fitoplanctônica em um evento de curta escala temporal}

Para identificação dos padrões de qualidade da água em curta escala de tempo foram analisados os dados coletados no reservatório Guarapiranga em setembro de 2010.

\subsubsection{Clorofila-a}

Os resultados relativos às concentrações de clorofila $a$ medidas na superfície do reservatório no dia 13/09/2010 mostraram que as maiores concentrações ocorriam nas regiões de desembocadura dos principais rios tributários, havendo a partir destas uma diminuição gradativa em direção ao corpo central, como pode ser observado na Figura 28. 


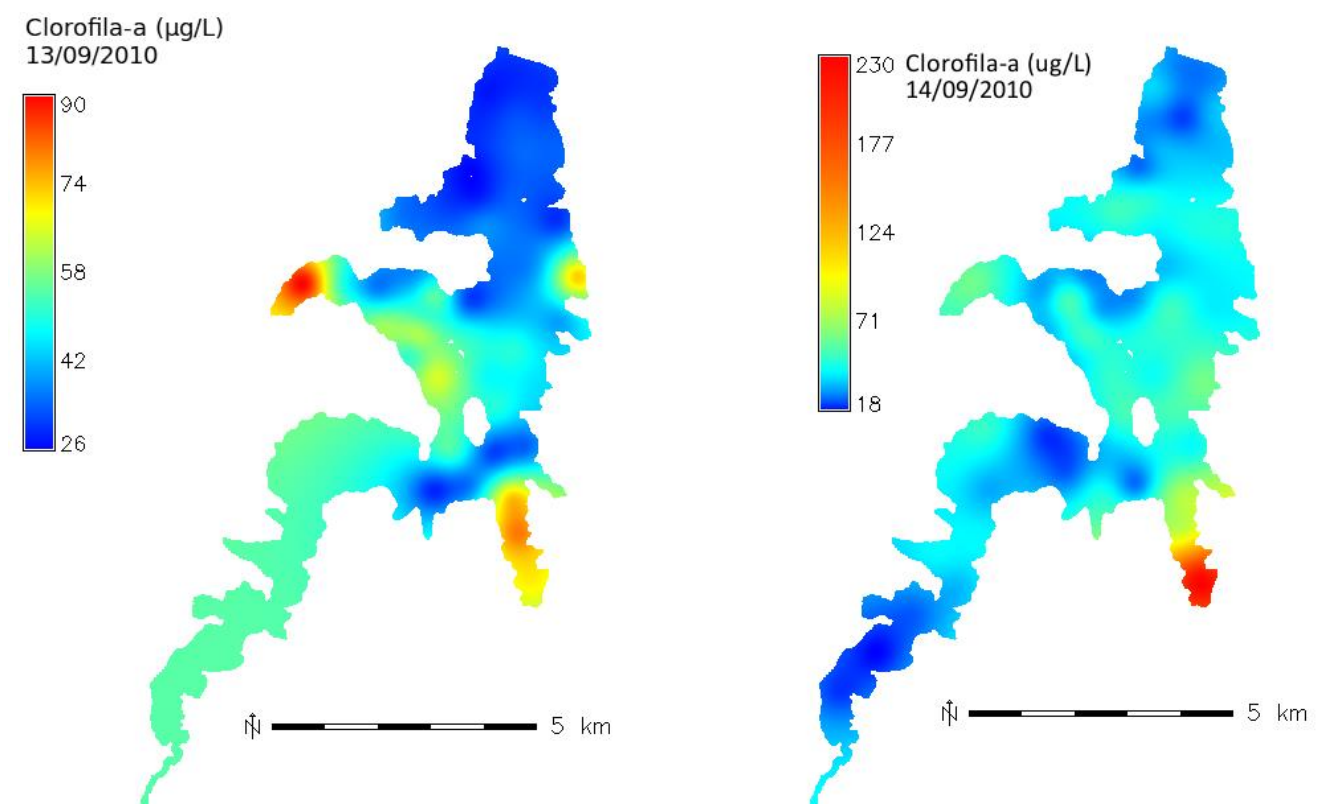

Figura 28- Distribuição espacial das concentrações de clorofila-a, em $\mu g \mathrm{~L}^{-1}$, no reservatório de Guarapiranga, São Paulo, SP, medidas nos dias 13 e 14 de setembro de 2010.

No dia 14/09 houve maior concentração de clorofila na foz do rio Parelheiros e um espalhamento em direção à barragem. Isso pode ser explicado pela mudança na direção dos ventos. A Tabela 3 mostra as direções e intensidades dos ventos durante o período em que foram realizadas as coletas. 
Tabela 3 - Direção e intensidade dos ventos durante o período em que foram realizadas coletas de água em 64 pontos para determinação das concentrações de clorofila a na camada de superfície do reservatório Guarapiranga, nos dias 13 e 14 de setembro de 2010 (Fonte: Santos et al., 2015).

\begin{tabular}{|c|c|c|c|c|}
\hline Dia & Hora & $\begin{array}{l}\text { Velocidade } \\
\text { do Vento } \\
(\mathrm{m} / \mathrm{s})\end{array}$ & $\begin{array}{c}\text { Direção } \\
\text { do Vento } \\
\left(^{\circ}\right)\end{array}$ & $\begin{array}{l}\text { Temperatura } \\
\text { do } \operatorname{Ar}\left({ }^{\circ} \mathrm{C}\right)\end{array}$ \\
\hline \multirow[t]{6}{*}{$12 / 09$} & \multicolumn{4}{|c|}{$\begin{array}{l}\text { A direção do vento segue o sentido horário com o } \\
\text { Norte sendo igual a } 0^{\circ} \text {. }\end{array}$} \\
\hline & $10: 00$ & 1.5 & $180 \uparrow$ & 20.25 \\
\hline & $13: 00$ & 1.5 & $180 \uparrow$ & 26.45 \\
\hline & $16: 00$ & 3.67 & $167 \uparrow$ & 23.2 \\
\hline & $19: 00$ & 2.65 & $180 \uparrow$ & 20.1 \\
\hline & $22: 00$ & 0.52 & $154 \uparrow$ & 18.4 \\
\hline \multirow[t]{8}{*}{$13 / 09$} & 01:00 & 0 & & 17.2 \\
\hline & 04:00 & 0.23 & & 16.6 \\
\hline & 07:00 & 0 & & 17 \\
\hline & $10: 00$ & 3.93 & $30 \vee$ & 24.14 \\
\hline & $13: 00$ & 3.46 & $54 \swarrow$ & 28.16 \\
\hline & $16: 00$ & 2.36 & $26 \downarrow$ & 29.85 \\
\hline & $19: 00$ & 1.24 & 232 Л & 23.64 \\
\hline & $22: 00$ & 0 & & 19.09 \\
\hline \multirow[t]{4}{*}{$14 / 09$} & 01:00 & 0 & & 19.55 \\
\hline & $04: 00$ & 4.32 & $332.4 \searrow$ & 22.4 \\
\hline & 07:00 & 2.14 & $360 \downarrow$ & 21.5 \\
\hline & $10: 00$ & 4.14 & 5 & 25.12 \\
\hline
\end{tabular}

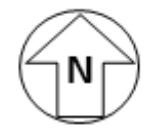

Um pouco antes de se iniciar a coleta no dia 13/09 por volta das 10:00 horas, o vento começou a soprar em direção à entrada do rio Embu Guaçu, tendo continuado até o começo da noite, quando então cessou. No final da madrugada do dia 14/09, o vento reiniciou a soprar com maior intensidade, mas agora em direção ao rio Parelheiros, situação que se estendeu até o final da coleta.

Dessa forma, as altas concentrações de clorofila encontradas na foz do rio Parelheiros foram, provavelmente, causadas pelo acúmulo do fitoplâncton empurrado pelo vento. 


\subsubsection{Comunidade fitoplanctônica}

O fitoplâncton é constituído por uma variedade muito grande de espécies, pertencentes a diferentes grupos taxonômicos. No presente estudo foram analisados somente os grupos que ocorreram em elevadas densidades e com potencial de formação de densos florescimentos no reservatório.

Para o estudo da distribuição espacial no reservatório foram analisadas as distribuições de 5 divisões de algas e as Cianobactérias, que foram os grupos mais abundantes no reservatório Guarapiranga durante o período do estudo de curta duração: Chlorophyta, Chryptophyta, Chrysophyta, Cyanophyta, Euglenophyta e Pyrrhophyta, cujos padrões de distribuição de densidade são mostrados nas Figuras 29 e 30.

O filo Chlorophyta foi o que mais contribuiu em termos de riqueza de táxons para a composição do fitoplâncton no reservatório de Guarapiranga em ambas as coletas e os representantes do filo Cyanophyta foram os grupos mais significativos na camada superficial deste corpo d' água. As maiores concentrações ficaram restritas ao corpo central e aos braços dos rios Embu-Mirim e Parelheiros, onde as concentrações de nutrientes são mais elevadas. Ambos grupos, clorofíceas e cianobactérias, atingiram concentrações bastante elevadas de aproximadamente 10.000 cels. $\mathrm{mL}^{-1}$ neste primeiro dia de amostragem, caracterizando desta forma um denso florescimento.

O padrão de distribuição espacial da concentração de algas e cianobactérias foi bastante similar àquele obtido para a distribuição das concentrações de nitrogênio particularmente na primeira coleta realizada no dia 13 de setembro de 2010. 

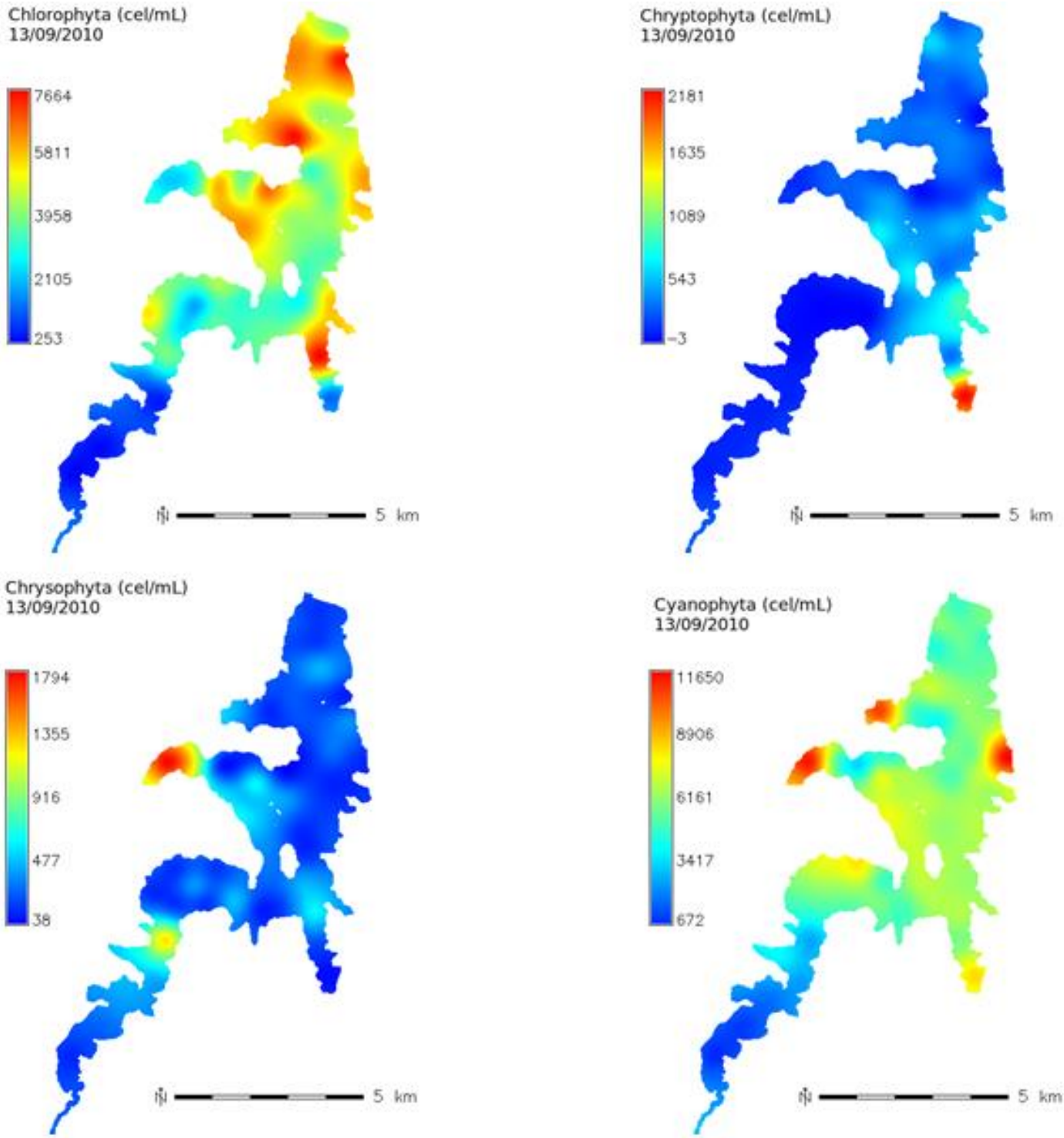

Euglenophyta (cel/mL) $13 / 09 / 2010$
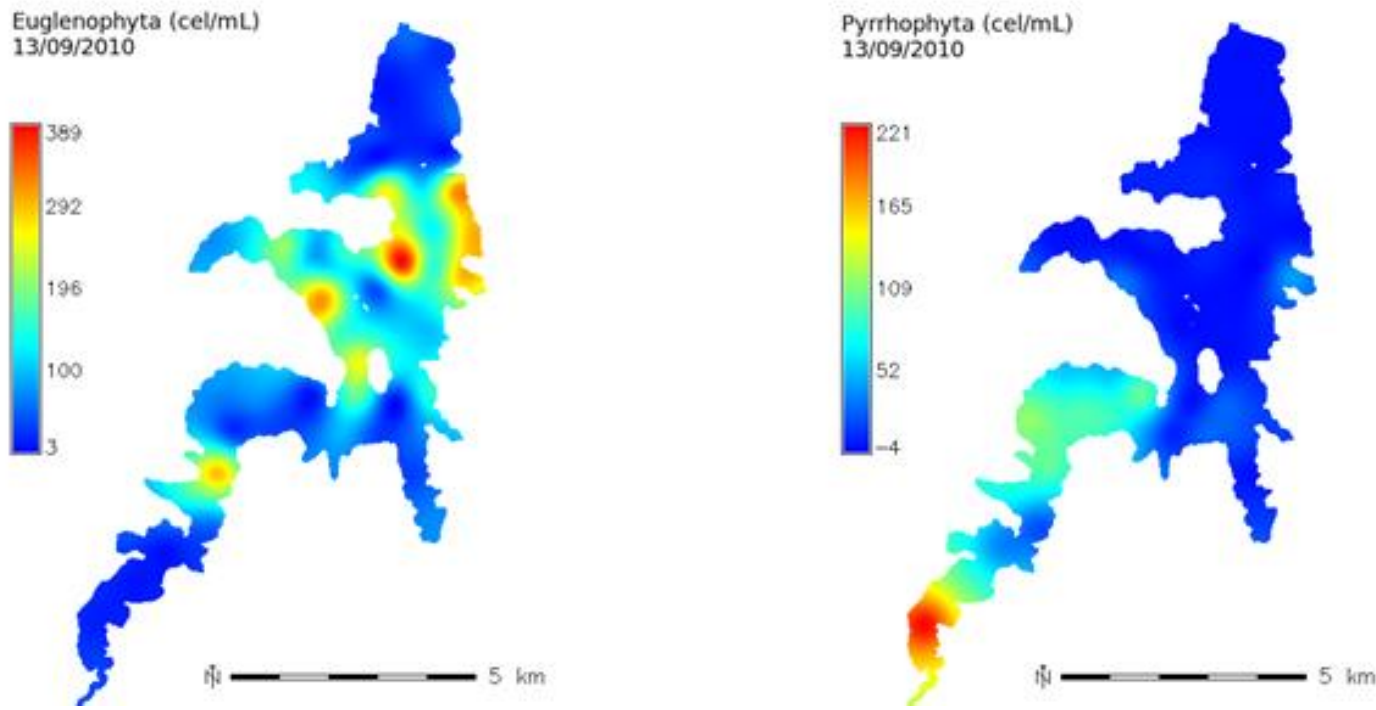

Figura 29 - Distribuição espacial dos principais grupos fitoplanctônicos coletados em 64 pontos na superfície do reservatório de Guarapiranga, São Paulo, SP, do dia 13/09/2010. As densidades dos organismos de cada grupo estão expressas em células por mL. 

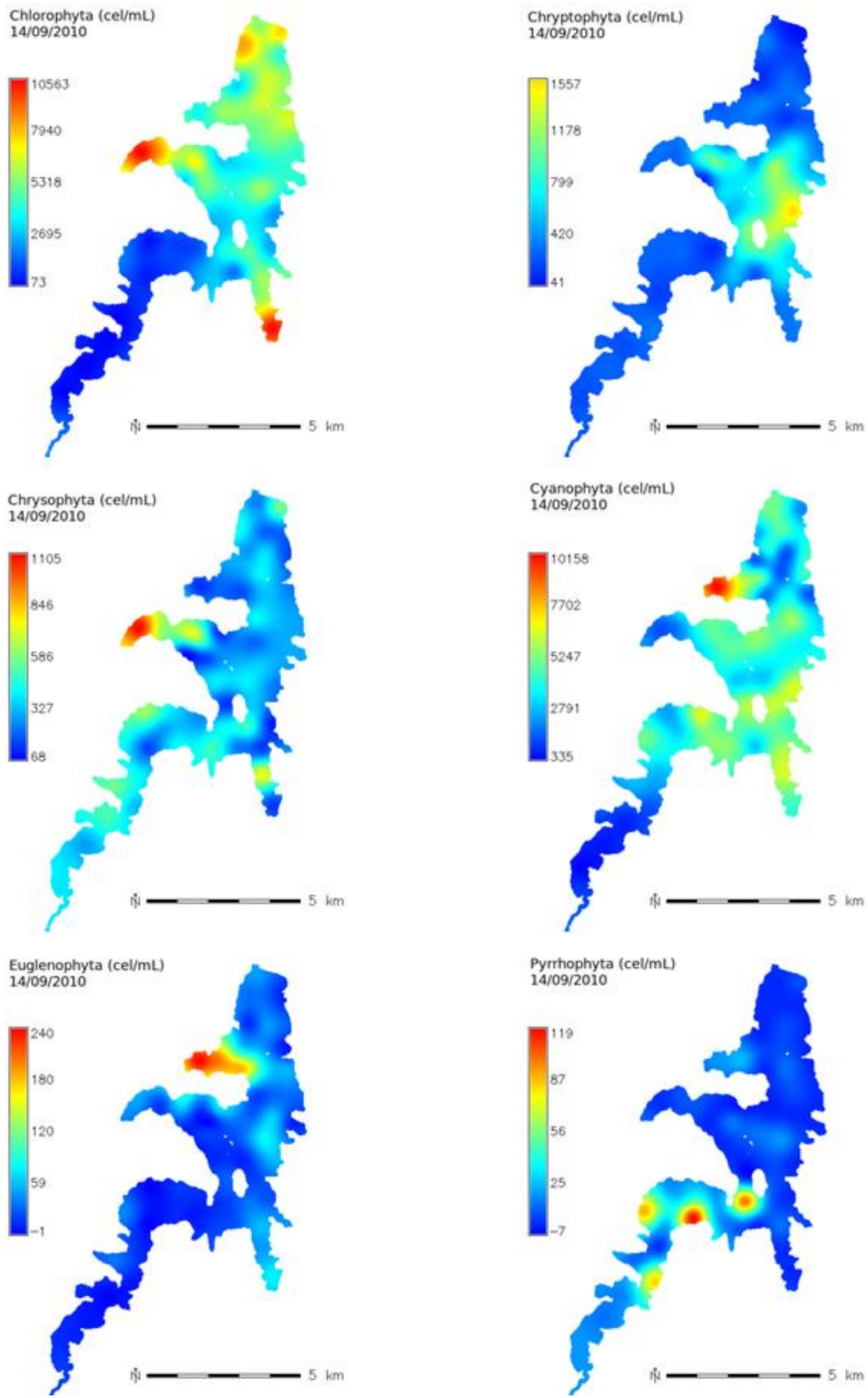

Figura 30- Distribuição espacial dos principais grupos fitoplanctônicos coletados em 64 pontos na superfície do reservatório de Guarapiranga, São Paulo, SP, do dia 14/09/2010. As densidades dos organismos de cada grupo estão expressas em células por $\mathrm{mL}$. 
As algas Cryptophyta ocorreram em maior concentração na foz do rio Parelheiros, sendo que o táxon mais abundante foi Cryptomonas sp.. As espécies deste gênero geralmente possuem baixos requerimentos de luz (VIEIRA \& KLAVENESS, 1986, KLAVENESS,1988), e dessa maneira, a sua presença na foz do rio Parelheiros pode estar relacionada com a baixa transparência da água nesta região durante o período da coleta.

As algas pertencentes ao filo Chrysophyta tiveram suas maiores concentrações encontradas na foz do rio Embu Mirim. O gênero mais abundante foi o Cyclotella sp., o qual ocorre em muitas partes do mundo e a sua presença parece ser maior em eventos de estratificação, pois esta diatomácea consegue sobreviver em camadas inferiores com baixa quantidade de luz e alta disponibilidade de nutrientes, podendo subir para as camadas superiores nos eventos de desestratificação.

Os representantes do filo Cyanophyta ocorreram em maiores concentrações no corpo central do reservatório e na parte represada da foz de alguns rios. No dia 13/09, as maiores concentrações foram registradas na foz dos córregos da Riviera, Guavirutuba, e dos rios Embu-Mirim, das Pedras e Parelheiros. Todos estes corpos de água recebem uma grande quantidade de esgoto sem tratamento. No dia 14/09, a maior concentração de algas e cianobactérias ocorreu na baía onde desembocam os córregos da Riviera e Guavirutuba.

Geralmente as cianobactérias são dominantes nos reservatórios tropicais eutrofizados devido à sua grande adaptabilidade e tolerância a elevadas temperaturas e baixa luminosidade. Elas possuem características fisiológicas que fazem com que a sua temperatura ótima de crescimento seja maior do que a de outros grupos (O' NEIL, 2011), possuem ainda a capacidade de utilizar várias formas de nitrogênio e fósforo particulados (DAVIS et al., 2010), além de outras vantagens como controle de flutuabilidade, que as tornam fortes competidoras.

Apesar de serem chamadas de microorganismos para todas as estações e climas, as cianobactérias exibem elevada sensibilidade a alterações mesmo pequenas nas condições climáticas ambientais. Apesar de tolerarem temperaturas elevadas de até 35$40{ }^{\circ} \mathrm{C}$, altas intensidades de radiações (PAR >1500 $\mu \mathrm{e} . \mathrm{m}^{-2} \mathrm{~s}^{-1}$ ) em águas superficiais, 
rápidas mudanças climáticas como quedas de apenas $5{ }^{\circ} \mathrm{C}$ podem bruscamente terminar com blooms persistentes (PEARL, 1988), assim como mudanças bruscas na velocidade ou na direção do vento tem impactos negativos similares sobre a ocorrência e intensidade dos blooms (PEARL, 1988).

Em ambas as coletas, a cianobactéria mais abundante no reservatório Guarapiranga foi Aphanocapsa delicatissima (NISHIMURA, 2012, SILVA, 2014) Embora os blooms mais comumente reportados para este reservatório em anos anteriores fossem espécies pertencentes aos gêneros Anabaena. e Microcystis (BEYRUTH, 2000; TUNDISI et al., 2006), é possível que mais recentemente o uso intensivo de algicidas nesse reservatório possa ter favorecido esta espécie, que tem maior tolerância.

As algas do filo Euglenophyta representadas pelo táxon Euglena sp. ocorreram em menor densidade que as clorofíceas e cianobactérias e tiveram maior abundância nas estações de coleta da região litorânea. No dia 13/09, as maiores concentrações foram encontradas na margem leste, próximo ao rio das Pedras, com uma mancha de concentrações menores em todo o corpo central, enquanto no dia 14/09, a maior densidade foi registrada na baía dos rios Guavirutuba e Riviera. Em ambos dias amostrados, os organismos da divisão Pyrrhophyta ocorreram em maiores concentrações na região do rio Embu-Guaçu.

A sucessão das comunidades planctônicas no tempo e no espaço, horizontalmente e verticalmente, depende da circulação e dos padrões hidrodinâmicos (STRASKRABA \& TUNDISI, 1999). O entendimento dos padrões e dos processos que os produzem é fundamental para o desenvolvimento de princípios de manejo e elaboração de modelos preditivos. (BICUDO et al. 2007).

\subsubsection{Caracterização da comunidade fitoplanctônica em um evento de longa escala temporal}

Os dados relativos à série temporal de 11 anos para as concentrações dos pigmentos clorofila-a e feofitina-a, densidade de cianobactérias e concentrações de fósforo na estação próxima à Captação, para o período de 2004 a 2015 são apresentados 
na Figura 31. Observa-se que as concentrações de ambos pigmentos tiveram um padrão de variação semelhante e que na maior parte do período as concentrações de clorofila-a variaram entre 5,0 e $70 \mu \mathrm{g} \mathrm{L}^{-1}$ sendo os valores na maior parte do tempo maiores que os de feofitina, com exceção do segundo semestre de 2004, primeiro semestre de 2005 e maior parte do ano de 2007, o que pode indicar uma maior mortalidade de algas nesses períodos. Uma análise conjunta das densidades de cianobactérias sugere que esta hipótese possa ser aceita.
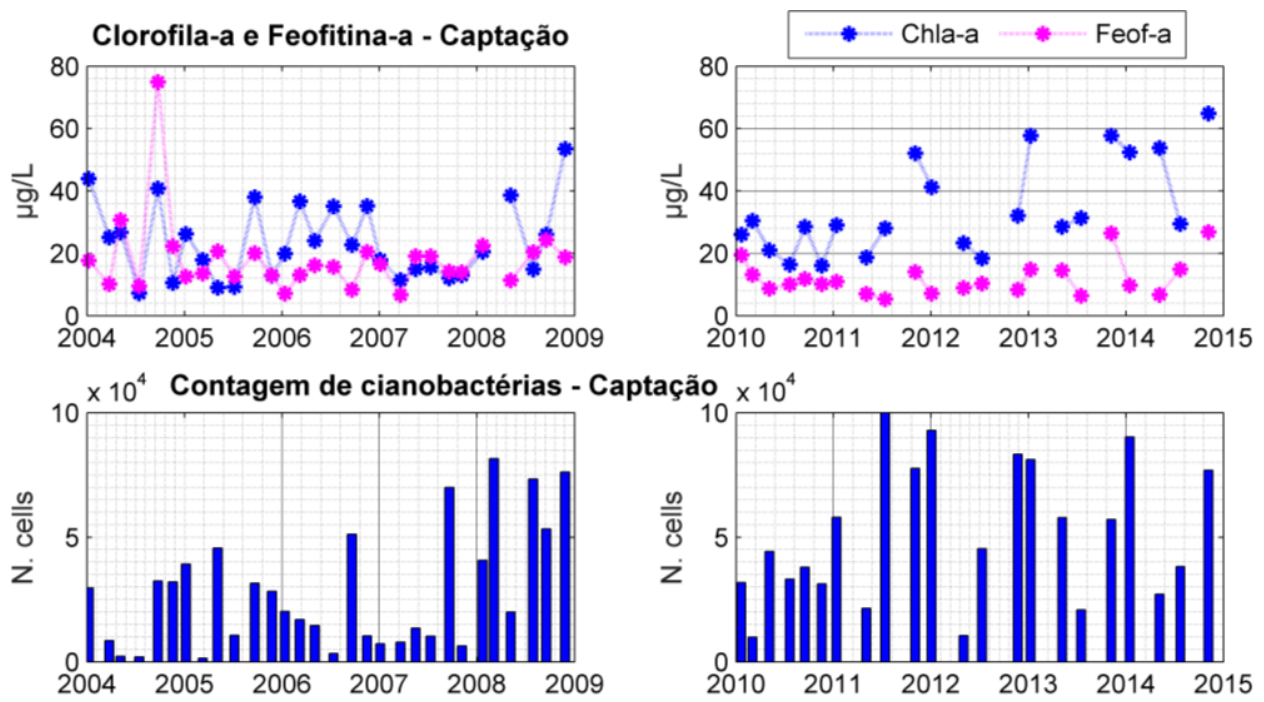

Figura 31 - Variação dos valores da concentração dos pigmentos Clorofila-a, Feofitina-a e densidade de cianobactérias obtidos pela CETESB na captação de água para abastecimento, na série temporal de 2004 a 2015. . (Fonte: http://aguasinteriores.cetesb.sp.gov.br).

Para a foz do rio Parelheiros, as concentrações de clorofila-a e da densidade das cianobactérias apresentadas na Figura 32, variaram entre 0,0 e $70 \quad \mu g \mathrm{~L}^{-1}$ acompanhando as oscilações das demais variáveis, porém com vários picos acima de $100 \mu \mathrm{g} \mathrm{L}^{-1}$, ou seja, maiores que as de feofitina, em praticamente todo o período. Em ambos os locais a contagem de cianobactérias evidenciou que as maiores densidades ocorreram em períodos correspondentes a diferentes condições climáticas, mas tendo os maiores valores sido predominantemente registrados nos meses de janeiro, maio, julho e novembro. 

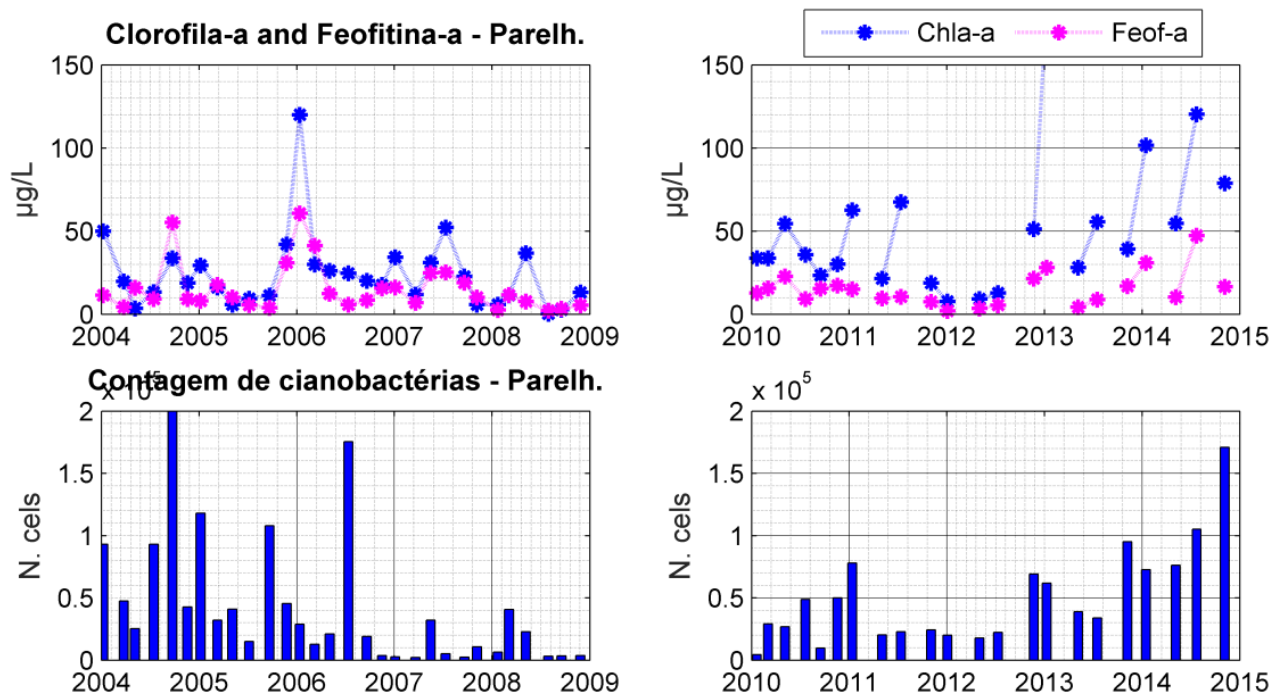

Figura 32 - Variação dos valores da concentração dos pigmentos Clorofila-a e Feofitina-a $\left(\mu \mathrm{g} \mathrm{L}^{-1}\right)$ e da densidade de cianobactérias (no. de células $\mathrm{mL}^{-1}$ ) obtidos pela CETESB na foz do rio Parelheiros, durante o período de 2004 a 2015. (Fonte: http://aguasinteriores.cetesb.sp.gov.br). 


\section{4 - Análise dos padrões espaciais de variação nas comunidades fitoplanctônica e de macrófitas no reservatório Guarapiranga.}

Para realização dessa análise, foram selecionados os padrões que ocorreram com maior frequência. As principais variáveis analisadas foram a turbidez, o fitoplâncton e as macrófitas.

Em um evento ocorrido no dia 19/03/1999, apresentado na Figura 33, uma grande quantidade de sólidos suspensos vindos dos rios Embu Guaçu e Parelheiros afluíram ao reservatório. O principal motivo dessa alta concentração foram as fortes precipitações ocorridas nos dias anteriores. (Tabela 1 do Anexo 1).

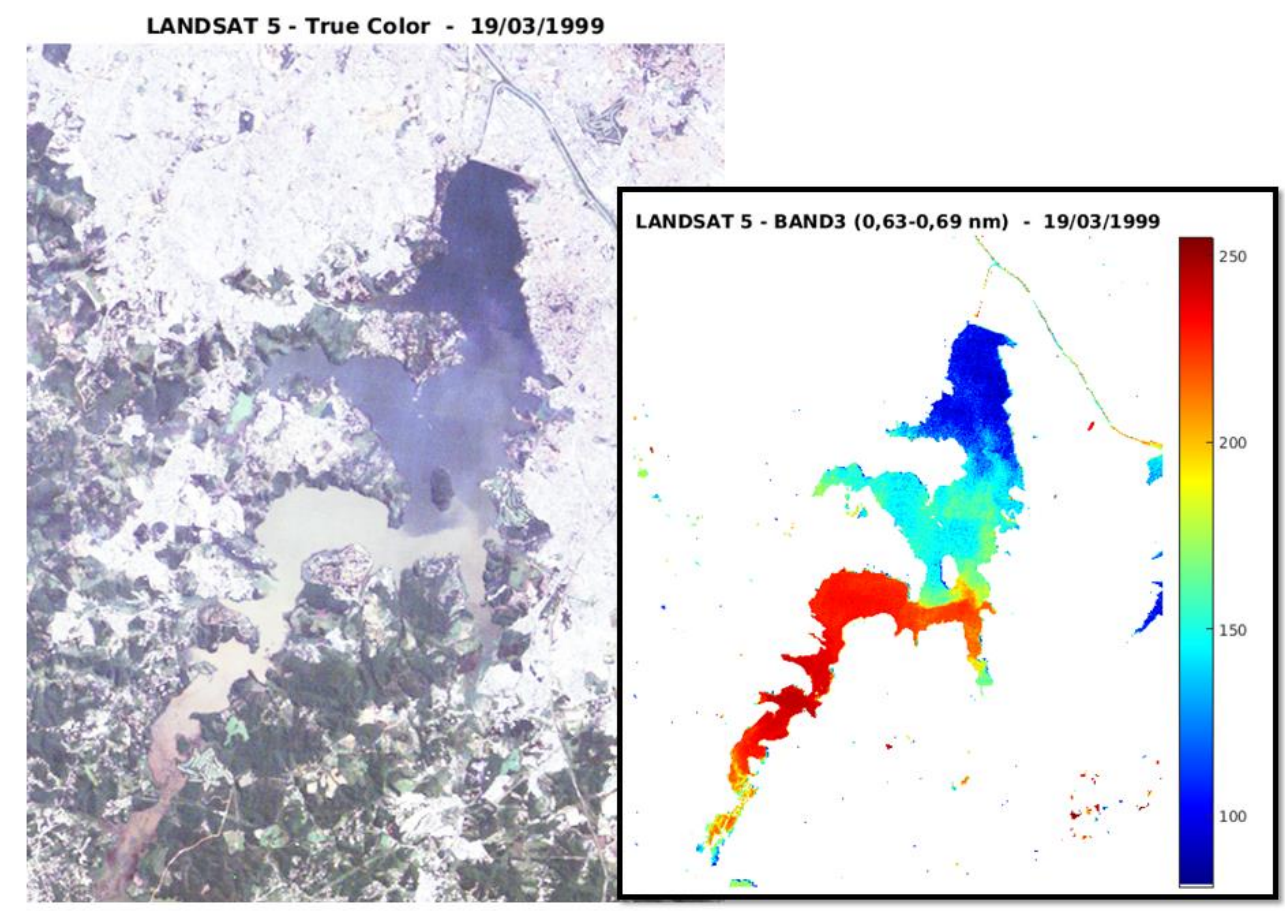

Figura 33 - Imagem do satélite Landsat5 coletada no dia 19/03/1999, para o reservatório de Guarapiranga, região metropolitana de São Paulo, SP. (Fonte: INPE)

Nesta imagem é possível observar o caminho percorrido pelas massas de água dos rios Embu Mirim e Parelheiros e a mistura destas no corpo central, evidenciando a existência de compartimentos dentro do reservatório e reforçando a importância da análise individual dos tributários.

Algumas variáveis como matéria orgânica dissolvida, densidade do fitoplâncton e de sólidos suspensos apresentam assinaturas espectrais semelhantes, muitas vezes dificultando a distinção entre os componentes. Além disso, o ângulo em que ocorre o 
imageamento e as condições climáticas podem também influenciar na qualidade das imagens

Na Figura 34, são mostrados os resultados das bandas 2 e 3, e assim como mostrado na Figura 33 há uma predominância de sólidos suspensos vindos dos rios Embu Guaçu e Parelheiros. Para uma análise precisa seria necessário obter amostras in situ simultâneas ao imageamento, já que a baixa resolução espectral não permite afirmar com segurança qual a composição do material suspenso na água. Apesar disso o padrão compartimentalizado apresentado anteriormente permaneceu.
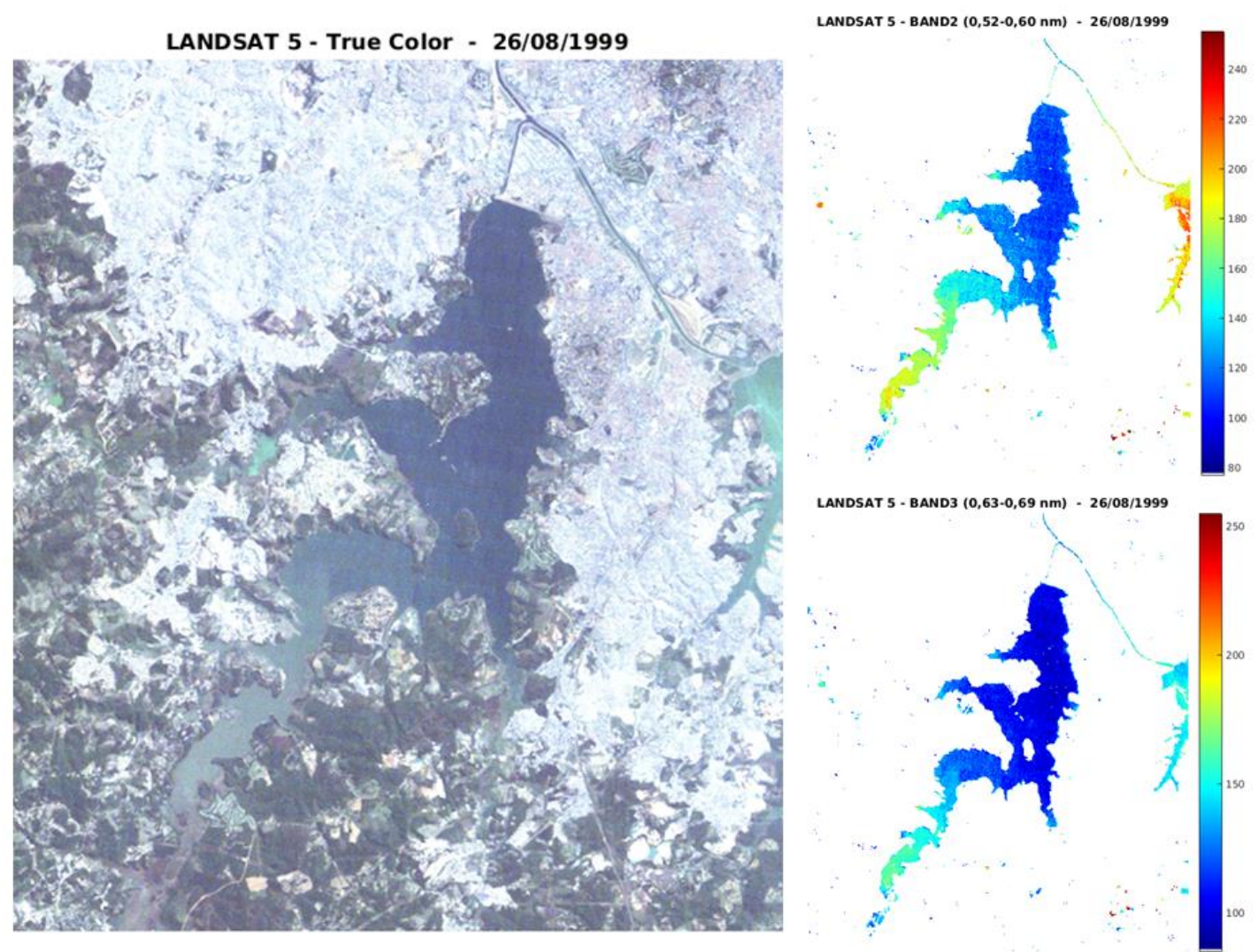

Figura 34 - Imagem do satélite Landsat5 coletada no dia 26/08/1999, para o reservatório de Guarapiranga, região metropolitana de São Paulo, SP. (Fonte: INPE)

A bacia hidrográfica do reservatório Guarapiranga é bastante heterogênea, com sub-bacias de diferentes formas e tamanhos, além de uma grande variação na ocupação e usos do solo, como pode ser observado na Figura 35. Isso implica em vazões afluentes com diferentes composições e magnitudes, e por se tratar de uma área muito grande, com os eventos de chuva podendo ocorrer de forma esparsa, fazendo com que as massas de água dos rios sejam alteradas de forma diferente em um mesmo evento. 


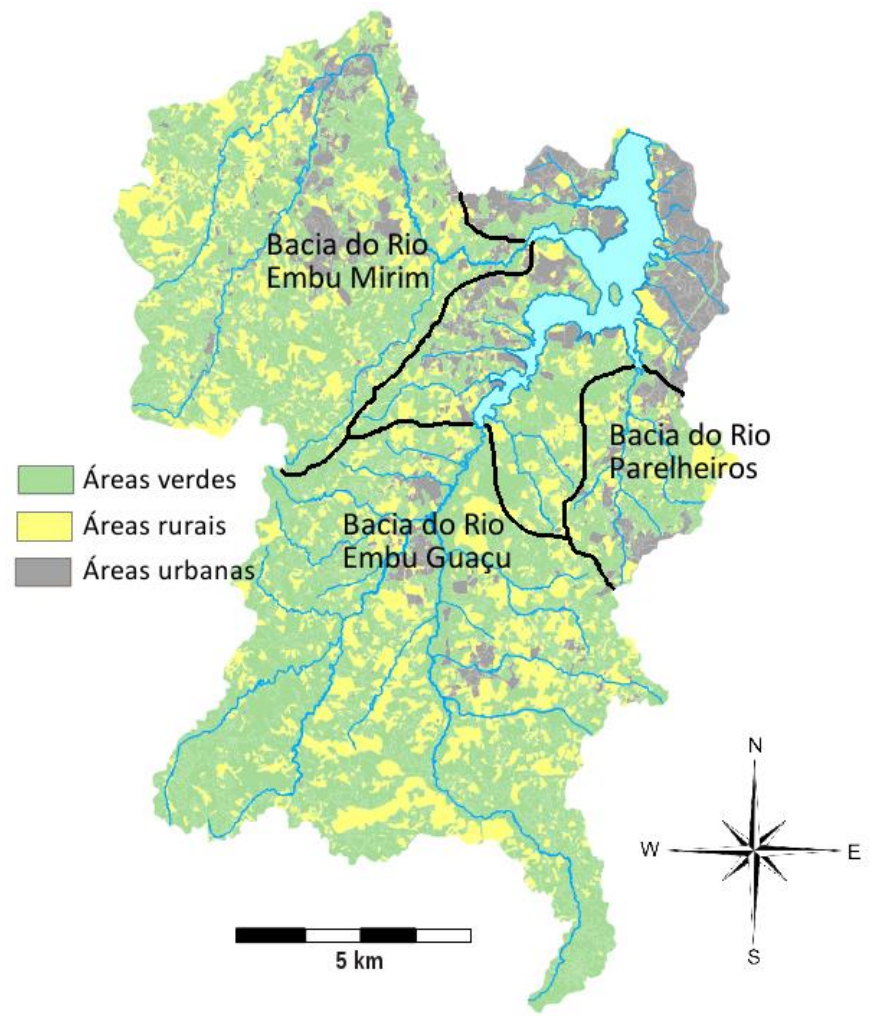

Figura 35- Mapa de usos do solo da represa Guarapiranga, São Paulo, SP, com a delimitação das principais bacias hidrográficas (adaptado de PRIME, 1998).

Quando as vazões aumentam, predominam os processos advectivos, carregando a massa de água dos rios na direção dos fluxos principais do reservatório, o que está representado na Figura 36, juntamente com a batimetria da represa.

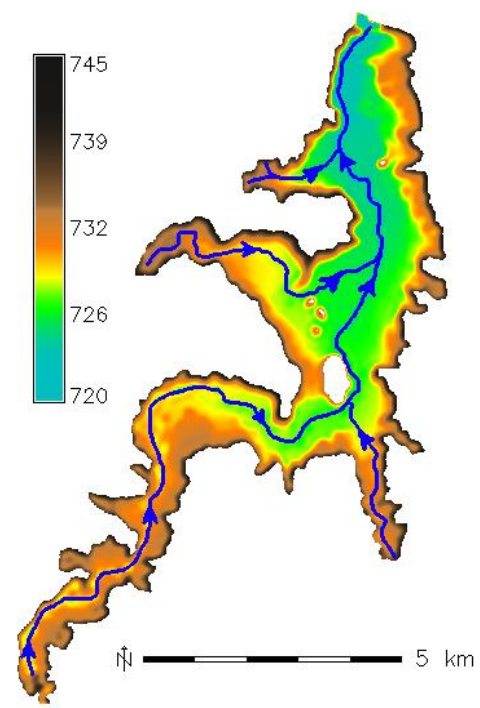

Figura 36 - Batimetria do reservatório Guarapiranga, São Paulo, SP, em metros acima do nível do mar e setas azuis indicando os fluxos principais.

Em um evento ocorrido em 10/03/2002, mostrado na Figura 37, a região na margem leste, próximo à barragem, apresenta uma mancha que aparenta ser um 
pequeno bloom. Isso se deve à ocorrência de ventos vindos de nordeste (Tabela 2 do Anexo I) que podem ter gerado resuspensão de sedimentos e a circulação das águas ricas em nutrientes dos córregos do Guavirutuba e da Riviera para essa região, que além de rasa é bastante estagnada, provavelmente favorecendo o desenvolvimento de organismos fitoplanctônicos.

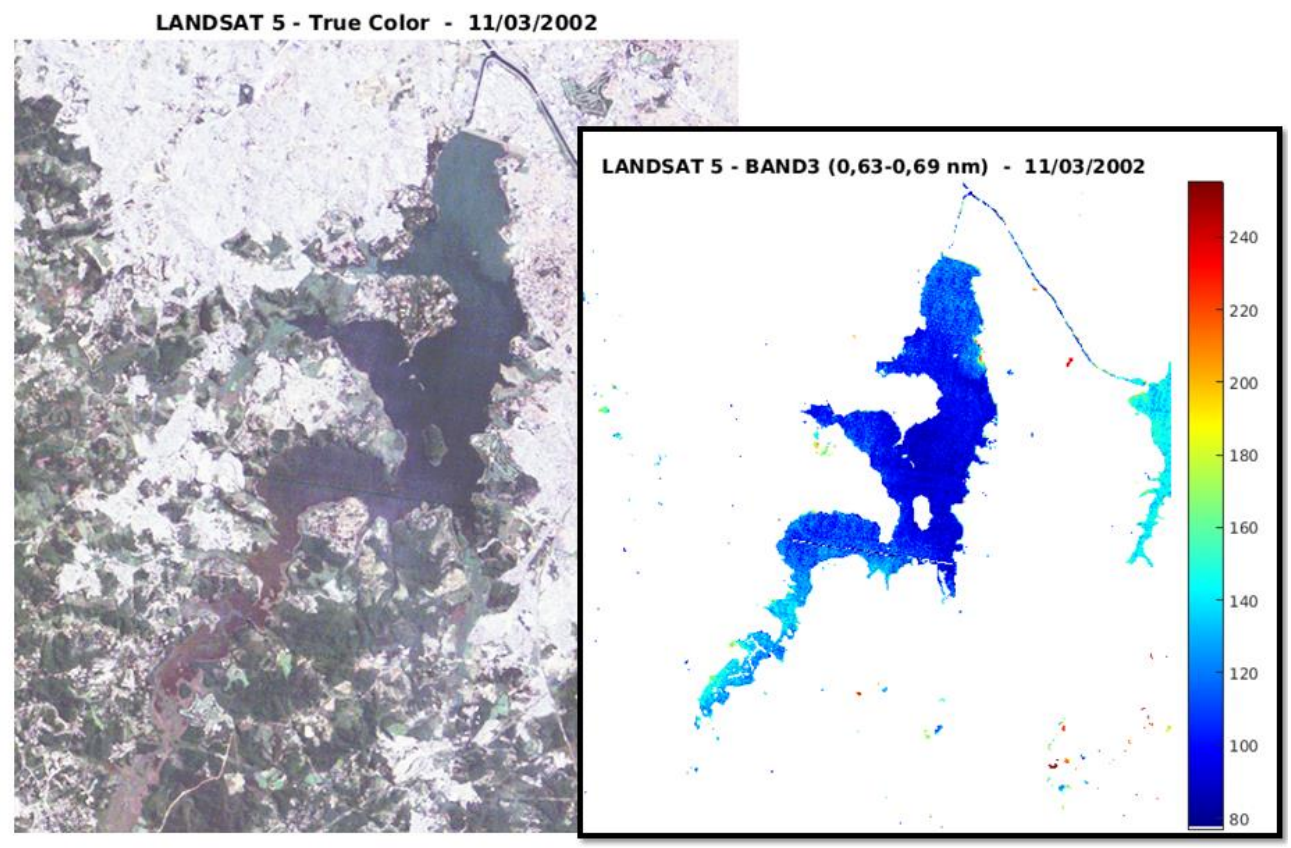

Figura 37 - Imagem do satélite Landsat5 coletada no dia 11/03/2002, para o reservatório Guarapiranga, São Paulo, SP. Fonte: INPE.

Os ventos possuem grande influência na dinâmica da camada superficial do reservatório e é através dela que são transmitidos os momentos para as camadas inferiores da coluna de água. A força exercida pelo vento depende de três fatores: a velocidade do vento, a rugosidade da superfície do reservatório e o comprimento da superfície na direção em que o vento está soprando (FISCHER et al., 1979).

As macrófitas flutuantes emergentes, por situarem-se acima da superfície da água, recebem uma influência maior do arrasto causado pelo vento. No ano de 2010, ocorreu um grande crescimento de macrófitas no reservatório Guarapiranga. Existiam diversas espécies de macrófitas flutuantes, principalmente, do gênero Salvinia e enraizadas do gênero Egeria, gerando uma série de problemas para a SABESP, pois elas podem afetar a qualidade da água e também danificar os sistemas de bombas de captação da água. Na Figura 38 são apresentadas algumas imagens desses eventos ao longo do ano de 2010. 

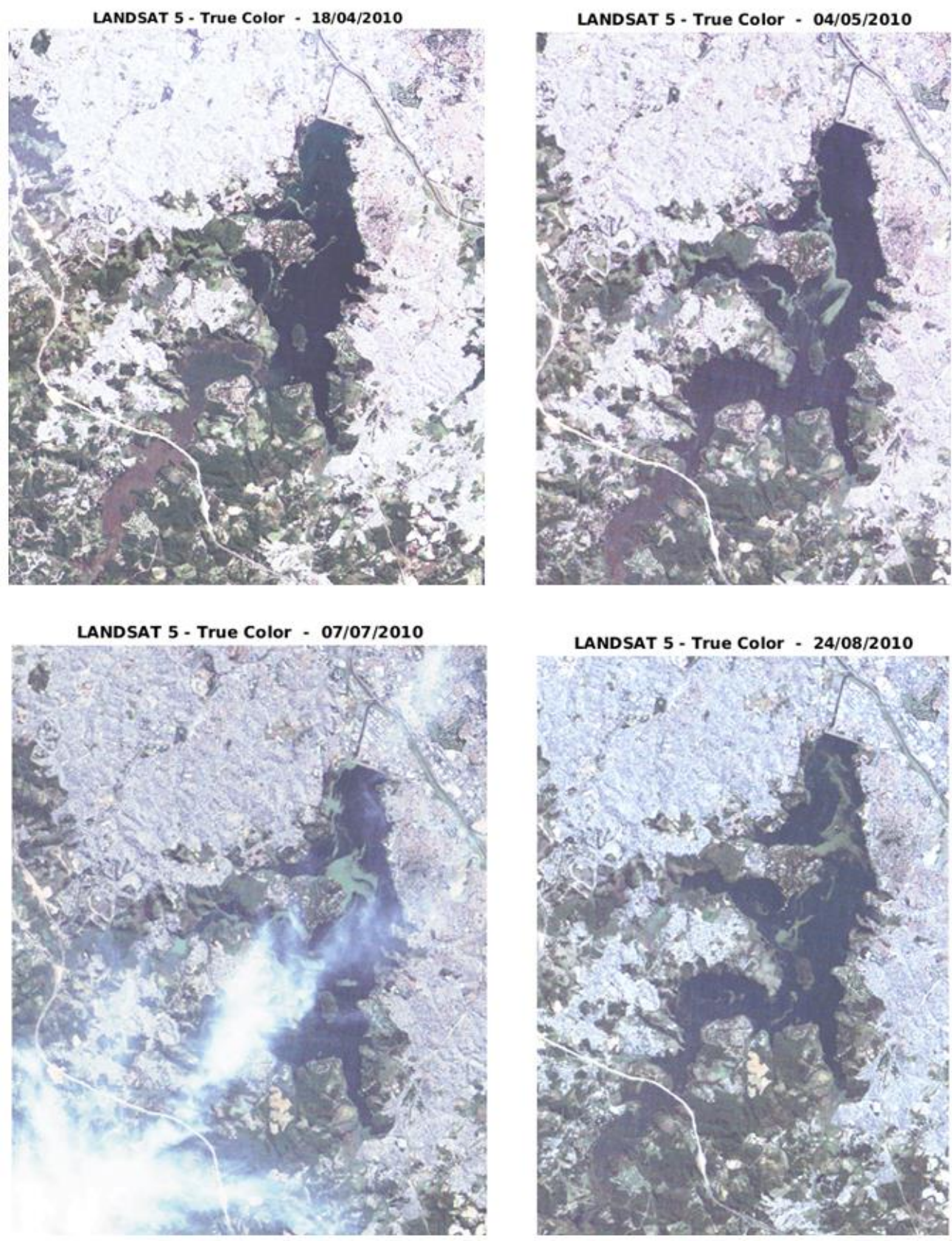

Figura 38 - Imagens do satélite Landsat 5 mostrando o crescimento exagerado de macrófitas (áreas na cor verde claro) no reservatório Guarapiranga, São Paulo, SP, durante o ano de 2010.

Nestas imagens podem ser observadas diferentes distribuições e concentrações de macrófitas. No dia 18/04/2010 as macrófitas estavam localizadas em sua maioria, nas margens do reservatório, com pequenas aglomerações na saída dos rios Guavirutuba, Embu Mirim e Embu Guaçu. Já no dia 04/05/2010, é possível visualizar uma grande área coberta por macrófitas no corpo central, bem próximo à saída do braço do rio Embu Mirim, demarcando o canal principal do reservatório. Nos dias 07/07/2010 e 
24/08/2010, ocorreu um acúmulo ainda maior de macrófitas no corpo central e na região próxima à barragem.

O deslocamento das macrófitas pode ocorrer rapidamente, dependendo das condições climáticas. Elas podem se deslocar centenas de metros em poucas horas.

Em uma coleta realizada no dia 23/04/2010, a distribuição de macrófitas era semelhante à apresentada na imagem da Figura 39, do dia 18/04/2010, em que boa parte das macrófitas encontravam-se nas margens e na foz dos rios Embu Mirim e Parelheiros. Porém, no período entre a tarde do dia 24/04/2010 e a manhã do dia 25/04/2010, ocorreu a entrada de uma frente fria vinda da serra do Mar, que gerou um aumento na velocidade dos ventos e levou a maior parte dessas macrófitas localizadas nas regiões litorâneas para a região da barragem.

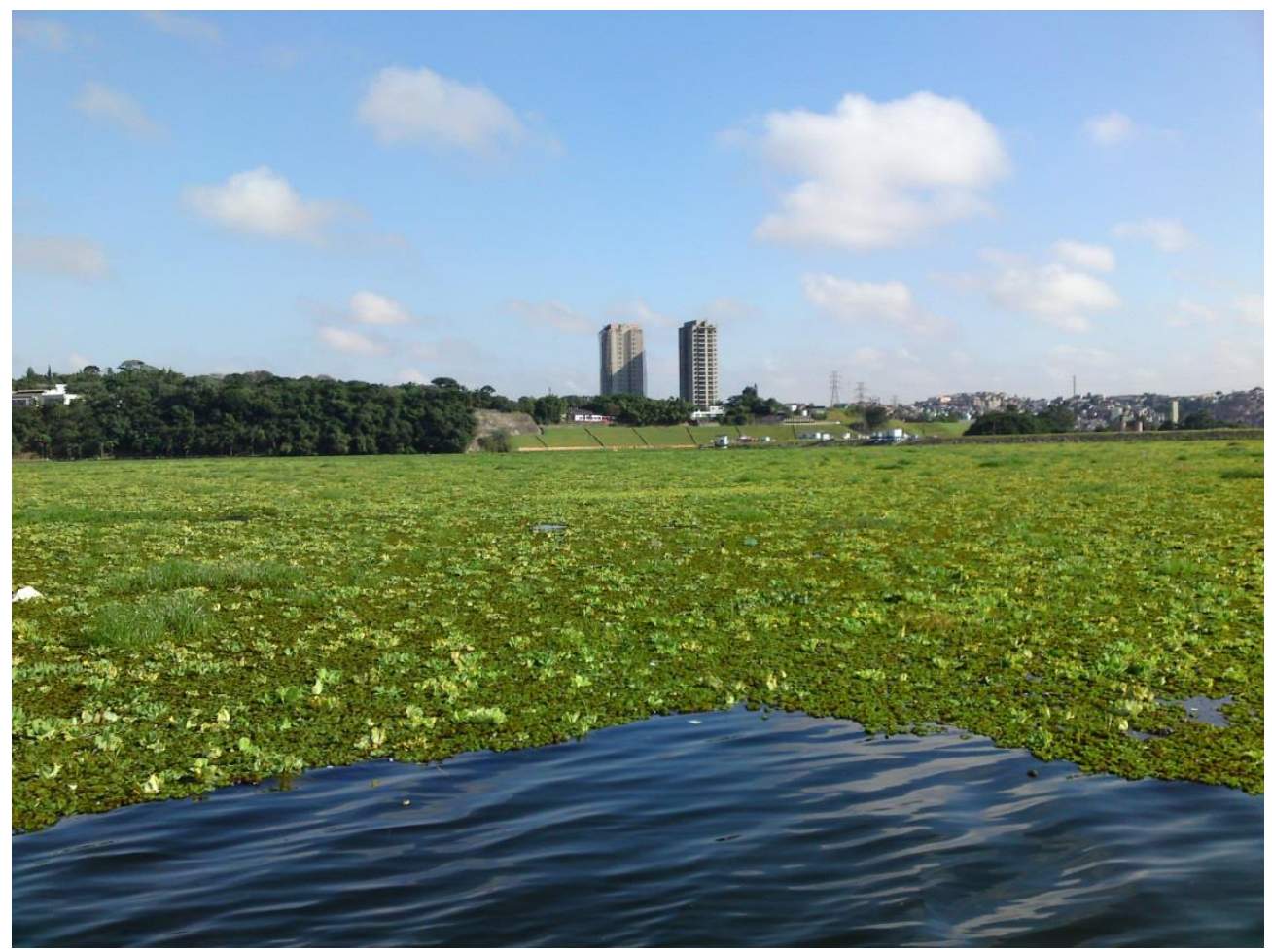

Figura 39- Foto mostrando o acúmulo de macrófitas na barragem do reservatório Guarapiranga no dia $25 / 04 / 2010$.

Essa movimentação ocorreu em menos de um dia e evidenciou a importância dos estudos de curta escala de tempo para análise da dinâmica de reservatórios tropicais polimíticos. As macrófitas flutuantes acabam muitas vezes auxiliando na acumulação e 
formação de ambientes favoráveis para o desenvolvimento do fitoplâncton, por outro lado, elas inibem a absorção de luz das espécies que ficam nas camadas imediatamente inferiores e dessa forma impedem o seu crescimento, detalhe das espécies flutuantes e enraizadas na Figura 40.
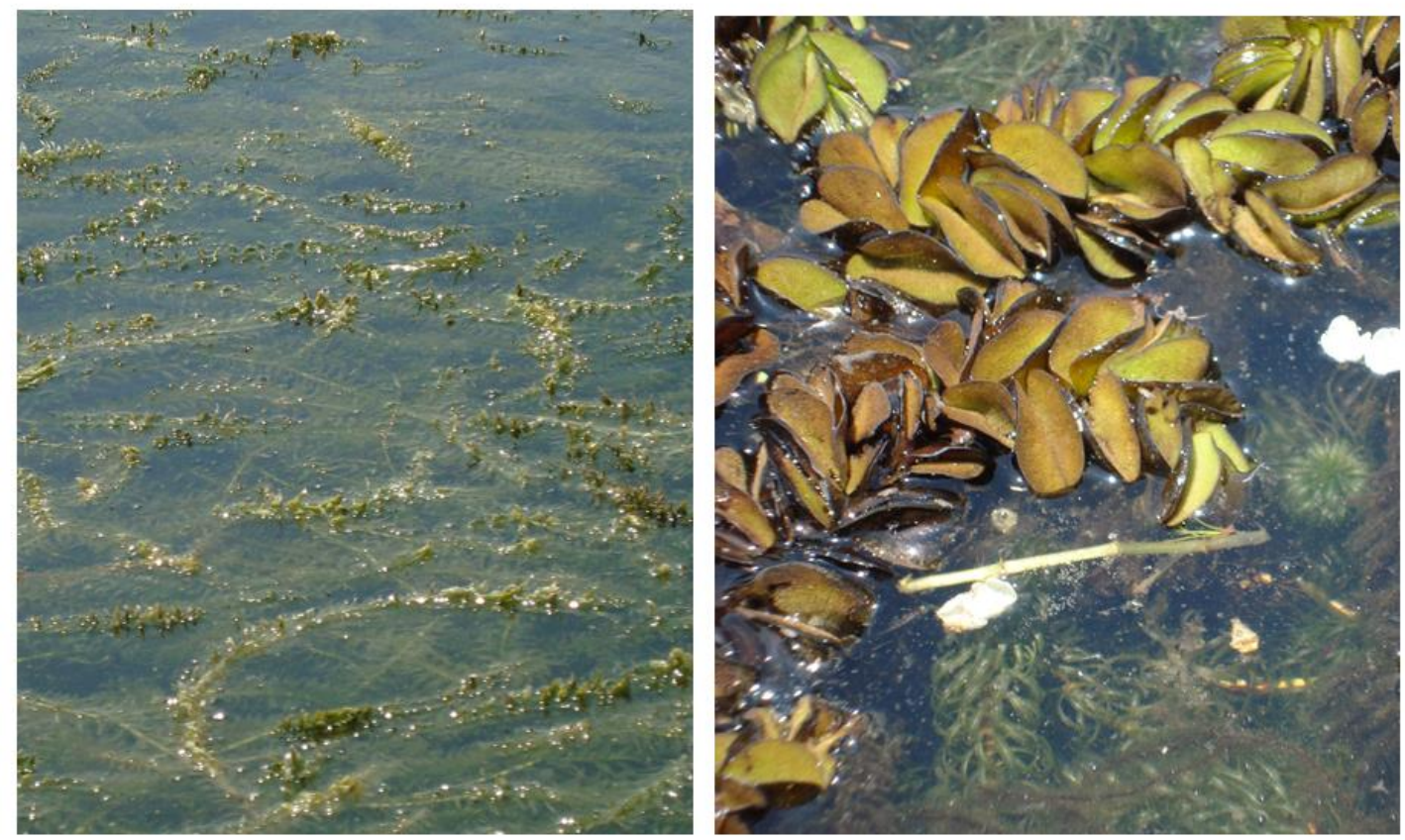

Figura 40- Vista das macrófitas flutuantes e enraizadas próximo à barragem do reservatório Guarapiranga no dia 25/04/2010.

O conhecimento sobre os padrões de distribuição de vento auxilia na determinação das regiões mais favoráveis para a ocorrência de acumulação, tanto de macrófitas, quanto de fitoplâncton.

Analisando os dados de vento para a cidade de São Paulo, fornecidos pelo Instituto de Astronomia, Geofísica e Ciências Atmosféricas (IAG-USP), obteve se uma distribuição estatística das velocidades e direções predominantes durante o ano de 2010, mostradas no histograma direcional da Figura 41. 

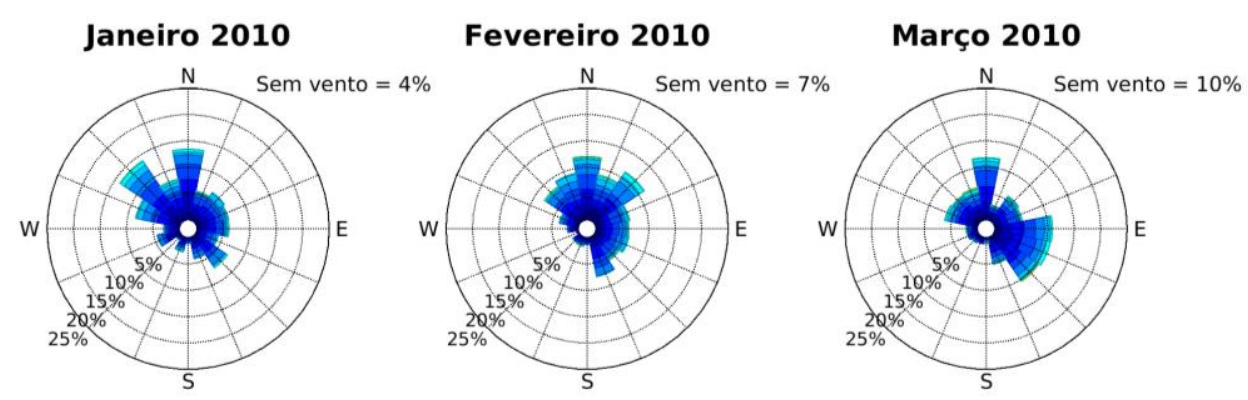

Abril 2010

Maio 2010
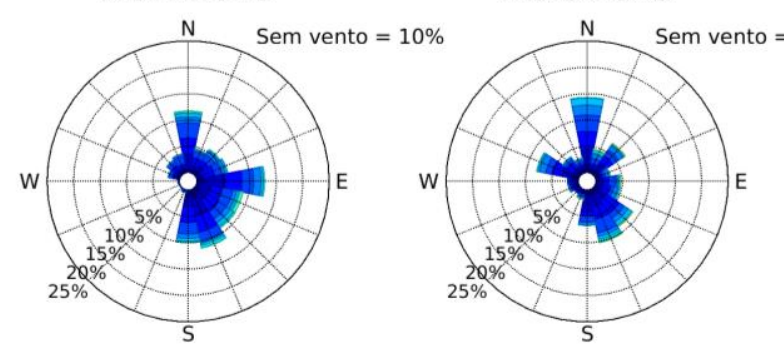

Junho 2010

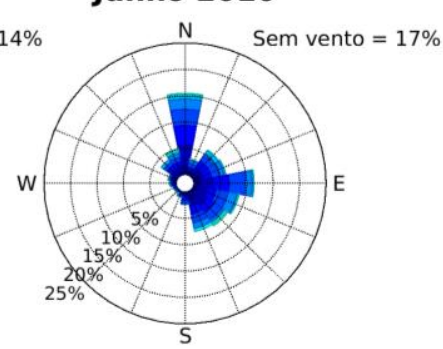

Julho 2010

Agosto 2010
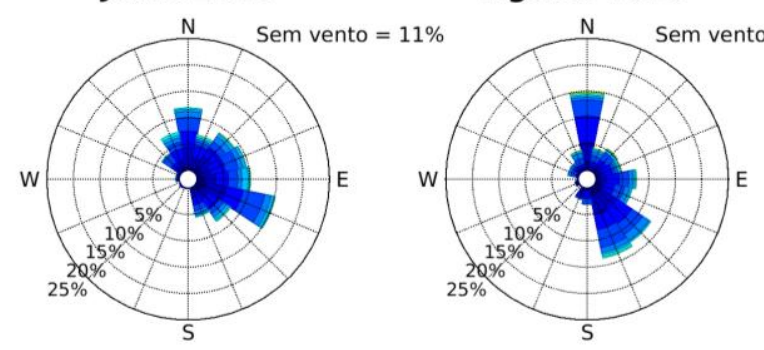

Outubro 2010
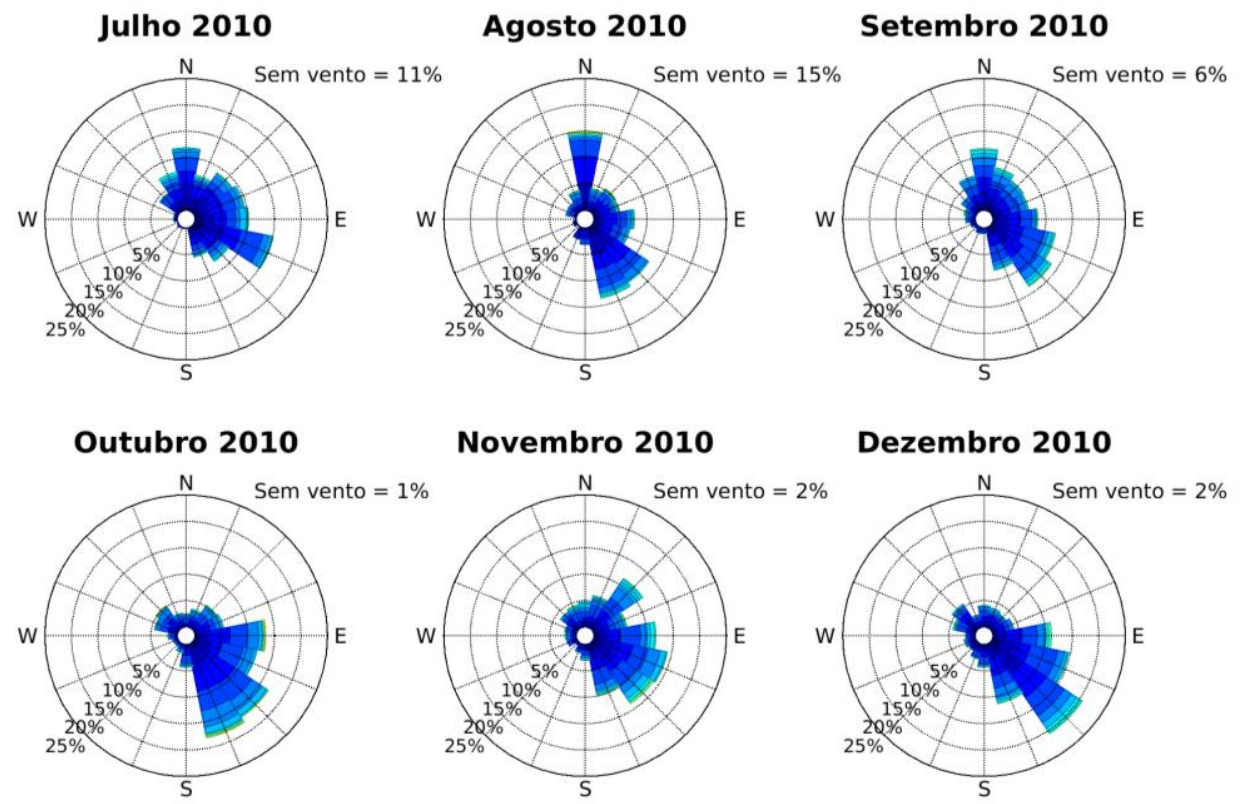

Dezembro 2010
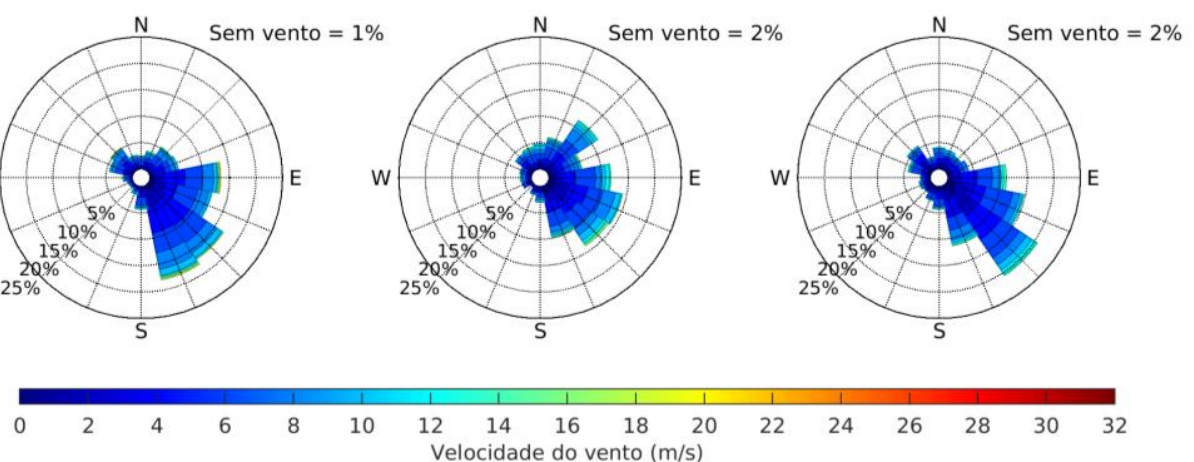

Figura 41- Histograma direcional com as velocidade dos ventos na cidade de São Paulo, SP, para o ano de 2010 .

Este histograma mostra que os ventos predominantes são provenientes do SulSudeste, Sudeste, Leste-Sudeste e Leste, e em menor frequência, ventos vindos de Norte.

Analisando a posição do reservatório e a distribuição de ventos é possível compreender porque ocorre maior acumulação de fitoplâncton nos braços do rio Embu- 
Mirim e Embu-Guaçu, já que a desembocadura de ambos no corpo principal, ocorre no sentido contrário aos ventos predominantes.

Explica também o motivo de ocorrerem grandes acumulações de macrófitas nessas regiões e também próximo à barragem, como no evento ocorrido em 07/04/2014, mostrado na Figura 42.

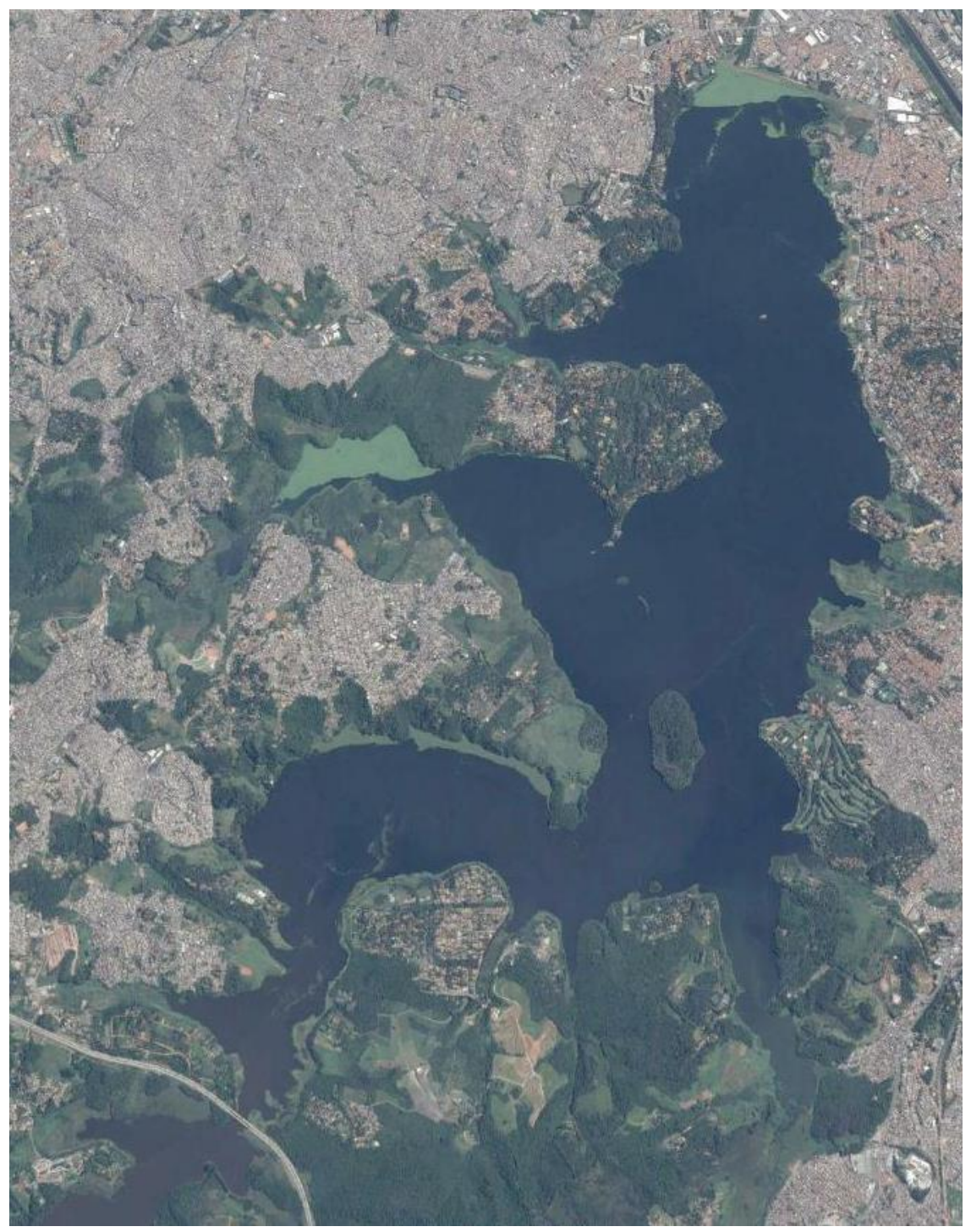

Figura 42 - Imagem de satélite WorldView obtida no dia 07/04/2014, para o reservatório de Guarapiranga, São Paulo, SP, mostrando a proliferação de macrófitas (àreas de coloração verde-claro). Fonte: (Google Earth).

Todos os pontos de acumulação estão localizados nas margens opostas à direção predominante dos ventos: na margem oeste da barragem, na foz do rio Embu Mirim e na região litorânea do braço do rio Embu Guaçu. 
$\mathrm{Na}$ foz do rio Embu Mirim existe uma pequena baía que fica abrigada e distante do corpo principal, tornando-a uma importante região para o acúmulo e crescimento de organismos fitoplanctônicos e também de macrófitas.

Na Figura 43 é possível observar o acúmulo de macrófitas no foz do rio Embu Mirim ao longo do ano de 2014, evidenciando que o formato da baía facilita a entrada e permanência dos organismos nessa região.

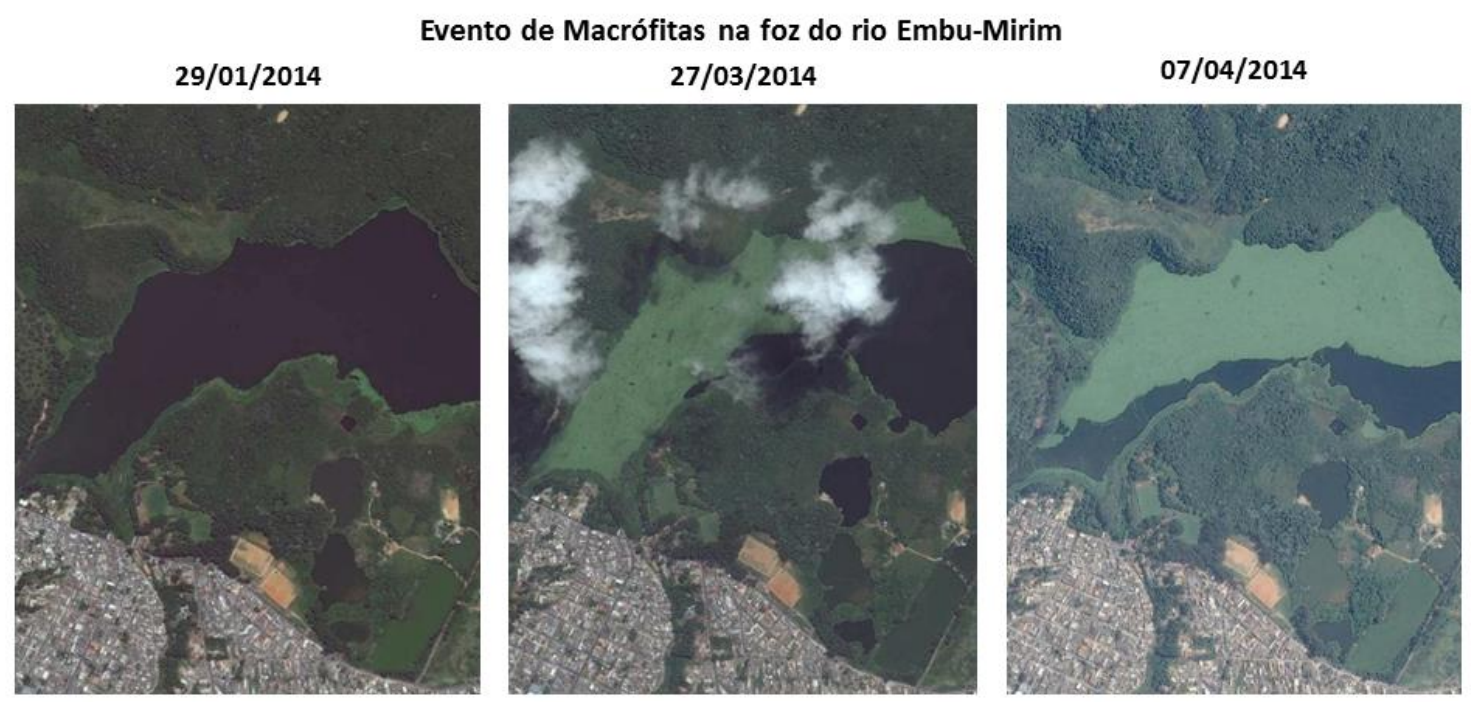

Figura 43- Evento de macrófitas na foz do rio Embu-Mirim, tributário do reservatório Guarapiranga, São Paulo, SP., durante o ano de 2014 (Fonte Google Earth).

Os valores de velocidade e direção do vento não apresentam componentes periódicas ou sazonais consistentes, mas apresentam um padrão de distribuição espacial dos ventos que evidencia as regiões com maior probabilidade de formação dos florescimentos algais, ou crescimento de macrófitas. Para esclarecer os motivos que levam a ocorrência desses padrões com certa frequência faz-se necessária a análise das demais variáveis envolvidas, como a alta concentração de nutrientes, a variada distribuição de turbidez e a distribuição dos pulsos hidrológicos espacial e temporalmente.

Uma das medidas tomadas para remediação desse evento de crescimento de macrófitas foi a remoção por meio de um equipamento mecânico, que coletava e transportava esses bancos de macrófitas, como mostrado por Matsumura-Tundisi et al. (2006), essa remoção pode ser um fator adicional de controle do ciclo do fósforo e do nitrogênio, já que o aumento de algas e macrófitas aquáticas gera mais matéria orgânica. 
E a medida que essa matéria orgânica se decompõe na água ou nos sedimentos, a concentração de oxigênio é reduzida. Em lagos rasos pode ocorrer a anoxia nas águas mais profundas e nos sedimentos. Os sedimentos anóxicos liberam fosfato e amônia para a coluna de água, enriquecendo ainda mais o lago. (MINOTI et al. 2001). 


\subsection{Análise da influência das componentes hidrodinâmicas no transporte da água dos rios principais dentro do reservatório.}

As simulações hidrodinâmicas tiveram diferentes configurações com o objetivo de destacar as características de dispersão de cada afluente e as influências de cada componente hidrodinâmica na dispersão das águas dos rios no reservatório.

\subsubsection{Simulação um - Simulação com todos os processos hidrodinâmicos incorporados.}

O resultado da simulação com todos os processos incorporados (vento e balanço de calor) é apresentado na Figura 44. Nela pode ser observado que o traçador liberado no rio Embu Guaçu leva mais tempo para atingir o corpo principal do reservatório. $\mathrm{O}$ retardamento é causado por uma combinação de fatores, pois este compartimento do reservatório além de ter um curso sinuoso, entra no reservatório em ângulo reto em relação à direção prevalecente do vento, que nesta simulação é na direção Norte e coincide com o eixo principal do reservatório. Isto significa que mesmo com uma vazão maior do que a dos outros tributários, o espalhamento do traçador é muito lento, especialmente quando o vento está vindo de Norte. No entanto, logo após passar a Ilha das Formigas, a dispersão ocorre rapidamente, à medida que o fluxo passa para o corpo central do reservatório.

O rio Embu Mirim, o qual está situado na parte oeste, próximo ao eixo principal, tem a segunda maior vazão entre os principais tributários e, portanto, o fluxo e a dispersão ocorrem rapidamente. Além de entrar diretamente no corpo central do reservatório, entre estes três principais tributários, este é o que está localizado mais próximo ao ponto de captação de água para o abastecimento urbano, sem qualquer impedimento morfológico à sua propagação em direção à represa (na direção $\mathrm{NNW}$ ). $\mathrm{O}$ rio Parelheiros é o de mais baixa vazão, mas ele segue a linha do eixo principal do reservatório (NS). Assim, sempre que o vento está soprando em direção à barragem, (NNW) a dispersão ocorrerá rapidamente, sendo limitada somente pela pequena vazão do rio. 


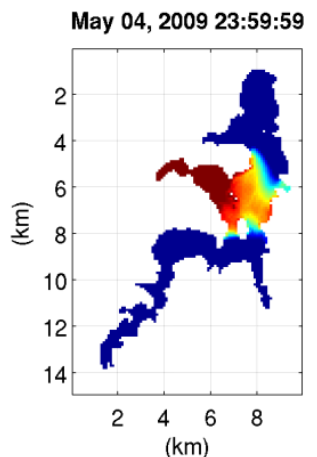

após 1 semana

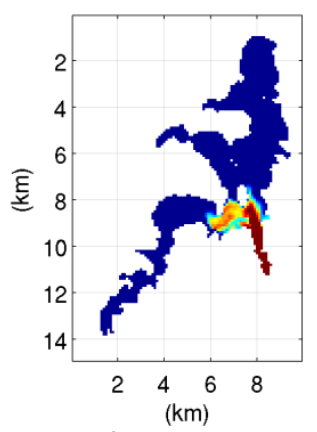

após 1 semana

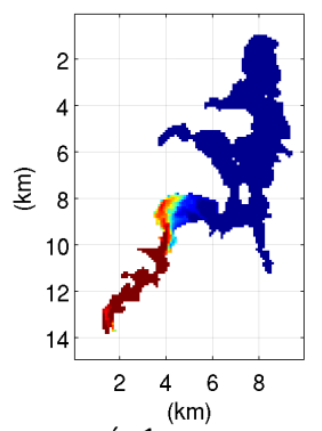

após 1 semana

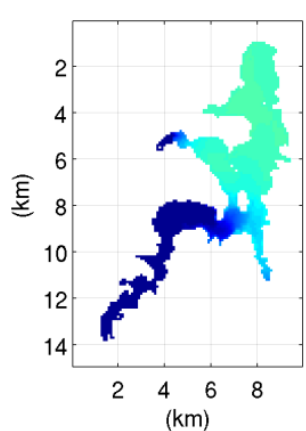

após 1 mês

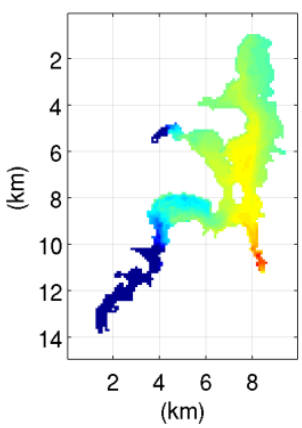

após 1 mês

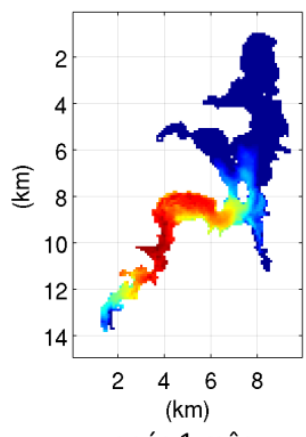

após 1 mês

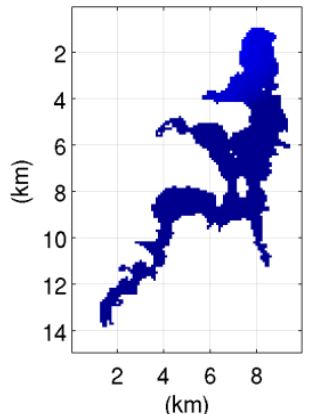

após 3 meses

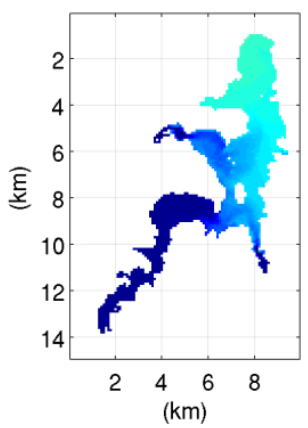

após 3 meses

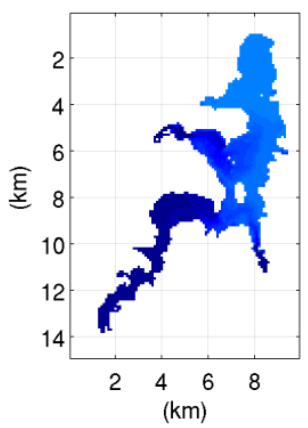

após 3 meses

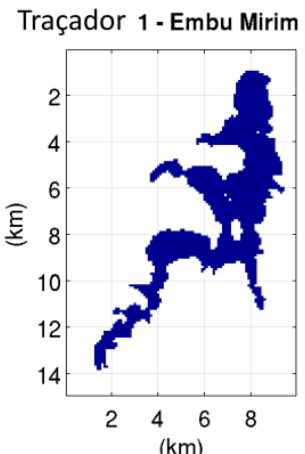

após 5 meses

Traçador 2 - Parelheiros

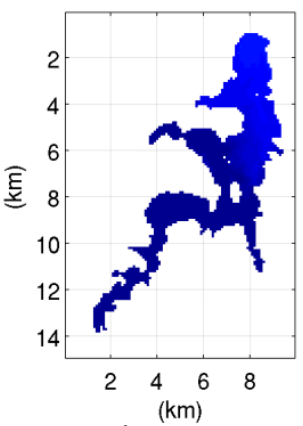

após 5 meses

Traçador 3 - Embu Guaçu

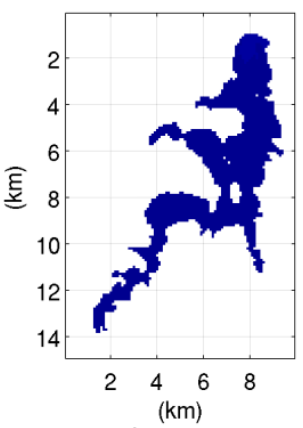

após 5 meses

Figura 44- Simulação do transporte de água dos três principais tributários (Embu-Mirim, Embu-Guaçu e Parelheiros) através do reservatório Guarapiranga, Sâo Paulo, SP, utilizando o modelo hidrodinâmico ELCOM, incluindo os três processos hidrodinâmicos selecionados: Vento, Morfometria, e Balanço de Calor.

\subsubsection{Simulação dois - Simulação sem Balanço de Calor e sem Introdução de momento pelo Vento}

Na segunda simulação, mostrada na Figura 45, o balanço de calor e o momento introduzido pelo vento são negligenciados. Então, a hidrodinâmica do reservatório é governada somente pela morfometria do reservatório e pela cinética e energia potencial do fluxo. O transporte da água do rio Embu Guaçu ocorre rapidamente, e a "nuvem" do traçador segue o caminho do antigo canal do rio Guarapiranga, sendo influenciado 
somente pelo maior fluxo. Nenhum retardamento ou movimento de retorno ocorre, mostrando que somente a morfologia ou a posição de entrada do rio no reservatório sozinhas não são suficientes para explicar o retardamento em sua propagação. Os traçadores lançados nos outros dois rios também se espalham rapidamente, desde que não exista influência da força exercida pelo vento na direção oposta ao fluxo. Além disso, os três traçadores estão distribuídos quase uniformemente na coluna d'água. Isto é consequência da ausência de estratificação, que leva ao aumento da inércia no corpo principal e nas regiões mais profundas, fazendo com que a dispersão ocorra mais lentamente.

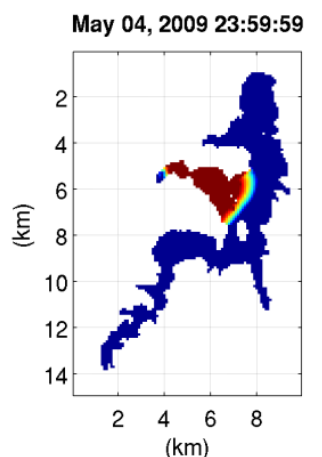

após 1 semana

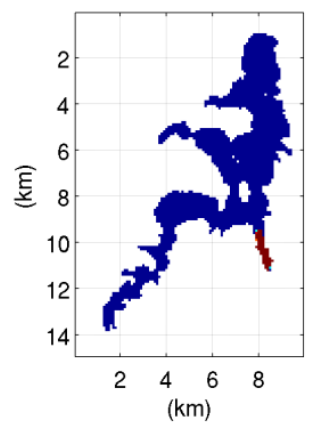

após 1 semana

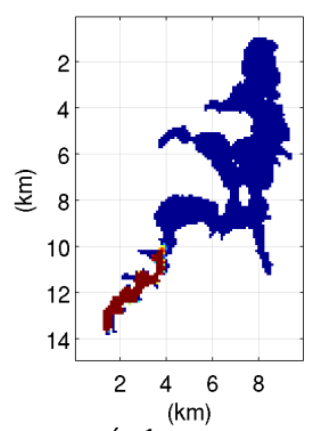

após 1 semana

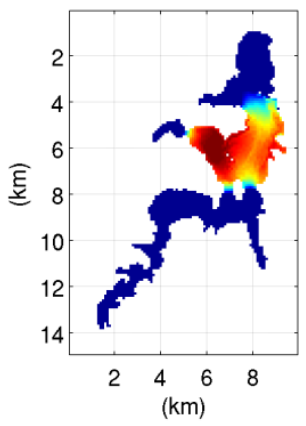

após 1 mês

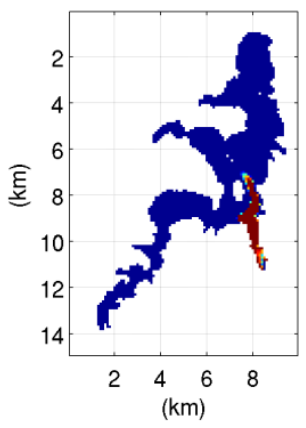

após 1 mês

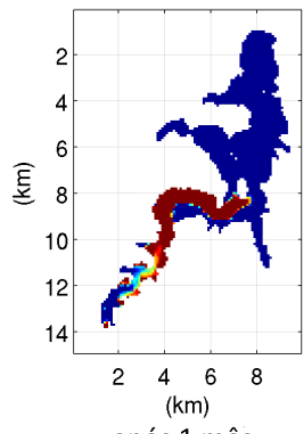

após 1 mês

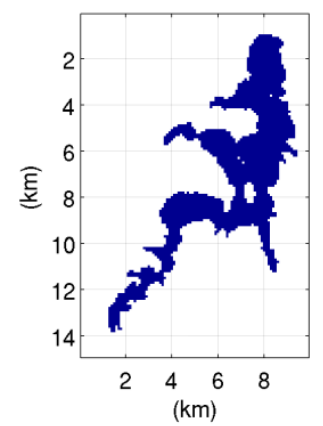

após 3 meses

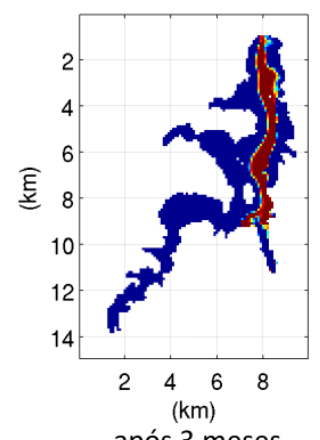

após 3 meses

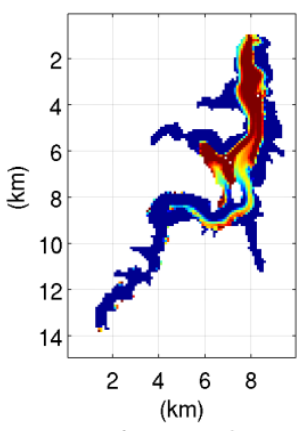

após 3 meses

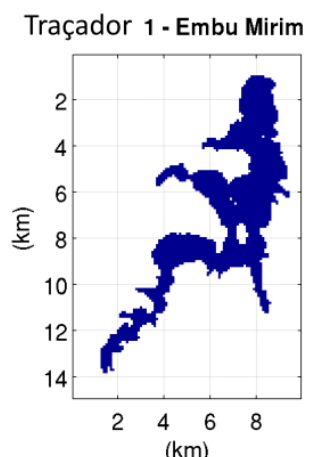

após 5 meses

Traçador 2 - Parelheiros

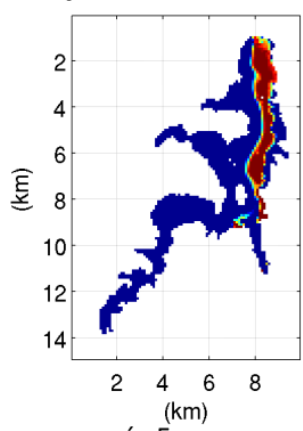

após 5 meses

Traçador - Embu Guaçu

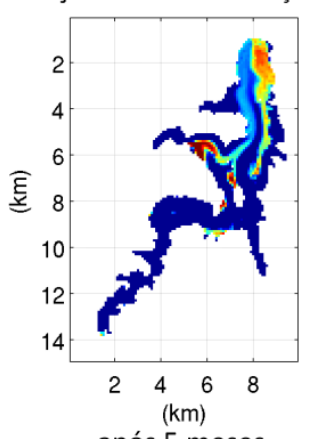

após 5 meses

Figura 45- Simulação do transporte de água dos três principais tributários (Embu-Mirim, Embu-Guaçu e Parelheiros) através do reservatório Guarapiranga utilizando o modelo de hidrodinâmica ELCOM, levando somente em consideração a morfometria do reservatório. 


\subsection{3 - Simulação três - Simulação com momento introduzido pelo vento, mas sem balanço de calor}

$\mathrm{Na}$ terceira simulação, mostrada na Figura 46, somente a componente do balanço de calor foi negligenciada no modelo. Esta simulação está sujeita ao momento devido ao vento, porém sem a ocorrência de estratificação e desestratificação térmica, por essa razão o comportamento do traçador foi similar ao apresentado na primeira simulação. No entanto, como a estrutura térmica vertical permaneceu uniforme, o espalhamento foi muito lento em alguns momentos, isso ocorria porque o momento era transferido da camada superficial para todo o restante da coluna de água.

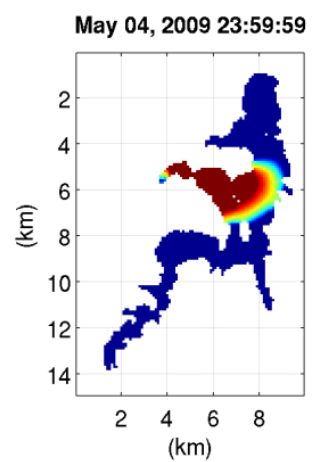

após 1 semana

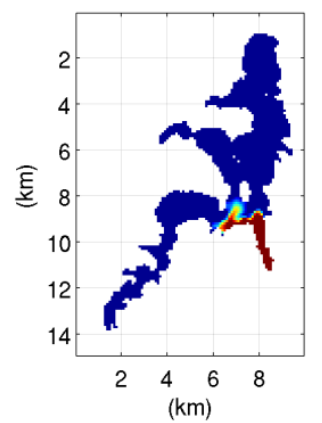

após 1 semana

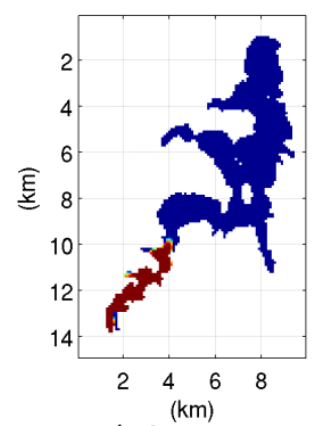

após 1 semana

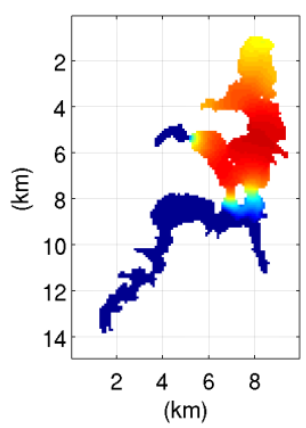

após 1 mês

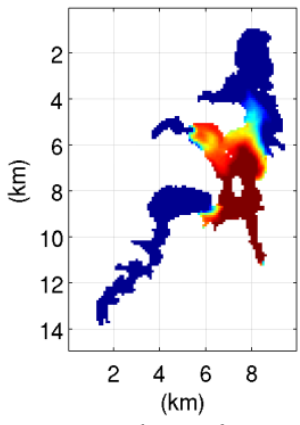

após 1 mês

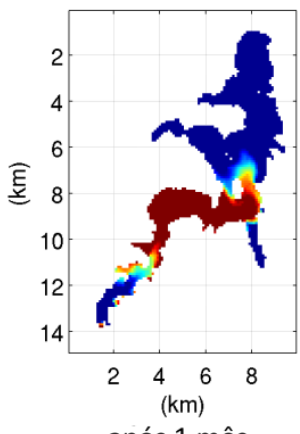

após 1 mês

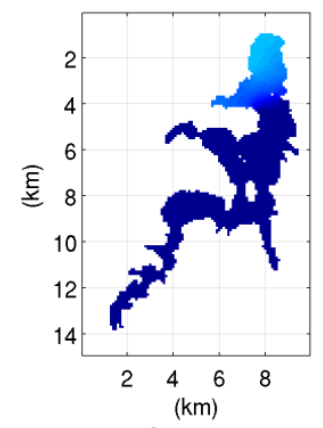

após 3 meses

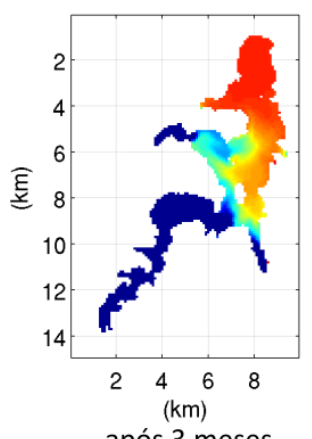

após 3 meses

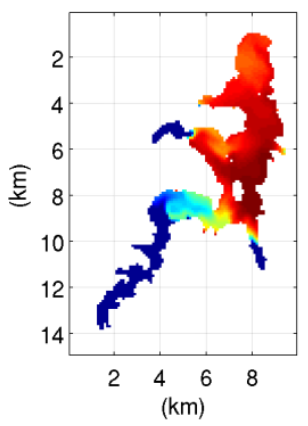

após 3 meses

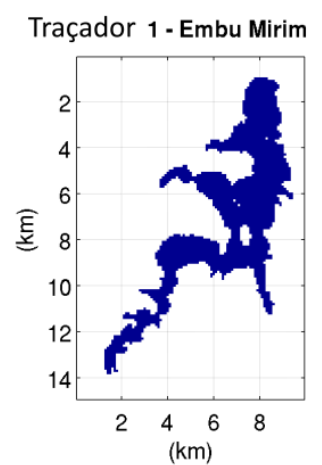

após 5 meses

Traçador 2 - Parelheiros

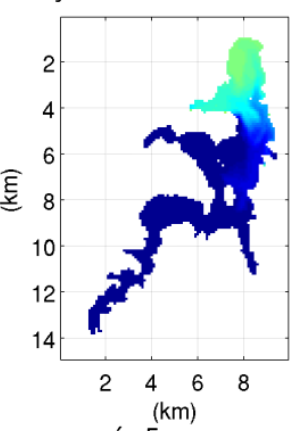

após 5 meses

Traçador 3 - Embu Guaçu

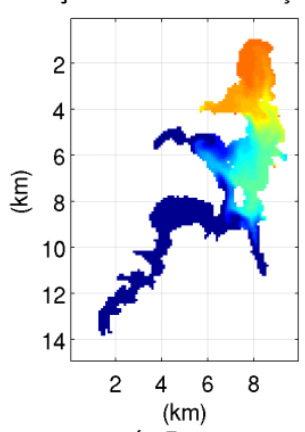

após 5 meses

Figura 46- Simulação do transporte de água dos três maiores tributários (Embu-Mirim, Embu Guaçu e Parelheiros) através do reservatório Guarapiranga, São Paulo, SP, utilizando o modelo hidrodinâmico ELCOM, introduzindo o momento induzido pelo vento mas sem o balanço de calor. 
Estas simulações demonstram a complexidade da análise dos tempos de transporte, e mostram que a dispersão dos traçadores dentro do reservatório é influenciada não só pelas variáveis hidrológicas e morfológicas, mas por uma combinação entre os caminhos percorridos, a direção predominante do vento e os eventos de estratificação. Observou-se também que, ao realizar uma análise do tempo de transporte em intervalos de tempo curtos, é necessário usar modelos que possam representar as mudanças que ocorrem nestes intervalos de tempo, uma vez que este é um reservatório tropical polimítico onde a estrutura térmica pode mudar rapidamente. As acelerações e atrasos observados na dispersão podem não ter uma grande influência no cálculo tempo de residência médio, mas são fundamentais para a análise do tempo de transporte numa escala de tempo curto.

\subsubsection{Simulação quatro - Simulação geral para análise de padrões espaciais}

Após analisar as variações da dispersão dos três principais tributários devido a cada uma das componentes hidrodinâmicas, buscou-se fazer uma comparação do tempo de residência médio de cada área do reservatório, com os tempos de transporte da água a partir de cada rio dentro do reservatório, já que o tempo de residência médio do reservatório pode mostrar claramente as áreas que têm o maior potencial para a troca ou renovação, enquanto o tempo de residência dos rios no reservatório pode demonstrar a influência de cada um dos três principais afluentes no reservatório. Para esta finalidade, foi realizada uma simulação durante o mesmo período. Notou-se alguma variação no comportamento do reservatório durante os eventos de chuva ou vento forte, mas em geral, houve uma consistência em relação à formação de compartimentos com renovação mais rápida ou mais lenta.

Na Figura 47 é mostrada a distribuição espacial do tempo de residência no reservatório para estas condições. Ao longo da simulação, houve um padrão predominante, com uma divisão clara do reservatório em três compartimentos separados, mostrando dois compartimentos com grande renovação nos braços correspondentes aos rios Embu-Guaçu e Embu-Mirim, e um compartimento com uma menor renovação no corpo central. 
Além disso, há uma área com tempo de residência maior no norte-nordeste do reservatório, que é uma região mais rasa e que se localiza no lado oposto ao canal principal do reservatório.

Durante as tempestades, quando ocorrem grandes vazões associadas com ventos fortes, existe uma distinção ainda mais clara entre os três compartimentos acima mencionados. No entanto, logo após estes eventos, o padrão retorna para ao primeiro observado, indicando a tendência para formar um padrão espacial com três compartimentos principais, alterando-se apenas na área que cada um abrange.

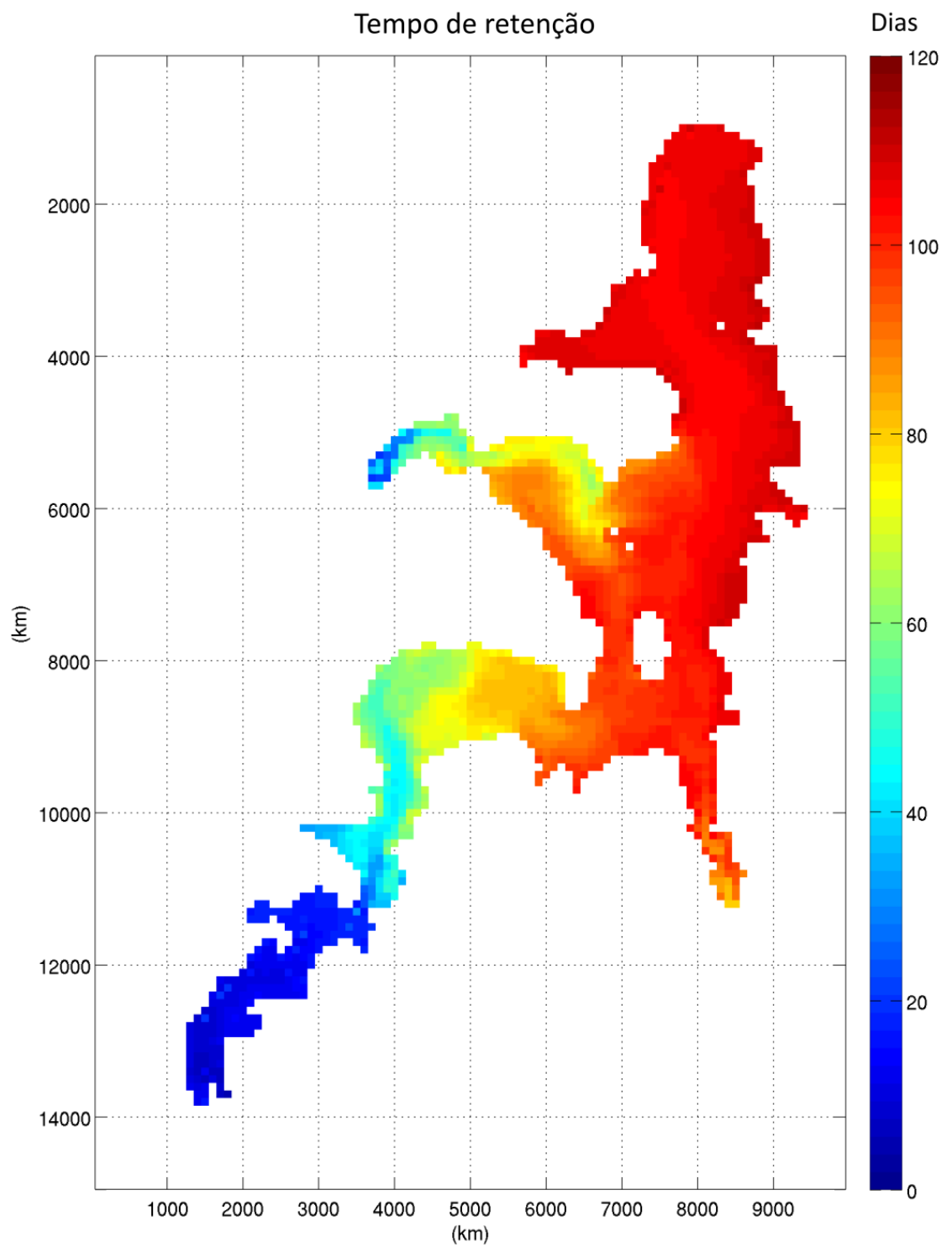

Figura 47- Mapa das variações do tempo de residência no reservatório Guarapiranga, São Paulo, SP, obtidas na quarta simulação. 
A análise dos tempos de residência no reservatório baseou-se na quantidade total de traçador presente no reservatório, assim como na variação da massa total de cada um dos traçadores, como mostrado na Figura 48. Nessa figura, pode ser visto um pico imediatamente depois que toda a massa de traçador é lançada, o que ocorre aproximadamente um dia após o lançamento; a manutenção desse pico mostra a retenção do traçador no reservatório.

A massa total de traçador começa a diminuir quando as primeiras partículas começam a deixar o reservatório. O tempo de residência é tido como o tempo médio entre o tempo necessário para as primeiras e as últimas partículas deixarem o reservatório, mas como o tempo para que todas as partículas deixem o reservatório é muito grande, serão utilizadas frações da massa inicial para analisar os tempos de propagação.
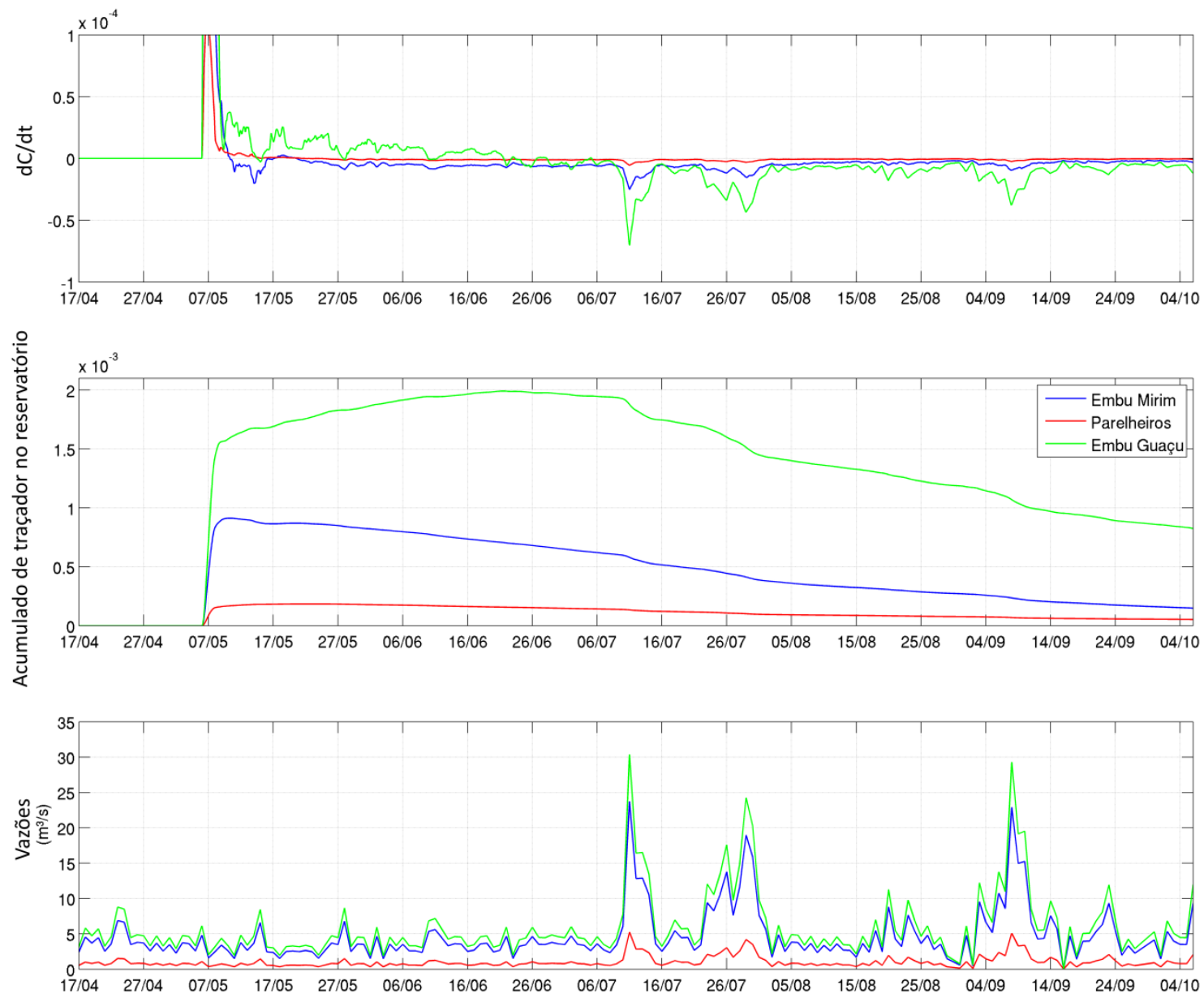

Figura 48 - Variações na massa total de traçador ao longo do tempo para os três maiores rios que alimentam o reservatório Guarapiranga, São Paulo, SP, computados por simulação numérica. O primeiro gráfico mostra a variação da concentração total ao longo do tempo, o segundo mostra o total acumulado e o terceiro mostra as vazões simuladas. 
O segundo gráfico mostra que o traçador do rio Parelheiros, em vermelho, atinge a quantidade máxima antes de começar a sair pela captação apenas quatro dias após o seu lançamento, enquanto o traçador do rio Embu-Mirim leva 16 dias e o do Embu Guaçu, 55 dias. Além disso, aos 52 dias, metade da massa inicial do traçador lançado para dentro do reservatório pelo rio Parelheiros já saiu, enquanto o traçador lançado no Embu Mirim levou 96 dias e o do Embu Guaçu levou 135 dias. Portanto é possível constatar que os potenciais de dispersão dos três rios são bastante diferentes, assim como os seus tempos de transporte.

No entanto, é preciso lembrar que estes valores só são válidos para esse período simulado uma vez que, como mostrado anteriormente, as condições meteorológicas têm uma forte influência sobre a dinâmica do reservatório. Os picos negativos no gráfico de variação da concentração no tempo $(\mathrm{dC} / \mathrm{dt})$ representam os períodos de chuvas e ventos fortes, onde os altos fluxos empurraram a pluma na direção da saída, causando quedas acentuadas no valor total de traçador no reservatório, mostrando assim a variação nos padrões de circulação em uma escala de tempo curta.

As simulações mostraram que, em adição à compartimentalização do reservatório, com as áreas onde o fluxo de cada rio tem uma influência mais forte, há também uma grande variação no tempo de dispersão das massas de água proveniente de cada rio. Por exemplo, se um composto ou carga perigosa fosse despejado intencionalmente ou acidentalmente no rio Embu Guaçu durante o período simulado, a sua dispersão na represa de Guarapiranga seria muito mais lenta do que se isso tivesse ocorrido no rio Embu Mirim ou no Parelheiros, permitindo mais tempo para remediação antes da chegada ao ponto de captação de água para abastecimento, mas por outro lado, se isso não fosse possível, o resultado pode ser uma distribuição maior de produto em todo o reservatório.

O tempo de retenção é uma variável-chave no funcionamento de um reservatório (STRASKRABA, 1999), no entanto, não é correto determinar o efeito apenas com base no tempo de residência médio, porque cada material tem um comportamento diferente na água, e podem ter diferentes respostas ao meio ambiente, em alguns casos, decantação, evaporação ou floculação. Nessas simulações, os traçadores são inertes. Eles não têm massa nem reagem com o meio ambiente e, portanto, apenas indicam as 
áreas com maior potencial de contaminação.

A variação do tempo em que os organismos ficam retidos pode provocar uma reorganização na cadeia alimentar de todo o reservatório. Para simular isso, as interações tróficas precisam ser melhor conhecidas, analisando-se o funcionamento nas zonas litorâneas e pelágicas em períodos com diferentes tempos de residência (STRASKRABA \& TUNDISI, 1999).

Tendo em conta que as águas dos rios afluentes ao reservatório têm diferentes composições, diferentes áreas de influência e diferentes tempos de residência, os dados adquiridos a respeito da dinâmica são informações que podem auxiliar na gestão dos reservatórios e também em questões relacionadas ao planejamento urbano, já que algumas áreas que têm uma baixa densidade populacional hoje, como a sub-bacia do rio Embu Guaçu, podem tornar-se críticas se atingirem níveis de ocupação semelhante à região na foz da bacia do rio Embu Mirim, sem saneamento ou infraestrutura adequada, pois o tempo de permanência das águas provenientes desse rio no reservatório é o maior entre os três afluentes principais, e além disso, desempenha um papel importante na dinâmica global do reservatório, uma vez que a sua contribuição de água para o reservatório é de cerca de $40 \%$. Dessa forma, a capacidade de exportação e retenção de nutrientes depende do tempo de residência, sendo uma característica fundamental para avaliar o estado trófico dos reservatórios (MATSUMURA-TUNDISI et al., 2006).

Assim, além de auxiliar em medidas para mitigar e controlar a qualidade da água do reservatório (HAMILTON, 1999; SAGGIO, 2001; RIO, 2003), estes modelos tridimensionais têm ampla aplicação no planejamento e administração também da região adjacente ao reservatório, visto que o manejo de qualquer corpo de água, incluindo os reservatórios requer o manejo integrado de toda a bacia de captação (BOULTON \& BROCK, 2001; TUNDISI, 2003; TUNDISI et al., 2003).

A eutrofização é um dos principais processos decorrentes da poluição das águas superficiais que são no Brasil a principal fonte de água para abastecimento humano, e que tem como consequência o crescimento exagerado de cianobactérias tóxicas, algas e macrófitas, que comprometem a qualidade da água e encarecem o tratamento da água de abastecimento. Pesquisadores e gerenciadores da água precisam cada vez mais unir 
esforços e trabalhar em diferentes escalas (compartimentos, reservatório e bacia hidrográfica) e ampliar o uso de ferramentas avançadas como o sensoriamento remoto e a modelagem numérica para enfrentar esta árdua tarefa de integrar a ciência e a preservação da água, este recurso cada vez mais escasso no século XXI. 


\section{5 - Conclusões}

O reservatório Guarapiranga apresenta um elevado grau de heterogeneidade ambiental. Existem compartimentos bem distintos, determinados pelas características físicas e químicas e geralmente associados ao tipo de ocupação das bacias hidrográficas dos rios afluentes.

Os ventos são bastante consistentes em relação às direções predominantes. Isso se deve principalmente ao posicionamento geográfico do reservatório. Além disso, o vento mostrou ser um dos fatores essenciais nas mudanças da qualidade da água, deslocando massas de água, provocando acumulação na superfície e também o afloramento de águas profundas.

Os estudos dos eventos de curto prazo mostraram que as variações meteorológicas que ocorrem ao longo de um dia, influenciam substancialmente a dinâmica de reservatórios rasos como o reservatório Guarapiranga, podendo alterar a estrutura térmica e redistribuir os organismos planctônicos.

Os dados de monitoramentos de longo prazo da SABESP e da CETESB evidenciam a existência de padrões sazonais, geralmente alterados em função de ações antropogênicas como lançamento de algicidas, mudanças na operação da barragem e da transposição e remoção dos bancos de macrófitas ou devido à anomalias climáticas.

As variáveis físicas e químicas estão em geral relacionadas com a distribuição da pluviometria, com as maiores concentrações ocorrendo nos períodos secos, com exceção dos períodos em que ocorrem florescimentos ou grande mortalidade de algas e que as concentrações de fósforo total e de nitrogênio amoniacal destoam desse padrão.

As Cyanophytas e Chlorophytas costumam ser os grupos mais abundantes na maior parte do reservatório, evidenciando a adaptabilidade. Os demais grupos geralmente concentram-se em locais mais propícios de acordo com suas características.

As imagens de satélite ainda que tenham sido insuficientes para determinar com exatidão as concentrações de fitoplâncton neste estudo, evidenciaram a recorrência dos 
padrões espaciais observados nas coletas e experimentos realizados. Estudos específicos podem ser realizados para criar-se uma ferramenta capaz de detectar as concentrações de diferentes grupos fitoplanctônicos remotamente.

Os experimentos de curta e de larga escala de tempo são bastante congruentes com relação à localização, recorrência e abrangência dos compartimentos encontrados.

As análises mostraram ainda que existem regiões e períodos mais favoráveis para o surgimento de florescimentos de cianobactérias ou acúmulo e crescimento de algas e macrófitas. De acordo com os dados analisados identificou-se a foz dos rios Embu- Mirim, Guavirutuba e Parelheiros como as principais regiões para desenvolvimento dos florescimentos algais (incubadoras), tanto em função da posição geográfica e dos padrões de ventos, quanto das características da água.

Após a acumulação ou crescimento nessas regiões pode ocorrer um espalhamento por todo o reservatório em função de variações meteorológicas e hidrodinâmicas.

A dinâmica observada durante o experimento de curta escala de tempo, em que surge um vento de norte antecedendo a entrada de uma frente fria mostrou que esse micro evento meteorológico pode provocar um ciclo de estratificação e desestratificação no reservatório, assim como a variação diurna.

As macrófitas por serem mais facilmente identificáveis e distinguíveis nas imagens de satélite se mostraram excelentes biomarcadores flutuantes ou "drogues" que auxiliam na indicação dos padrões de circulação superficial no reservatório.

Os valores brutos dos métodos integrados de cálculo do tempo de residência muitas vezes são próximos àqueles gerados pelas simulações, no entanto, mais do que determinar o tempo em que a água permanece no reservatório, é necessário discretizar os processos de transporte e compreender os caminhos que as água percorrem dentro do reservatório, pois a sua morfologia, os ventos predominantes e os eventos de 
estratificação podem acelerar ou retardar o fluxo no reservatório em curta escala de tempo.

Além disso, as diferentes magnitudes, origens, percursos e composições das águas afluentes de cada tributário evidenciam a necessidade de uma análise individual dos tempos de residência de cada tributário.

A análise sinótica do corpo de água permite identificar padrões espaço temporais e também as áreas mais propícias a ocorrência de trocas ou de mistura, sendo uma importante ferramenta para o controle e gestão dos recursos hídricos

As características e eventos aqui observados não são exclusivos do reservatório Guarapiranga, e portanto, esse tipo de abordagem pode ser utilizada no processo de planejamento de medidas de controle de reservatórios urbanos tropicais polimíticos em geral. 


\section{Referências Bibliográficas}

ABE, D.S., TUNDISI, J. G., MATSUMURA-TUNDISI,T., SIDAGIS GAÇÇI, C. Avaliação da capacidade deremoção de nitrogênio em uma várzea da cabeceira do Reservatório Guarapiranga, Região Metropolitana de São Paulo, pp. 241-253. In: J. G. Tundisi, Matsumura-Tundisi, T. \& Sidagis-Galli, C. (Eds.) Eutrofização, na América do Sul, Causas, consequências e tecnologias de gerenciamento e controle. Instituto Internacional de Ecologia, Inc. São Carlos, SP, Brazil, 531 pp. 2006.

ANAGNOSTIDIS, K.; KOMÁREK, J.. Modern approach to the classification system of cyanophytes. 3 - Oscillatorialles. Archiv für Hydrobiologie, v. 50-53, p. 327-472, 1988.

AMBROSETTI, W, BARBANTI \& L, SALA, N.,Residence time and physical processes in lakes. J. Limnol. 62, 1-15, 2003.

ANTENUCCI, J, IMBERGER, J \& SAGGIO, A., Seasonal Evolution of the basin-scale internal wave field in a large stratified lake. Limnology and Oceanography. 45; 1621$1638,2000$.

ARENZ, R. F., LEWIS, W. M. \& SAUNDERS, J. F., Determination of chlorophyll and dissolved organic carbon from reflectance data for Colorado Reservoir. International Journal of Remote Sensing , 17, 1547-1566, 1996

BECKER, V., HUSZAR, V.L.M., CROSSETTI, L. O., Responses of phytoplankton functional groups to the mixing regime in a deep subtropical reservoir. Hydrobiologia (The Hague), v. 628, p. 137-151, 2009.

BEYRUTH, Z. Comunidade fitoplanctônica da represa de Guarapiranga: 1991-1992. Aspectos ecológicos, sanitários e subsídios para reabilitação da qualidade ambiental. 1996. 191 f. Tese (Doutorado em Saúde Ambiental) - Faculdade de Saúde Pública, Universidade de São Paulo, São Paulo, 1996. 
BEYRUTH, Z., 2000. Periodic disturbances, trophic gradient and phytoplankton characteristics related to cyanobacterial growth in Guarapiranga Reservoir, São Paulo State, Brazil. Hydrobiologia, vol. 424, no. 1-3, p. 51-65.

BICUDO, C.E.M. Gêneros de algas de águas continentais do Brasil: chave para identificação e descrições. São Carlos: RiMa, 2005, 502 p.

BICUDO, D. C., FOnSECA, B. M., BICUDO, C. E. M., BINI, L. M., ARAUJOJESUS, T.. Remoção de Eichhornia crassipes em um reservatório tropical raso e suas implicações na classificação trófica do sistema: estudo de longa duração no Lago das Garças, São Paulo, Brasil. In: Tundisi, J.G.; Matsumura-Tundisi, T., Sidagis-Galli, C.V. (Org.). Eutrofização na América do Sul: causas, conseqüências e tecnologias de gerenciamento e controle. 1ed.São Carlos: Instituto Internacional de Ecologia, 2006, v. , p. 413-438.

BOLD, H.C., WYNNE, M.J. Introduction to the algae. New Jersey: Prentice Hall Inc, 1985.

BOURRELLY, P. Les algues d'eau douce: iniciation à la systématique. Tome II: les algues jaunes et brunes. Paris: Ed. N. Boubée, 1968, 517 p.

BOULTON, A.J. \& BROCK, M.A., Australian Freshwater Ecology: Processes and Management. $1^{\text {st }}$. Ed., Gleneables Publishing, Adelaide, 300 pp., 1999

BUNTGEN, U., TEGEL, W., NICOLUSSI, K., MCCORMICK, M., FRANK, D., Trouet, V., KAPLAN, J.O., HERZIG, F., HEUSSNER, K.-U., WANNER, H., LUTERBACHER, J. and ESPER, J., 2500 years of European climate variability and human susceptibility. Science 331: 578-582, 2011.

CALIJURI, M. C., DOS SANTOS, A. C. A. \& JATI, S., Temporal changes in the phytoplankton community structure in a tropical and eutrophic reservoir (Barra Bonita, S.P. - Brazil). J. Plankton Res., vol. 24, no. 7, p. 617-634, 2002. 
CASTELlANO, L, AMBROSETTI, W, BARBANTI, L, ROLLA, A., The residence time of the water in Lago Maggiore (N. Italy): first results from an Eulerian-Lagrangian approach. Journal of Limnology, 69(1), 15-28, 2010.

CHALAR, G., Dinamica de la eutrofización a diferentes escalas temporales: Embalse Salto Grande (Argentina-Uruguai). In. Eutrofização na América do Sul: Causas consequências e tecnologias de gerenciamento e controle, IIE, 87-101, 2006.

COLINA, M.; GARDINER, P.H.E. Simultaneous determination of total nitrogen, phosphorus and sulphur by means of microwave digestion and ion chromatography. Journal of Chromatography, A, v.187, n. 1/2, p. 285-290, 1999.

DELACOURT, C., ALLEMAND, P., JAUD, M., GRANDJEAN, P., DESCHAMPS, A., AMMANN, J., CUQ, V., \& SUANEZ., DRELIO: An Unmanned helicopter for imaging coastal areas, ,SI 56 (Proceedings of the 10th International Coastal Symposium), 14891493. Lisbon, Portugal, ISSN 0749-0258, 2009.

DINCA-PANAITESCU, M, LI, J, DINCA-PANAITESCU, S., Simulation of the cumulative effects of chemical spills using a spatial-temporal dynamics analysis algorithm. Journal of hazardous materials, 149(3), 707-719, 2007.

DOMAGALSKI, J., LIN, C., LUO, Y., KANG, J., WANG, S., BROWN, L. \& MUNN, M., Eutrophication study at the Panjiakou-Daheiting Reservoir system, northern Hebei Province, People's Republic of China: Chlorophyll-a model and sources of phosphorus and nitrogen. Agricultural Water Management. Elsevier, Volume 94, pp. 43-53, 2007.

EIGER, S. A Simplified 2D-Vertical Plane Numerical Solution for Reservoir Flows. pp. 175-209. In: Tundisi, J. G. \& Straskraba, M. (Eds.). Theoretical Reservoir Ecology and its Applications. Brazilian Academy of Sciences, International Institute of Ecology and and Backhuys Publishers, Leiden, 585 pp, 1999.

FISCHER, H. B., LIST, E. J., KOH, R. C. Y., IMBERGER, J. \& BROOKS, N. A., Mixing in in- land and coastal waters. Academic Press, Inc., New York, 1979. 
FISHER, M.M., MILLER, S.J., CHAPMAN, A.D. \& KEENAN, L.W., Phytoplankton dynamics in a chain of subtropical blackwater lakes: the Upper St. Johns River, Florida, USA. Lake Reserv. Manage. 25:73-86, 2009.

GIN, K.Y.H., KOH, S.T. \& LIN, I.I., Study of the effects of suspended marine clay on the reflectance spectra of phytoplankton, International Journal of Remote Sensing, 23, pp. 2163-2178, 2001.

GITElSON, A. A., GARBUZOV, G., SZILAGYI, F. \& KAISER, A. Quantitative remote sensing methods for real time monitoring of in-land waters quality. International Journal of Remote Sensing, 14, 1269-1295, 1993.

GITELSON, A., Algorithms for remote sensing of phytoplankton pigments in inland waters. Advanced Space Research, 13 (5), 197-201, 1993.

GOLTERMAN, H.L. CLYMO, R.S. \& OHNSTAD, M.A.M., Methods for physical and chemical analisys of freshwater. Oxford: BlackwellScientific Publications, 213p, 1978.

HAI, X., PAERL, H. W., QIN B.,ZHU G. \& GAO, G., Nitrogen and phosphorus inputs control phytoplankton growth in eutrophic Lake Taihu, China. Limnology and Oceanography, 55:420-432, 2010.

HAMILTON, D. P. Numerical Modelling and Reservoir Applications of the DYRESM Model. pp. 153-173. In: Tundisi, J. G. \& Straskraba, M. (Eds.). Theoretical Reservoir Ecology and its Applications. Brazilian Academy of Sciences, International Institute of Ecology and and Backhuys Publishers, Leiden, 585 pp, 1999.

HAN, L. \& RUNDQUIST, D. C., Comparison of NIR/RED ratio and first derivative of reflectance in estimating algal-chlorophyll concentration: A case study in a turbid reservoir. Remote Sensing of Environment 62, 253-261, 1997.

HARDIN, P.J. \& JACKSON, M.W., An Unmanned Aerial Vehicle for Rangeland Photography. Rangeland Ecology \& Managemen, 2005. 
HELOU, L. C., SILVA, L. G., Estudo de operação de reservatório de Guarapiranga. Ver. DAE, v. 48, n. 151, p29-47, 1987.

HIPSEY M.R., ROMERO J., ANTENUCCI J. \& HAMILTON D., Computational Aquatic Ecosystem Dynamics Model (CAEDYM), v3.2 Science Manual. Centre for Water Research, University of Western Australia, 2009.

HODGES, B., IMBERGER, J., SAGGIO, A. \& WINTERS K., Modeling basin-scale internal waves in a stratified lake. Limnology and Oceanography, 45(7): 1603-1620, 2000 .

HODGES B.R. \& DALliMORE C., Estuary and Lake Computer Model Science Manual Code, Version 2.2, Centre for Water Research, University of Western Australia, 2009.

HU, C., LEE, Z., MA, R., YU, K., LI, D., \& SHANG, S., Moderate Resolution Imaging Spectroradiometer (MODIS) observations of cyanobacteria blooms in Taihu Lake, China, J. Geophys. Res., 115, C04002, 2010.

HUTCHINSON G. E., A Treatise on Limnology, 1: geography, physics and chemistry. John Wiley and Sons, Inc., New York, 1015p, 1957.

IMBERGER, J., PATTERSON, J., A dynamic reservoir simulation model: DYRESM 5, pp. 310-361. In: Fisher, H.B. (Ed.), Transport Models of Inland and Coastal Waters. Academic Press, 1981.

IMBERGER \& PATTERSON, Physical limnology. Adv. Appl. Mech. 27 , pp. 303-475, 1990.

IMBERGER, J., Transport processes in lakes: A review, p. 99-193. In R. Margalef [ed.], Limnology now: A paradigm of planetary problems, Elsevier, 1994.

IMBERGER, J., A lake diagnostic system for managing lakes and reservoirs, Water Resources Impact, 6(1): 7-10, 2004. 
IMBODEN, D.M., Mixing and transport in Lakes: Mechanisms and ecological relevance, Large Lakes: Ecological structure and Function (Eds: M.M. Tilzer and C. Serruya), 1990.

IPCC, Intergovernamental Panel on Climate Change, Climate Change, 2007: Synthesis report. An assessment of the Intergovernamental Panel on ClimateChange. IPCC Plenary XXVII, Valencia, Espanha, Disponível em https://www.ipcc.ch/pdf/assessmentreport/ar4/syr/ar4_syr_spm.pdf, 2007.

JORGE, L. A. C., TRINDADE JUNIOR, O, AGUIAR, J \& CEREDA JUNIOR, A. Monitoramento agrícola a partir de imagens aéreas e Web Mapping. São Carlos: Embrapa Instrumentação Agropecuária, (Boletim de Pesquisa \& Desenvolvimento), 2004.

JORGE, L. A. C.. Determinação da cobertura de solo em fotografias aéreas do Projeto ARARA. São Carlos: USP-ICMC (Dissertação de Tese Mestrado), 2001.

JORGENSON, S. V., Standard Case 1 algorithms in Danish coastal waters. International Journal of Remote Sensing, 20 (7), 1289-1301, 1999.

JØRGENSEN, S., The application of models to find the relevance of residence time in lake and reservoir management. J. Limnol. 62, 16-20, 2003.

KLAVENESS, D. Ecology of Cryptomonadida: A First Review. Chapter 3 pp. 105 133. In: Craig D. Sandgren (Ed.) Growth and Reproductive Strategies of Freswater Phytoplankton. Cambridge University Press, Cambridge, 442p. 1988

KOMÁREK, J.; FOTT, B. Chlorophyceae - Chlorococcales. In: HUBERPESTALOZZI, G. Das phytplankton des Süwassers: systamatik und biologie. Stuttgart: E. Schweizerbart'sche Verlagsbuchlandlung. Pt. 7, Die Binnerngewässer, August Thienemann, 16. ed., 1983, 1044 p.

KOMÁREK, J.; ANAGNOSTIDIS, K. Modern approach to the classification system of cyanophytes. 4 - Nostocales. Archiv für Hydrobiologie, v. 56, p. 247- 345, 1989. 
KOMÁREK, J.; ANAGNOSTIDIS, K. Chroococcales. In: ETTL, A.; GERLOFF, J.;

HEYNIG, H.; MOLlENHAUER, D. SüBwasserflora von Mitteleuropa. Bd. 19. Stutgart: G. Fischer Verlag, 1999, 548 p.

KOROLEFF, F., Determination of ammonia. IN: Grasshoff, K. (ed). Methods of seawater analysis, Verlag Chemie, Weinheim, 126-133 pp., 1976.

KIRK, J. T. O., Light and photosynthesis in aquatic ecosystems, $2^{\text {nd }}$ edn. Cambridge University Press, pp. 55-57, 1994.

KUNDU, P., COHEN, I. M., Fluid Mechanics, 3º Ed., Elsevier, 920 pp., 2004.

LABORDE, S., ANTENUCCI, J., COPETTI, D. \& IMBERGER, J., Inflow intrusions at multiple scales in a large temperate lake, Limnology and Oceanography, 55(3): 1301$1312,2010$.

LALIBERTE, A.S., HERRICK, J. E., \& RANGO, A., Acquisition, orthorectification, and object-based classification of unmanned aerial vehicle (UAV) imagery for rangeland monitoring. Photogrammetric Engineering and Remote Sensing 76(6):661$672,2010$.

LEE, Z.P \& CARDER, K. L. Absorption spectrum of phytoplankton pigments derived from hyperspectral remote-sensing reflectance. Remote Sensing of Environment, 89: 361-368. 2004

LI, L., LI, L. \& SONG, K.. Remote sensing of freshwater cyanobacteria: An extended IOP Inversion Model of Inland Waters (IIMIW) for partitioning absorption coefficient and estimating phycocyanin. Remote Sensing of Inland Waters, 157, 2015.

LONDE L. R.; NOVO, E. M. L. M. \& CALIJURI, M.C., Avanços no estudo do comportamento espectral do fitoplâncton e identificação remota de algas. In: Simpósio Brasileiro de Sensoriamento Remoto (SBSR), 12., 2005, Goiânia. Anais ... São José dos Campos: INPE, 2005. Artigos, p. 389-396. On-line. ISBN 85-17-00018-8. Disponível em: <http://urlib.net/ltid.inpe.br/sbsr/2004/11.21.17.27>. Acesso em: 01 set. 2008. 
LONERAGAN, N. R. \& BUNN, S. E., River flows and estuarine ecosystems: Implications for coastal fisheries from a review and a case study of the Logan River, southeast Queensland, Australian Journal of Ecology 24, 431-440, 1999.

MARGALEF, R., Limnología. Ediciones Omega, S. a., Barcelona. 1010p.

MATSUMURA-TUNDISI, T., TUNDISI, J., ROCHA, O. \& CALIJURI, M., The ecological significance of the metalímnion in lakes of Middle Rio Doce Valley. In: Limnological studies on the Rio Doce Valley lakes, Brazil. p. 373 - 390, 1997.

MATSUMURA-TUNDISI, T., LUZIA, A. P., \& TUNDISI, J. G. Trophic State of the cascade of reservoirs in the middle and lower Tietê river (SP) and the management of eutrophication. In. Eutrofização na América do Sul: Causas consequências e tecnologias de gerenciamento e controle, IIE, 141-160, 2006.

MEYBECK, M., How to establish and use world budgets of riverine materials. In Physical and Chemical Weathering in Geochemical Cycles (Lerman, A. \& Meybeck, M., eds). Kluwer Academic, The Hague, pp. 247-272, 1988.

MINOTI, R. T., ABE, DONATO SEIJO ; MATSUMURATUNDISI, T. ; TUNDISI, J. G.. Planejamento e Gerenciamento de Lagos e Reservatórios: uma abordagem integrada ao problema da eutrofização. In: IETC; UNEP, PNUMA; IIE; PROÁGUA; UNESCO; ANA. (Org.). Pamolare. São Carlos: Rima Artes e Textos, 2001, v. 1, p. 1-385.

MONSEN, N., CLOERNV, J., LUCAS, L. \& MONISMITH, S., A comment on the use of flushing time, residence time, and age as transport time scales. Limnology and Oceanography, 47:1545-1553, 2002.

MORAIS, M. A., CASTRO, W. A. C. \& TUNDISI, J. G., Climatologia de frentes frias sobre a região metropolitana de São Paulo(RMSP) e sua influência na limnologia dos reservatórios de abastecimento de água. Revista Brasileira de Meteorologia, v. 25, n. 2 , 205-217, 2010. 
MORENO-OSTOS, E., CRUZ-PIZARRO, L., BASANTA, A. \& GEORGE, D. G., Spatial Heterogeneity of Cyanobacteria and Diatoms in a Thermally Stratified CanyonShaped Reservoir, International Review of Hydrobiology, Volume: 94 Issue: 3, 245-257, 2009.

NISHIMURA, P.Y. A comunidade fitoplanctônica nas represas Billigns e Guarapiranga Região Metropolitana de São Paulo). Tese (Doutorado). Universidade de São Paulo, $135 \mathrm{p}$.

NITTROUER, C. A., BRUNSKILL, G. J. \& FIGUEIREDO, A. G. Importance of tropical coastal environments, Geo-Marine Letters 15, 121-126, 1995.

NG, S, ANTENUCCI, J.P. , HIPSEY, M.R. TIBOR, M.R. \& ZOHARY, T.. Unravelling of Phytoplankton Group Characteristics by Spatial Analysis of Satellite Images, Israel Oceanographic and Limnological Research, Ltd., Haifa, Israel, 2010.

NOVO, E. M. L. de M., Sensoriamento Remoto. 2 ed. São Paulo: Edgard Blucher, 1992.

NUSH, E. A. Comparison of different methods for chlorophyll and phaeopigments determination. Archiv für Hydrobiologie, v. 14, p. 14-36, 1980.

O’ NEIL, J. M., DAVIS, T. W., BURFORD, M. A. \& GOBLER, C., J., The rise of harmful cyanobacteria blooms: The potential roles of eutrophication and climate change. Harmful Algae 14: 313-334, 2012

OKELY, P., IMBERGER, J. \& SHIMIZU, K., Horizontal dispersion due to interplay of motions in the surface layer of a small reservoir. Limnology and Oceanography, 55(2): 589-603, 2010 .

ÖRNÓLFSDÓTTIR, E., LUMSDEN, S. \&PINCKNEY, J., Nutrient pulsing as a regulator of phytoplankton abundance and community composition in Galveston Bay, Texas. Journal of Experimental Marine Biology and Ecology, 303(2), 197-220, 2004. 
OSTOS et. al., Spatial Heterogeneity of Cyanobacteria and Diatoms in a Thermally Stratified Canyon-Shaped Reservoir, International Review of Hydrobiology, Volume 94, Issue 3, pages 245-257, June, DOI:10.1002/iroh.200811123, 2009.

PALMER S. C.J. Palmer, KUTSER, T. \& HUNTER, P. D. Remote sensing in inland waters: Challenges, progress and future directions. Remote Sensing of Environment $157,1-8,2015$.

PAERL, H.W. Growth and Reproductive Strategies of Freswater Blue-Green Algae (Cyanobacteria) Chapter pp 261-315, In: Craig D. Sandgren (Ed.) Growth and Reproductive Strategies of Freswater Phytoplankton. Cambridge University Press, Cambridge, 442p., 1988.

PAERL H. W., HUISMAN J., Blooms like it hot. Science, 320:57-58, 2008.

PAERL, H. W., HALL, N. S., CALANDRINO, E. S., Controlling harmful cyanobacterial blooms in a world experiencing anthropogenic and climatic induced change. Science of the Total Environment, Elsevier, 2011.

PEREIRA, E., Unmanned Air Vehicles for coastal and environmental researchin, 10th International Coastal Symposium (ICS 2009), pp.-, 2009

PILKAITYTE, R., RAZINKOVAS, A., Seasonal changes in phytoplankton composition and nutrient limitation in a shallow Baltic lagoon. Boreal environment research, 12(5), 551-559, 2007.

PRIME Engenharia, Relatório Síntese - Programa Guarapiranga, (CETESB), Maio 1998.

PRISCOLLI, J. D., Water and civilization: Using history to reframe frame water policy debates and to build a new ecological realism, Water Policy, 1 (6), 623 - 636, 1998.

QUIBELL, G., Estimating Chlorophyll Concentrations Using Upwelling Radiance from Different Freshwater Algal Genera. Int. Journ. of Remote Sensing, v. 13, n. 14, p. 2611- 
$2621,1992$.

RANDOLPH, K., WILSON, J., TEDESCO, L., LI, L., PASCUAL, D.L., \& SOYEUX E., Hyperspectral remote sensing of cyanobacteria in turbid productive water using optically active pigments, chlorophyll a and phycocyanin, Remote Sensing of Environment 112, pp. 4009-4019, 2008.

RANGO, A. LALIBERTE, A., HERRICK, J., WINTERS, C., HAVSTAD, K., STEELE, C., \& BROWNING, D., Unmanned aerial vehicle-based remote sensing for rangeland assessment, monitoring, and management, Journal of Applied Remote Sensing, Vol. 3, 2009.

RIO, C.M.M.G. Modelagem da circulação de um Reservatório Tropical Polimítico (Tese de Doutorado). Universidade Federal de São Carlos, 99 pp, 2003.

RUEDA, F., COWEN, E., The residence time of a freshwater embayment connected to a large lake. Limnol. Oceanogr. 50(5), 1638-1653, 2005a.

RUEDA, F., COWEN, E., The residence time of river water in reservoirs. Ecological Modelling, 191:260-274, 2005b.

RUTTNER, F., Fundamental of Limnology, Univ. Toronto Press, Toronto, 295 pp.,1963.

SANT'ANNA, C. L., AZEVEdo, M. T. P., Agujaro, L. F., CARVAlHO, M. C., CARVALHO, L. R. \& SOUZA, R. C. R., Manual Ilustrado para Identificação e Contagem de Cianobactérias Planctônicas de Águas Continentais Brasileiras. Sociedade Brasileira de Ficologia. Editora Interciência. Rio de Janeiro, 2006.

SAGGIO, A., IMBERGER, J., Mixing and turbulent fluxes in the metalimnion of a stratified lake, Limnol. Oceanogr., 46(2), 392-409, 2001.

SAGGIO, A., IMBERGER, J., Internal wave weather in stratified lakes. Limnology and Oceanography, 43(8): 1780-1795, 1998. 
SANTOS, R. M., Estrutura das comunidades fito e zooplanctônicas do Reservatório Guarapiranga (São Paulo) e relações com a hidrodinâmica e a eutrofização. - (Tese de Doutorado) São Carlos : UFSCar, 2010.

SCHRRMEISTER, B.E., ANISIMOVA, M., ANTONELLI, A. \& BAGHERI, H. C. Evolution of cyanobacterial morphotypes: Taxa required for improved phylogenomic approaches. Communicative \& Integrative Biology, 4: 424-427. 2011.

SCHRRMEISTER, B.E., DE VOS J.M., ANTONELLI, A. \& BAGHERI, H. C.Evolution of multicellularity coincided with increased diversification of cyanobacteria and the Great Oxidation Event. PNAS, 110: 1791-1796, 2013.

SELUCHI, M. E.; CHOU, Sin Chan . Synoptic patterns associated with landslide events in the Serra do Mar, Brazil. Theoretical and Applied Climatology, v. 98, p. 67-77, 2009.

SIMIS, S. G. H., PETERS, S. W. M., \& GONS. H. J., Remote sensing of the cyanobacterial pigment phycocyanin in turbid inland water. Limnology and Oceanography, 50: 237-245, 2005.

SIMONSEN, R. The diatom system: ideas on phylogeny. Bacillaria, v. 2, p. 9-71, 1979.

SON, Y. B., CHOI, B., KIM, Y. H. \& PARK, Y., Tracing floating green algae blooms in the Yellow Sea and the East China Sea using GOCI satellite data and Lagrangian Transport. Remote Sensing of Environment, 56, 21:33, 2015.

SPINDOLA, L. A.. Macrófitas aquáticas em duas lagoas marginais do rio Taquari, Coxim, MS, Brasil. Dissertação de Mestrado. Fundação Universitária de Mato Grosso do Sul, Campo Grande. 47p, 2007.

STRASKRABA, M. Retention time as a key variable of reservoir Limnology. pp 385410. In: Tundisi, J. G. \& Straskraba, M. (Eds.). Theoretical Reservoir Ecology and its Applications. Brazilian Academy of Sciences, International Institute of Ecology and and Backhuys Publishers, Leiden, 585 pp, 1999. 
STRASKRABA, M., TUNDISI, J., Diretrizes para o gerenciamento de lagos: gerenciamento de qualidade da água de represas. Tradução Dino Vannucci; ed Tundisi J. G. São Carlos , 280p. v.1, 2000.

STRICKLAND, J.D.H. \& PARSONS, T. R., A manual for sea water analysis. Bull. Fish. Res. Bd. Canada, 167:71-75, 1968.

TAMM, M., FREIBERG, R., TÕNNO, I., NÕGES, P., \& NÕGES ,T.: Pigment-based chemotaxonomy - a quick alternative to determine algal assemblages in large shallow eutrophic lake, PLoS ONE, 10, e0122526, doi:10.1371/journal.pone.0122526, 2015.

TEIXEIRA, C.; TUNDISI, J.G; \& KUTNER, M.B. Plankton studies in a mangrove II. The standing stock and some ecological factors. Bol. Inst. Oceanogr., v.24, p.23-41, 1965.

THIEMANN, S. \& KAUFMANN, H. Determination of chlorophyll concentration and trophic state of lakes using field spectrometer and IRS-IC satellite data in the Mecklenburg Lake District, Germany. Remote Sensing of Environment, 73, 227-235, 2000 .

TUNDISI, J. G., MATSUMURA-TUNDISI, T., Limnologia. São Paulo: Oficina de Textos, 631p., 2008.

TUNDISI, J. G. \& STRASKRABA, M. (Eds.). Theoretical Reservoir Ecology and its Applications. Brazilian Academy of Sciences, International Institute of Ecology and and Backhuys Publishers, Leiden, 585 pp, 1999.

TUNDISI, J.G. 2003. Água no Século XXI. Enfrentando a Escassez. 1a . Ed. Rima Editora/ Instituto Internaciuonal de Ecologia. São Carlos, 248 pp.

TUNDISI, J. G., MATSUMURA-TUNDISI,T., RODRIGUES, S.L. Gerenciamento e Recuperação das Bacias Hidrográficas dos Rios Itaqueri e Lobo e da Represa da UHE Carlos Botelho (Lobo, Broa), 1ª Ed. Rima Editora/ Instituto Internaciuonal de Ecologia. São Carlos, 72 pp, 2003. 
TUNDISI, J. G., MATSUMURA-TUNDISI,T., ARANTES JUNIOR, J.D., TUNDISI, J.E.M., MANZINI, The response of Carlos Botelho (Lobo, Broa) reservoir to the passage of cold fronts as reflected by physical, chemical, and biological variables. Braz. J. Biol. vol.64, n.1, pp. 177-186, 2004.

TUNDISI, J.G., ABE, D. S., MATSUMURA-TUNDISI, T., TUNDISI, J. E.M. TUNDISI \& VANNUCI, D. Reservatórios da Região Metropolitana de São Paulo: Consequências e Impactos da Eutrofização . pp 161-182, In: J. G. Tundisi, MatsumuraTundisi, T. \& Sidagis-Galli, C. (Eds.) Eutrofização, na América do Sul, Causas, consequências e tecnologias de gerenciamento e controle. Instituto Internacional de Ecologia, Inc. São Carlos, SP, Brazil, 531 pp. 2006.

VALDERRAMA, J.C., The simultaneous analisys of total nitrogen and phosphorus in natural waters. Mar. Chem., v.10, p.109-122, 1981.

VANE, G.; GOETZ, A.F.H., Terrestrial Imaging Spectrometry: Current Status, Future Trends. Remote Sensing of Environment, v. 44, n. 2/3, p. 117-126, jun. 1993.

VIEIRA, A.A.H. \& KLAVENESS, D. The utilization of organic nitrogen compounds s sole nitrogen source by some freshwater phytoplankters. Nord. J. Bot., 6: 93-7.

VILHENA, L., HILLMER, I. \& IMBERGER, J., The role of climate change in the occurrence of algal blooms; Lake Burragorang, Australia, Limnology and Oceanography, 55(3): 1188-1200, 2010.

VINCENT R. K., QINA X., R. MCKAYB M. L. , MINERB, J., CZAIJKOWSKI, K., SAVINOD J. \& BRIDGEMAN, T., Phycocyanin detection from LANDSAT TM data for mapping cyanobacterial blooms in Lake Erie, Remote Sensing of Environment, 89, 381-392, 2004.

VÖRÖSMARTY, C. J, SHARMA, K. P., FEKETE, B. M., COPELAND, A. H., HOLDEN, J., MARBLE, J. \& LOUGH, J. A., The storage and aging of continental runoff in large reservoir systems of the world. Ambio 26: 210-219, 1997. 
WANNIKHOF, R., Relationship between gas exchange and wind speed over the ocean., J. Geophys. Res., 97, pp. 7373-7381, 1992.

WEBB, W.L., NEWTON, M., \& STARR, D., Carbon dioxide exchange of Alnus rubra: a mathematical model. Oecologia 17, pp. 281-291, 1974.

WETZEL, R. G., Limnology: Lake and River Ecossystems. $3^{\text {rd }}$ Edition. Academic Press, San Diego, CA, 2001.

WHATELY, M., CUNHA, P., Seminário Guarapiranga - Proposição de ações prioritárias para garantir água de boa qualidade para abastecimento público. Instituto Socioambiental. São Paulo, p. 171, 2006.

ZHAO, D., CAI, Y., JIANG, H., XU, D., ZHANG, W. \& NA, S., Estimation of water clarity in Taihu Lake and surrounding rivers using Landsat imagery, Advances in Water Resources, 34, 165-173, 2011. 


\section{Anexo I}

Tabela 4 - Dados de precipitação diária referentes ao mês de março de 1999.

\begin{tabular}{|c|c|c|c|c|}
\hline \multicolumn{5}{|c|}{ Valores diários de precipitação - março de 1999} \\
\hline Data & $\begin{array}{c}\text { Altura } \\
\text { total } \\
(\mathrm{mm})\end{array}$ & $\begin{array}{c}\text { Duração } \\
\text { total } \\
\text { (min) }\end{array}$ & $\begin{array}{c}\text { Máxima } \\
\text { altura } \\
\text { horária }\end{array}$ & $\begin{array}{c}\text { Freq. } \\
\text { (horas) }\end{array}$ \\
\hline 1 & 40,9 & 185 & 35,5 & 4 \\
\hline 2 & 17,0 & 47 & 17,0 & 1 \\
\hline 3 & 0,1 & 10 & 0,1 & 1 \\
\hline 4 & 0,0 & 0 & 0,0 & 0 \\
\hline 5 & 0,0 & 0 & 0,0 & 0 \\
\hline 6 & 0,0 & 0 & 0,0 & 0 \\
\hline 7 & 0,0 & 0 & 0,0 & 0 \\
\hline 8 & 0,0 & 0 & 0,0 & 0 \\
\hline 9 & 35,1 & 75 & 34,9 & 2 \\
\hline 10 & 4,6 & 203 & 3,1 & 5 \\
\hline 11 & 25,5 & 200 & 19,5 & 8 \\
\hline 12 & 32,3 & 475 & 10,3 & 12 \\
\hline 13 & 1,6 & 120 & 0,9 & 5 \\
\hline 14 & 0,0 & 0 & 0,0 & 0 \\
\hline 15 & 0,0 & 0 & 0,0 & 0 \\
\hline 16 & 0,0 & 0 & 0,0 & 0 \\
\hline 17 & 0,0 & 0 & 0,0 & 0 \\
\hline 18 & 0,0 & 0 & 0,0 & 0 \\
\hline 19 & 0,0 & 0 & 0,0 & 0 \\
\hline 20 & 0,0 & 0 & 0,0 & 0 \\
\hline 21 & 0,0 & 0 & 0,0 & 0 \\
\hline 22 & 0,0 & 0 & 0,0 & 0 \\
\hline 23 & 19,3 & 367 & 7,9 & 9 \\
\hline 24 & 0,0 & 0 & 0,0 & 0 \\
\hline 25 & 0,0 & 0 & 0,0 & 0 \\
\hline 26 & 0,0 & 0 & 0,0 & 0 \\
\hline 27 & 0,0 & 0 & 0,0 & 0 \\
\hline 28 & 0,0 & 0 & 0,0 & 0 \\
\hline 29 & 0,0 & 0 & 0,0 & 0 \\
\hline 30 & 0,2 & 45 & 0,1 & 2 \\
\hline 31 & 0,1 & 20 & 0,1 & 1 \\
\hline
\end{tabular}


Tabela 5 - Dados de ventos diários referentes ao mês de março de 2002.

\begin{tabular}{c|ccc|cc}
\cline { 2 - 6 } Data & \multicolumn{2}{c|}{ Valores diários } & \multicolumn{2}{c}{ Rajadas máx. } \\
\hline & Dir. & Vel. & Vel. & Vel. & Dir. \\
& & Méd. & Máx. & & \\
(km/h) & $(\mathbf{k m} / \mathbf{h})$ & $(\mathbf{m} / \mathbf{s})$ & \\
\hline $\mathbf{1}$ & WNW & 5,1 & 12 & 7 & WNW \\
$\mathbf{2}$ & ESE & 3,6 & 8 & 6 & SSE \\
$\mathbf{3}$ & ENE & 5,5 & 12 & 8 & ESE \\
$\mathbf{4}$ & ESE & 5,8 & 14 & 13 & NNW \\
$\mathbf{5}$ & NE & 5,9 & 10 & 7 & E \\
$\mathbf{6}$ & WNW & 6,5 & 12 & 11 & NE \\
$\mathbf{7}$ & ENE & 6,2 & 13 & 12 & SSE \\
$\mathbf{8}$ & NE & 4,0 & 11 & 6 & SE \\
$\mathbf{9}$ & NE & 4,2 & 10 & 8 & SSE \\
$\mathbf{1 0}$ & NE & 5,3 & 13 & 6 & ESE \\
$\mathbf{1 1}$ & NNE & 5,7 & 9 & 7 & WNW \\
$\mathbf{1 2}$ & E & 5,5 & 12 & 6 & E \\
$\mathbf{1 3}$ & SE & 4,3 & 10 & 6 & SSE \\
$\mathbf{1 4}$ & WNW & 4,5 & 8 & 5 & WNW \\
$\mathbf{1 5}$ & ESE & 4,8 & 10 & 7 & ESE \\
$\mathbf{1 6}$ & ESE & 6,0 & 11 & 6 & SSE \\
$\mathbf{1 7}$ & NE & 6,5 & 12 & 9 & SE \\
$\mathbf{1 8}$ & NNE & 5,3 & 9 & 6 & ESE \\
$\mathbf{1 9}$ & ESE & 4,8 & 10 & 7 & N \\
$\mathbf{2 0}$ & NNW & 8,3 & 20 & 11 & NNW \\
$\mathbf{2 1}$ & SSE & 7,8 & 10 & 8 & SSE \\
$\mathbf{2 2}$ & E & 10,0 & 17 & 11 & ENE \\
$\mathbf{2 3}$ & ENE & 7,0 & 13 & 7 & NE \\
$\mathbf{2 4}$ & NNE & 7,7 & 11 & 9 & NNE \\
$\mathbf{2 5}$ & WNW & 7,7 & 11 & 7 & WNW \\
$\mathbf{2 6}$ & ESE & 4,3 & 10 & 5 & SE \\
$\mathbf{2 7}$ & ENE & 5,8 & 11 & 6 & ENE \\
$\mathbf{2 8}$ & ESE & 3,9 & 8 & 4 & ENE \\
$\mathbf{2 9}$ & E & 5,6 & 12 & 6 & N \\
$\mathbf{3 1}$ & WNW & 6,5 & 13 & 8 & WNW \\
& & 4,7 & 12 & 7 & WNW \\
\hline
\end{tabular}

